Portland State University

PDXScholar

$1-1-1982$

\title{
Social support and well-being in middle-aged and elderly spinal cord injured persons: a social- psychological analysis
}

Susan Dee Decker

Portland State University

Follow this and additional works at: https://pdxscholar.library.pdx.edu/open_access_etds Let us know how access to this document benefits you.

\section{Recommended Citation}

Decker, Susan Dee, "Social support and well-being in middle-aged and elderly spinal cord injured persons: a social-psychological analysis" (1982). Dissertations and Theses. Paper 538.

https://doi.org/10.15760/etd.538

This Dissertation is brought to you for free and open access. It has been accepted for inclusion in Dissertations and Theses by an authorized administrator of PDXScholar. Please contact us if we can make this document more accessible: pdxscholar@pdx.edu. 


\title{
SOCIAL SUPPORT AND WELL-BEING IN MIDDLE-AGED AND ELDERLY SPINAL CORD INJURED PERSONS: \\ A SOCIAL-PSYCHOLOGICAL ANALYSIS
}

\author{
by \\ SUSAN DEE DECKER
}
A dissertation submitted in partial fulfillment of the requirements for the degree of

\author{
DOCTOR OF PHILOSOPHY \\ in
}
URBAN STUDIES

Portland State University

1982 
AN ABSTRACT OF THE DISSERTATION OF Susan Dee Decker for the Doctor of Philosophy in Urban Studies presented November 29, 1982 .

Title: Social support and Well-Being in Middle-Aged and Elderly Spinal Cord Injured Persons:

A Social-Psychological Analysis.

APPROVED BY MEMBERS OF THE DISSERTATION COMMITTEE:

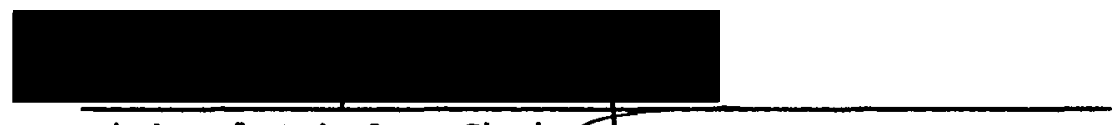

Richard Schulz, Chairegrson

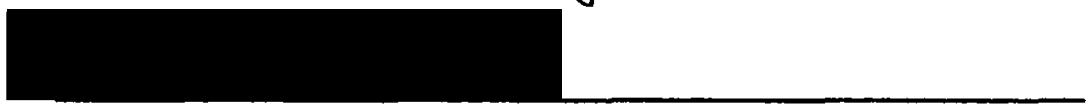

Leonard D Cain

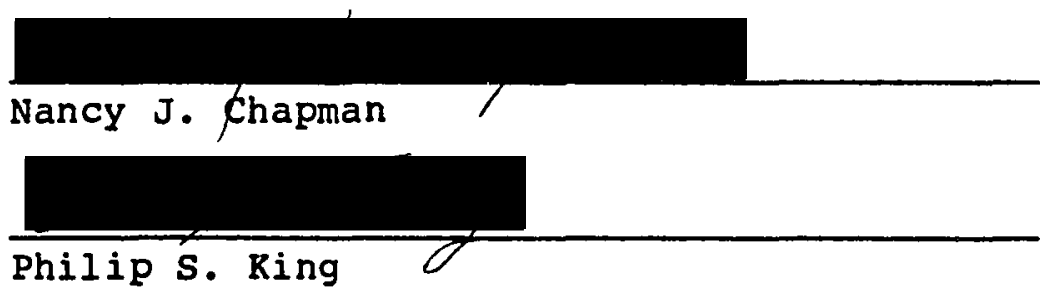

Advances in health care science are enabling greater numbers of spinal cord injured persons to live to old age. As these persons grow older, there may be additional problems in coping due to stressors such as decreasing health and income and loss of significant others. The purpose of this study was to determine those factors that contribute to the well-being of middle-aged and elderly community-residing spinal cord injured persons. 
One hundred spinal cord injured persons ranging in age from 40 to 73 were interviewed. Extensive data were collected in order to investigate the relationship anong social support, types of social comparisons made, perceived control, health status and psychological well-being and life satisfaction.

In general, respondents reported a degree of wellbeing that was slightly lower than that reported in studies of nondisabled populations on the same measures of psychological well-being, life satisfaction, and depression. Pearson correlations and multiple linear regressions showed that persons reporting high levels of well-being made favorable social comparisons, reported high levels of perceived control over their lives, had high levels of social support, and judged their health status to be good. They also viewed their disability more favorably and tended to have higher incomes, more education, to be employed, and to be more religious than those indicating lower levels of well-being. The severity of the spinal cord injury was not correlated highly with subjective well-being, although there was a tendency for persons with greater disabilities to report lower levels of well-being. Persons who were younger and who incurred their disability at a younger age also tended to report higher levels of well-being.

A model of well-being is proposed. This model suggests that social support fosters the perception of control and the making of favorable social comparisons 
which, in turn, foster a sense of well-being and satisfaction with life. This model provides direction for future research and has valuable implications for clinical application. 
TO THE OFFICE OF GRADUATE STUDIES AND RESEARCH:

The members of the Committee approve the dissertation of Susan Dee Decker presented November 29, 1982.
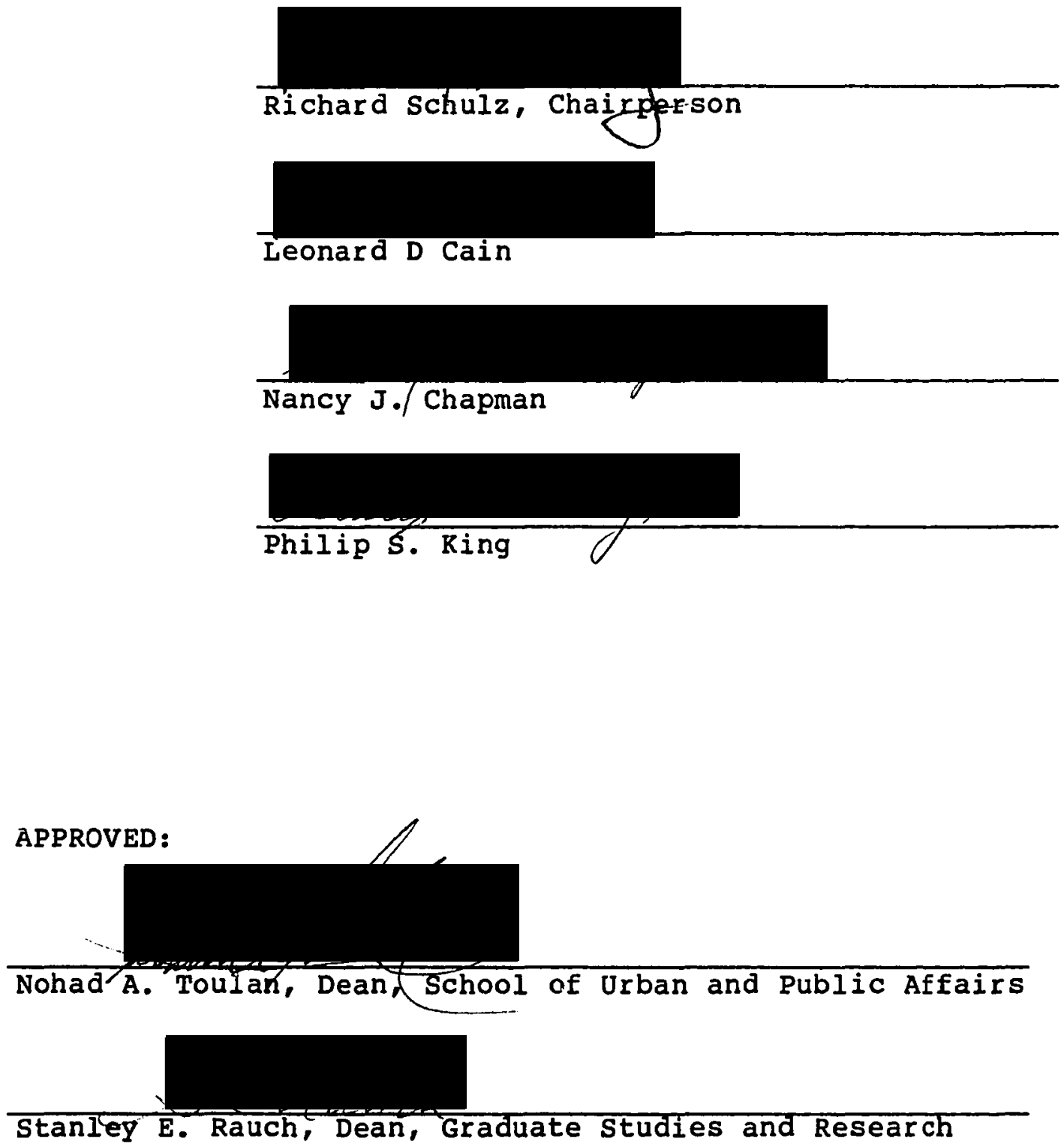


\section{ACKNOWL EDGMENTS}

The writer wishes to express her appreciation for the mentorship of Dr. Richard Schulz, and for the guidance given by Dr. Leonard Cain, Dr. Nancy Chapman, and Dr. Philip King in the preparation of this dissertation. 
TABLE OF CONTENTS

PAGE

ACKNOWLEDGEMENTS $\quad$ iii

LIST OF TABLES vii

LIST OF FIGURES ix

CHAPTER

I STATEMENT OF THE PROBLEM AND PURPOSE . . . . . 1

Demographic Characteristics of

Spinal Cord Injured Persons. . . . . . 1

Subjective Well-Being of the Elderly . . . 4

Adjustment to Spinal Cord Injury . . • . 6

Purpose. . . . . . . . . . . . 10

I I CONCEPTUAL FRAMEWORK . . . . . . . . . . 11

Social Support as a Facilitator of Coping

with Spinal Cord Injury. . . . . . . . . 11

Mechanisms of Social support . . . . . 16

Social support as a Correlate or Consequence of Coping

Social Support as a Mediator of Coping

Social Psychological Theoretical

Perspectives

summary. . . . . . . . . 34

III METHODS. . . . . . . . . . . . 36

The Sample............ 36

Data Collection and Human Subjects

Protection ........... 37 
PAGE

Research Questions... . . . . . 39

Operational Definitions. . . . . . . . 4l

Subjective Well-Being

Social support

Level of Spinal cord Injury

Instruments. . . . . . . . . . . .

Elderly spinal Cord Injury Questionnaire

Index of Psychological Well-Being (IPWB) (Berkman, 1971)

The Life Satisfaction Index-A (LSIA-A) (Adams, 1969)

Center for Epidemiological studiesDepression scale (CES-D) (Radloff, 1977)

Data Analysis Procedures . . . . . . 51 IV FINDINGS . . . . . . . . . . . . 55

Question 1: What are the Demographic

Characteristics of the Sample? . . . 55

Question 2: What is the Extent and Nature of Subjects' Participation in Recreational, Group, and Community Activities and Services?. . . . . . . . 58

Question 3: What are the Health Status Characteristics of Respondents?. . . 60

Question 4: What is the Degree and Nature of Social Support Perceived by Respondents? . . . . . . . . 62

Question 5: What is the Nature of the Social Comparisons Made by Respondents? . . . . . . . . . .

Question 6: What is the Degree and Nature of Respondents' Perception of Control

Over Various Life Situations?. . . .

Question 7: What is the Degree and Nature of Respondents' Subjective Well-Being? 
Question 8: What are the Correlates of Subjective Well-Being in this Sample?. 86

Question 9: To what Extent can Subjective Well-Being be Predicted by Measures of Perceived Social Support, Social Comparison, Control and other socialPsychological and Demographic variables. . . . . . . . . . 99

$\mathrm{V}$ CONCLUSIONS. . . . . . . . . . . . . 107

Overview of the study. . . . . . . . 107 Major Findings . . . . . . . . . 109 Predictors of Well-Being: A Causal Model. 112 Implications of the Model for Research and Practice . . . . . . . . . . . . . 114 Summary. • . . . . . . . . . 117 REFERENCES. • • . . . . . . . . . . . . . . . 119 APPENDICES

A Elderly Spinal Cord Injury Questionnaire . . 130

B Client Interview Codebook. . . . . . . . 146

C Correspondence . . . . . . . . . . 161

D Informed Consent Form. . . . . . . . 163 


\section{LIST OF TABLES}

TABLE

PAGE

I Life Expectancies for spinal Cord Injury

Victims by Age at Time of Injury and

Impairment Category. . . . . . . . . . 3

II Pearson Correlations Between Hope and selected

Predictor Variables. . . . . . . . . 79

II Comparative Distribution of scores on the Index

of Psychological Well-Being. . . . . . . 80

IV Mean Scores on the LSIA and LSIA-A of Selected

Samples. . . . . . . . . . . . 82

$\mathrm{V}$ Mean Scores on the CES-D of selected Samples. - 85

VI Correlations Among Seven Measures of Subjective Well-Being . . . . . . . . . . . 87

VII Major Correlates of Three Measures of Subjective

WelI-Being (IPWB, LSIA-A, CES-D) . . . . . 89

VIII Pearson Correlation Coefficients for Age, Age at

Injury, Blaming Self, Perceived Avoidability

of Disability and Three Measures of

Well-Being . . . . . . . . . . . . 94

IX Summary Results of One-Way Analysis of Variance

and Two-Tailed T-Tests on selected outcome

Measures . . . . . . . . . . . 96 
viii

PAGE

$x$ Multiple Linear Regression Analysis of Predictor Variables on IPWB . . . . . . . . . 100

XI Multiple Linear Regression Analysis of Predictor Variables on LSIA-A . . . . . . . . 101

XII Multiple Linear Regrassion Analysis of Predictor Variables on CES-D. . . . . . . . . . 102

XIII Intercorrelations Among All Variables in the Multiple Linear Regression Analyses . . . 103 


\section{LIST OF FIGURES}

FIGURE

PAGE

1. Social Psychological Model of Subjective Well-Being. . . . . . . . . . . . 113 
CHAPTER I

STATEMENT OF THE PROBLEM AND PURPOSE

DEMOGRAPHIC CHARACTERISTICS OF SPINAL CORD INJURED PERSONS

Each year in the united states between 6,000 and 11,000 persons suffer traumatic spinal cord injuries which result in varying degrees of permanent paralysis (Bachman, 1978; Roessler \& Bolton, 1978). It is estimated that the total number of persons in the united states disabled as a result of spinal cord injury varies beween 125,000 and 250,000 (Bachman, 1978) or as estimated by DeVivo, Fine and Stover (1979), 30 per million persons. The majority of the injuries occur in males between the ages of 15 and 29 , with the leading causes being vehicular accidents, followed by falls, sports injuries, and penetrating wounds (Trieschmann, 1980).

The population at highest risk for sustaining spinal cord injury is the teen/young adult male. However, the long-term survival rate of persons with this injury has greatly increased because of advances in antibiotic therapy and rehabilitation medicine. Before the widespread use of antibiotics, many people with spinal cord injury died from urinary tract or respiratory infections, or from septicemia generated from decubitus ulcers (Abramson, 1967). Fine 
(1979-80, p. 237) points out that many of the advances responsible for the improved prognosis of the spinal cord injured person occurred during world war II:

The short and long term prognosis for the cord-injured patient did not improve until the Second world war when the British pioneered far-reaching medical achievements in the care of their patients. The efforts and achievements of Guttman and others have markedly increased life expectancy of the spinal cord injured patient and have enabled practitioners to consider sequelae of cord injuries much as their predecessors considered the progression of infections and non-chronic disorders.

Trieschmann (1980) states that with advances in medical science, some spinal cord injured persons may achieve a life-expectancy similar to that of the able-bodied person. The increased longevity of spinal cord injured persons is illustrated in Table $I$. The individual who incurs a spinal cord lesion at age 30 can expect to live from 16-45 years or more, depending on the level of the lesion, whether it was complete or incomplete, and the gender of the individual. Thus, a quadriplegic male with an incomplete lesion injured at age 30 can expect to live into his sixties, and a similar female into her seventies.

In addition to the increased long-term survival of cord injured persons, the incidence of cord injuries among the middle-aged and elderly has been substantial and may be on the increase. Data from the National spinal Cord Injury Model Systems Conference Proceedings (1978) indicate that 18.87 percent were aged 40 or over at the onset of spinal cord injury. A study at a large spinal injury unit serving 
TABLE I

LIFE EXPECTANCIES FOR SPINAL CORD INJURY VICTIMS BY AGE AT TIME OF INJURY AND IMPAIRMENT CATEGORY

\begin{tabular}{|c|c|c|c|c|c|c|}
\hline \multirow{3}{*}{$\begin{array}{l}\text { Age at } \\
\text { Hospital } \\
\text { Discharge }\end{array}$} & \multirow[b]{3}{*}{ Gender } & \multicolumn{5}{|c|}{ Life Expectancy (Remaining Years) } \\
\hline & & \multirow{2}{*}{$\begin{array}{c}\text { General } \\
\text { Population }\end{array}$} & \multicolumn{2}{|c|}{ Paraplegia } & \multicolumn{2}{|c|}{ Quadriplegia } \\
\hline & & & Incomplete & Complete & Incomplete & Complete \\
\hline 10 & $\begin{array}{l}\text { Male } \\
\text { Female }\end{array}$ & $\begin{array}{l}59.09 \\
65.59\end{array}$ & $\begin{array}{l}57.22 \\
64.09\end{array}$ & $\begin{array}{l}42.20 \\
50.94\end{array}$ & $\begin{array}{l}49.88 \\
58.05\end{array}$ & $\begin{array}{l}28.60 \\
37.81\end{array}$ \\
\hline 20 & $\begin{array}{l}\text { Male } \\
\text { Female }\end{array}$ & $\begin{array}{l}49.65 \\
55.85\end{array}$ & $\begin{array}{l}47.85 \\
54.41\end{array}$ & $\begin{array}{l}33.73 \\
41.75\end{array}$ & $\begin{array}{l}40.88 \\
48.75\end{array}$ & $\begin{array}{l}21.57 \\
29.56\end{array}$ \\
\hline 30 & $\begin{array}{l}\text { Male } \\
\text { Female }\end{array}$ & $\begin{array}{l}40.61 \\
46.24\end{array}$ & $\begin{array}{l}38.95 \\
44.82\end{array}$ & $\begin{array}{l}26.29 \\
32.85\end{array}$ & $\begin{array}{l}32.57 \\
39.24\end{array}$ & $\begin{array}{l}16.15 \\
21.83\end{array}$ \\
\hline 40 & $\begin{array}{l}\text { Male } \\
\text { Female }\end{array}$ & $\begin{array}{l}31.53 \\
36.80\end{array}$ & $\begin{array}{l}29.98 \\
35.47\end{array}$ & $\begin{array}{l}18.55 \\
24.40\end{array}$ & $\begin{array}{l}24.13 \\
30.27\end{array}$ & $\begin{array}{l}10.49 \\
14.77\end{array}$ \\
\hline 50 & $\begin{array}{l}\text { Male } \\
\text { Female }\end{array}$ & $\begin{array}{l}23.08 \\
27.84\end{array}$ & $\begin{array}{l}21.70 \\
26.64\end{array}$ & $\begin{array}{l}11.96 \\
17.03\end{array}$ & $\begin{array}{l}16.61 \\
22.06\end{array}$ & $\begin{array}{l}5.90 \\
9.29\end{array}$ \\
\hline 60 & $\begin{array}{l}\text { Male } \\
\text { Female }\end{array}$ & $\begin{array}{l}15.75 \\
19.50\end{array}$ & $\begin{array}{l}24.65 \\
18.52\end{array}$ & $\begin{array}{r}7.08 \\
10.94\end{array}$ & $\begin{array}{l}10.61 \\
14.86\end{array}$ & $\begin{array}{l}2.97 \\
5.37\end{array}$ \\
\hline 70 & $\begin{array}{l}\text { Male } \\
\text { Female }\end{array}$ & $\begin{array}{r}9.72 \\
11.84\end{array}$ & $\begin{array}{r}9.00 \\
11.15\end{array}$ & $\begin{array}{l}3.93 \\
6.02\end{array}$ & $\begin{array}{l}6.29 \\
8.68\end{array}$ & $\begin{array}{l}1.50 \\
2.55\end{array}$ \\
\hline
\end{tabular}

Source: Deviro, M. J., Fine, P. R,, and Stover, S. L. The prevalence of SCI: A re-estimation based on life tables. Model Systems' SCI Digest, Vol. 1, winter, 1979 , p. 7. 
central England revealed that between 1955 and 1974, about 11 percent of all admissions were aged 60 and over. When admissions were analyzed in five-year periods, the data showed that the percentage of elderly spinal cord injured patients steadily increased from 6 to 18 percent in a 19-year period (Watson, 1976). The author attributed this increase to a larger proportion of eiderly persons in the population; the major cause of these injuries was accidents in the home.

These data suggest that we can expect both an increase in the number of newly acquired spinal cord injuries among the elderly and an increase in the number of young spinal cord injured persons living to old age. In view of the many coping problems associated with being old, along with the additional demands of being severely disabled, it becomes important to ask what factors contribute to the well-being of the elderly in general and to the well-being of the spinal cord injured elderly in particular. Issues such as health, independence, financial security and interpersonal relationships which may have been resolved at one point in life, may again require readjustment as life circumstances change with increasing age.

SUBJECTIVE WELL-BEING OF THE ELDERLY

Forty years of research on older Americans reveals that those who are ill or physically disabled are much less 
likely than others to report contentment with their lives (Edwards \& Klemmack, 1973; George, 1978; Palmore \& Kivett, 1977; Palmore \& Luikart, 1972; Spreitzer \& Snyder, 1974; Thompson, 1973). In view of this, one would expect that elderly persons experiencing mobility-limiting disabilities such as spinal cord injury, amputation, or rheumatoid arthritis would express less contentment about their lives than would nondisabled jersons. However, the question still remains as to what factors in addition to health status are associated with better coping and adjustment within the disabled elderly population. Why do some elderly disabled persons report more life satisfaction than others?

Based on a comprehensive review of the literature, Larson (1978) reported that aside from health status, socioeconomic factors and social interaction were the variables most strongly related to the life satisfaction, morale, and adjustment of the elderly. Adams (1971) also reviewed the literature on correlates of satisfaction in the elderly, and concluded that social relationships were probably the most important determinant cr satisfaction and that health and socioeconomic status were also important. The role of health and socioeconomic status in facilitating life satisfaction is relatively well understood, but debate still exists regarding the relationship between social interaction and life satisfaction. Lohmann (1980) reports that although many studies demonstrate a positive 
relationship between social interaction and life satisfaction (Graney, 1975; Lawton, 1972; Palmore \& Luikart, 1972; Pihlblad \& Adams, 1972; Seymour, 1972), others show that this relationship disappears when other variables are controlled (Bull \& AuCoin, 1975; Edwards \& Klemmack, 1973; Lemon, Bengtson, \& Peterson, 1972) and still others report no relationship between social interaction and life satisfaction (Cumming \& Henry, 1961; Thompson, 1973).

It seems likely that much of the confusion regarding the relationship between social interaction and life satisfaction is due to variations in measurement, a lack of conceptual clarity regarding the nature of social interaction, and an emphasis on correlational as opposed to experimental research. What is it about social interaction that facilitates coping with stress and promotes life satisfaction? One of the goals of this study is to answer this quesion by examining those mechanisms through which interpersonal relationships promote positive outcomes.

\section{ADJUSTMENT TO SPINAL CORD INJURY}

Persons sustaining a severe spinal cord injury face numerous adaptation demands. In addition to problems associated with loss of mobility and sensation, the spinal cord injured person undergoes tremendous psychological stresses. Spinal cord injury represents a threat to life, self-identity, social position, job, and love relation- 
ships. Persons who become severely disabled frequently exhibit a grieving process similar to that of persons responding to the death of a loved one. Indeed, several authors (Milhouse, 1979; Weller \& Miller, 1977) characterize the spinal cord injured person as passing through several stages identified as shock, denial, depression, anger, and reconstruction, although little systematically collected data exist to verify these stages. According to these authors, the individual ideally should move through the grieving process to acceptance of the disability and then re-establish a productive and meaningful life. However, problems associated with the psychological adjustment to a severe injury of this type may hinder the achievement of this desired outcome. For example, Tucker (1980) suggests that the mourning for lost physical capacity is never completed but is repeatedly reworked as the individual encounters situations which trigger awareness of the disability.

The spinal cord injured person faces difficult psychological tasks related to self-acceptance. In a society where disability is accorded a negative status, Vargo (1978) states that in order to truly adapt, individuals must combat misconceptions (Wright, 1960, p. 172) which devalue them as human beings. These include:

1. My disability is a punishment.

2. It is important to conform, not to be different.

3. Most people are physically rormal. 
4. Normal physique is one of the most important values.

5. Physique is important for personal evaluation.

6. A deformed body leads to a deformed mind.

7. No one will marry me.

8. I will be a burden on my family.

9. My deformity is revolting.

10. I am less valuable because I cannot get around as others do.

Deloach and Greer (1981, p. 20) cite the conclusions of an extensive literature survey on psychological adjustment of the disabled conducted by Roessler and Bolton (1978); these are:

1. There are no specific personality traits associated with specific disabilities.

2. There is no proven relationship between severity of disability and psychological adjustment.

3. There is no uniform degree to which similarly disabled persons adjust.

These conclusions are consistent with the view that how a person interprets a disability, or any potentially "negativen event, influences adjustment to the disability or stressor.

Gunther (1969) suggests that spinal cord injured individuals experience fragmentation of the cohesive adult self. In order to adjust to the disability, they must undergo a painful reintegration process which includes 
dealing with feelings of self-blame, self-hatred, depression, dependency, and an altered body image (Geis, 1972; Tucker, 1980). Such individuals must develop a value system that allows them to feel good about themselves.

Deloach and Greer (1981) similarly describe the severely disabled person as having to incorporate the disability into his/her self-state, defined as "one's overall appraisal of oneself at a specified time and place" (p. 215). These authors feel that an essential element in coming to terms with a physical disability is confidence in one's ability to cope. In order to explain why severely disabled persons don't necessarily exhibit lower life satisfaction than able-bodied persons, they state that part of the answer lies in the individual's ability to redefine situations.

The literature on adjustment to spinal cord injury strongly suggests that in addition to the tangible sorts of life-changes one must make in order to live with a severe disability, there are cognitive adjustments one must make in order to maintain a sense of worth and effectiveness. As the spinal cord injured person grows older, there may be additional problems in coping as a result of stressors associated with old age, such as loss of friends and family. Particularly for the individual who has relied upon relatives (e.g., parents) for psychological and physical support, the loss of these support persons through death creates a new set of adaptation demands. The list of 
potential stressors becomes even longer when we consider the increased probability of additional health problems and/or the aggravation of existing ones with increasing age.

\section{PURPOSE}

The purpose of this study is to determine those factors that contribute to the successful adjustment of middle-aged and elderly community-residing spinal cord injured persons. Adjustment will be determined by measures of mental health and subjective well-being described later in this report. Concepts of specific theoretical relevance to subjective well-being and to be investigated in this study include social support, learned helplessness (perceived control), and social comparison. It is hoped that an outcome of this study will be a greater understanding of the nature and function of social support in facilitating adjustment to a difficult life situation. 
CHAPTER II

\section{CONCEPTUAL FRAMEWORK}

SOCIAL SUPPORT AS A FACILITATOR OF COPING WITH SPINAL CORD INJURY

For the past three decades, much of the research in social gerontology has been aimed at finding ways for maximizing levels of wellness in older persons. Frequently, researchers and practitioners have sought ways of facilitating the individual's ability to cope with major life stressors. Successful coping is typically characterized by (1) the absence of psychological distress and the presence of a self-perception of well-being and (2) the maintenance of functioning in interpersonal societal roles. Frequently, one of the important contributors to successful coping has been identified as the availability of social support to an individual.

Although numerous definitions of social support exist, Cohen and Mckay (1980) state that the term has been widely used to refer to both psychological and nonpsychological mechanisms by which interpersonal relationships buffer one against a stressful environment. Cobb (1976) defines the concept of social support in terms of information available to an individual which leads him or her to believe that he or she is loved, valued, and belongs 
to a network of communication and mutual obligations. Caplan (1974) uses the term social support to refer to interpersonal ties which people can rely on to provide emotional support and reassurance, tangible assistance, and information to assist in the handling of problems. Although social support is defined with varying degrees of comprehensiveness and specificity by different researchers, there is much overlap in their conceptualization of social support.

Literature from various sources supports the idea that social support is a facilitator of coping with stressful life events (Adams, 1971; Caplan, 1974, 1979; Cassel, 1975; Cobb, 1976; Heller, 1979; Litwak, 1979). For example, Aguilera and Messick (1974, p. 64) consider social supports (i.e., persons in the environment who can be depended upon to help solve a.problem) as a crucial factor in determining whether or not an individual will experience a stressful event as a crisis. They suggest that the persons who provide social support facilitate coping by alleviating feelings of loss and reinforcing feelings of ego-integrity through their appraisals of the individuals. Similarly, Veroff, Douvan, and Kulka (1981) concluded that turning to others for support is one of the critical ways Americans deal with their life problems.

A recent longitudinal study by Berkman and syme (1979) further illustrates the importance of social support in the general population. They assessed the relationship 
between social and community ties and mortality in a random sample of 6,928 adults in Alameda County, California. An analysis of mortality rates within this population nine years later revealed that people who lacked social and community ties were more likely to die in the follow-up period than those with more extensive contacts. The association between social ties and mortality was found to be independent of self-reported physical health status, socio-economic status, and health practices at the time of the original survey. The most important sources of social contact seemed to be marriage and contact with close friends and relatives, followed by church membership and informal and formal group associations. In every age category, people who reported having few friends and relatives and/or who saw them infrequently had higher mortality rates than those with many friends and relatives whom they saw frequently. These differences in mortality rates were found for both men and women.

These are only a few of the many studies indicating a relationship between social support and coping. Indeed, there are studies identifying social support as a mediator of individual well-being when confronted with any one of a large number of life stressors, including rape (Burgess \& Holmstrom, 1978), open heart surgery (Kimball, 1969), chronic kidney disease (MacElveen-Hoehn \& Smith-DiJulio, 1978), cancer (Jamison, Wellisch, \& Pasnau, 1978; Vachon et al., 1979; Weisman, 1976; Weisman \& Worden, 1975), terminal 
illness (Carey, 1974), job termination (Cobb \& Rasl, 1977), and bereavement (Clayton, Halikas, \& Maurice, 1972; Maddison \& Walker, 1967; Walker, MacBride, \& Vachon, 197/).

Of particular interest to this discussion are studies showing a relationship beween family support and coping with physical disability. For example, Remp and Vash (1971) compared productive and less productive spinal cord injured persons and identified interpersonal support as a decisive variable fostering a constructive orientation. Productivity was defined as including employment, avocational pursuits, group participation, and family responsibilities. Persons with quadriplegia were less productive than those with paraplegia in the absence of high emotional support. However, in the presence of high support, no difference in productivity between those with paraplegia and those with quadriplegia was noted. In a study of 145 spinal cord injured veterans $(70$ percent paraplegic and 30 percent quadriplegic), Frielich (1977) found that rehabilitation success as measured by vocational and avocational adjustment was significantly correlated with being married and maintaining interpersonal relationships. In another study of 35 quadriplegics, 1.5 to 4.5 years post-discharge from a rehabilitation program, Rogers and Figone (1979) concluded that the affiliative network was crucial in facilitating adaptation. These researchers asked subjects the primary ways in which subjects' support persons were influential in helping them 
adapt to their disability. The greatest number of responses, 78 percent, indicated that others helped them adapt by giving psychological support and encouragement, both passive and active. passive psychological support included such things as standing by, being available, listening and understanding; active support included behaviors such as giving encouragement, pushing subject to go on, telling subject not to give up, and "standing up for me."

Similarly, Harris, Patel, Greer, and Naughton (1973) found the family to be an important determinant of the individual's reaction to physical disability, Litman (1964) found that the amount of positive reinforcement from family members was related to better performance in rehabilitation, and Rerr and Thompson (1972) noted that most persons in their sample rated as having made an excellent adjustment to spinal cord injury came from very warm and loving backgrounds.

Finally, Peterson, Ring, and Davis (1978) studied a population of older ( 50 years $t$ ), noninstitutionalized amputees and concluded through field interviews that the existence of strong family support was a key factor in the older person's readjustment after amputation. Their study indicated that a strong family support network existed for most persons in this group and that interaction with family and friends increased markedly after the amputation. Friends were found to play an increasingly important role 
as the older amputee aged. The importance of family support is demonstrated in numerous studies. Stable, supportive relationships between a disabled person and his or her family are repeatedly found to be important facilitators of adjustment (Guttman, 1976; Kerr \& Thompson, 1972; Petrus \& Balaban, 1953; Thorn, Von Salzer, \& Fromme, 1946).

MECHANISMS OF SOCIAL SUPPORT

The literature described thus far is correlational, but suggestive of a causal relationship between social support and successful coping with life stressors in general and with severe physical disability in particular. The task remaining is to identify what processes operate, within the context of what we collectively call social support, that might account for the observed relationships. In the next sections, three types of explanations are examined. First, explanations that emphasize the possibility that the correlational data in fact do not reflect a causal relationship between social support and successful coping are examined. Second are explanations that assume causality and identify mechanisms through which social support may operate to improve well-being. Third, these same mechanisms are examined through the lenses of three social psychological theoretical perspectives. 
Social support as a correlate or consequence of coping

Because of the correlational nature of most of the research in this area, several investigators have raised questions concerning the causal relationships between social support and better coping (Heller, 1979; Silver \& Wortman, 1980a). A prospective longitudinal study in which different levels and types of social support at one time are shown to predict coping at a later time has not been carried out (silver \& Wortman, 1980a). In the absence of such a study, observed relationships between social support and coping are open to several alternative explanations.

Underestimation of suppert. Individuals who are poor copers, badly adjusted, or ill may underestimate the amount of support available. This explanation suggests that persons who are coping poorly have a distorted view of their world. They may underestimate the availability of support because of factors such as low self-esteem or anxiety.

Coping as a Determinant. How well one copes may determine the level of social support one receives. Persons who do not cope well may alienate their support system because of social incompetencies. Poor copers may be more likely to behave in socially inappropriate ways, making others feel vulnerable, awkward, or inadequate (Coates, Wortman, \& Abbey, 1979; Wortman \& Dunkel-Schetter, 1979). An example of this phenomenon is provided in an experimental study by Coyne (1976), who found that 
depressed individuals induced depression, anxiety, and hostility in nondepressed persons conversing with them by telephone. Through nonreciprocal high levels of disclosure of intimate problems, the depressed individuals seemed to arouse guilt in others while inhibiting any direct expression of annoyance or hostility.

\section{Social support as a Mediator of coping}

Notwithstanding the explanations discussed above, it is generally believed that social support plays an important ameliorative role by tempering the impact of stressful events on human beings. Based on a synthesis of work by numerous others (Brandt \& Weinert, 1981; Caplan, 1974; Cobb, 1976; Coelho, Hamburg, \& Adams, 1974; Cohen \& Mckay, 1980; Cronenwett \& Kunst-Wilson, 1981; Gore, 1973; Hirsch, 1980; Lewinsohn, 1974; Norbeck, Lindsey \& Carrieri, 1981; Pinneau, 1976; Silver \& Wortman, 1980a; Vachon et al., 1979; Walker, MacBride, \& Vachon, 1977; Wortman \& Dunkel-schetter, 1979), social support will be conceptualized as instrumental, affective and cognitive in nature. These three categories of support are viewed as conceptually encompassing the forms of support identified in the literature. These three categories of support are viewed as being distinct from one another but closely related; a given behavior may entail more than one kind of support. The mechanisms through which social support might operate through these three modes is the focus of discussion here. 
Instrumental support. An important role of support persons is frequently the provision of tangible aid whether it be financial assistance, transportation, or help in carrying out activities of daily living. Individuals providing social support may become extensions through which one is able to indirectly control outcomes which were previously under one's direct control. Heller (1979) suggests that the perception that a supportive group of individuals is behind you may be as important in some instances as the actual help provided.

Cegnitive support. Support persons may also provide a large variety of information that enhances the individual's capacity to negotiate her or his world. The information provided may range from the very specific "how to" variety to more subtle types concerning how the individual should feel as well as the appropriateness of certain feelings and goals. For example, support persons may help the individual to realistically appraise the threat of a situation and his or her ability to deal with the stressors involved. This may take the form of acknowledging the appropriateness of the individual's beliefs and feelings or of assisting him or her in modifying perceptions. Such information should be critical to the development of feelings of autonomy, the elimination of counterproductive defense mechanisms, and the establishment of realistic goals. Support persons may be very important in helping the disabled person to redefine 
the disabled state in a way that facilitates acceptance and the attribution of positive meaning to the disability.

Affective support. Finally, social support likely has an effect on the recipient by communicating direct positive affect. The individual is given feedback that he or she is loved and respected and "belongs." such support is likely to foster positive self-esteem and a sense of self-efficacy.

Undoubtedly, these three types of support are highly interactive in mediating the effects of environmental stress. In addition, it is important to note that the perceived availability of these benefits may be as valuable as the actual receiving of them. Thus, the individual who feels that instrumental, cognitive or affective support is available should she or he need it may benefit as much as the individual who actually receives these benefits. The social pschological theoretical perspectives that follow should further clarify how these social support mechanisms facilitate coping and satisfaction with life.

\section{Social Psychological Theoretical Perspectives}

To the previous explanations of social support, we can add perspectives gained from three social psychological theories: learned helplessness (perceived control), social comparison, and exchange. By examining these perspectives jointly, it should be possible to identify with greatex clarity and confidence the specific mechanisms involved. 
Learned Helplessness Theory. Seligman (1975) first proposed learned helplessness theory as a model to explain depression in humans. According to this theory (Abramson, Seligman, \& Teasdale, 1978; Seligman, 1975), when individuals are exposed to uncontrollable outcomes they develop expectations that future outcomes will also be uncontrollable. This in turn leads to the motivational, cognitive, and emotional deficits associated with helplessness and depression.

In a reformulation of the learned helplessness theory, Abramson et al. (1978) proposed that the degree of helplessness and depression will vary as a function of the type of attribution the individual makes about the cause of the noncontingency. Attributions about the cause can be classified along three orthogonal dimensions: internal/external--internal causes stem from the individual and external causes from the environment; (b) stable/unstable--stable factors are long-lived and recurrent, whereas unstable factors are short-lived and intermittent; and (c) global/specific--global factors occur across situations, whereas specific factors are unique to a particular context. Each type of attribution has specific consequences for the individual: attributions to internal/ external factors should affect self-esteem, attributions to stable/unstable factors should determine the long-term conseguences of a particular experience, and attributions to global/specific factors should determine the extent to 
which individuals will generalize a particular experience to other situations. In general, the most damaging effects are expected when an individual makes internal, stable, global attributions concerning the cause of an undesirable event. As an example, consider a man who loses his spouse, blames himself, and believes that the death was largely due to his uncaring and negligent nature (internal, global, stable attribution). Compared with another man who is convinced that he lost his wife because of a rire, incurable disease (external, unstable, specific attribution), the former it is hypothesized should suffer greater self-esteem deficits, the experience should generalize to a larger variety of events and situations, and the negative impact of the loss should be longer lasting. In trying to understand the elderly spinal cord injured individual's adjustment to his or her disability, this perspective suggests that one must examine not only the individual's perception of control over her or his present daily life, but also the degree to which the individual feels she or he had control over the situation which led to the disabling event.

Although this model has not been rigorously tested with an aged population, it has stimulated considerable research on aging in general and on the impact of institutionalization on aged individuals in particular. Several researchers (Langer \& Rodin, 1976; Schulz, 1976, 1978) have suggested that aging is a process characterized 
by large decreases in the individual's ability to control important outcomes as a result of shrinking financial resources, decreased physical ability, loss of work role, etc. According to this view of aging, then, the withdrawal and high rates of depression observed among the aged are attributable in part to the shrinking sphere of personal control over the environment. Several studies have been carried out to test derivations from this model. In particular, data are now available demonstrating the positive impact of control-enhancing interventions on the institutionalized aged (Langer \& Rodin, 1976; Schulz, 1976), the long-term effects of these interventions (Rodin \& Langer, 1977; Schulz \& Hanusa, 1978), the relationship between these interventions and individual differences (Schulz \& Hanusa, 1980), and the relationship between competence and control in promoting health-related outcomes among the institutionalized aged (Schulz \& Hanusa, 1979). Lending further support to the theoretical soundness of the learned helplessness perspective as applied to psychological adjustment of the elderly is an instrument designed by Reid and ziegler (1980) to measure the desire for, and expectancy of, control over various aspects of daily life. When the contributions of expected and desired control subscores on the instrument were compared with various measures of adjustment, it was always the expectancy of control score that received the greater weight. Those results support the view that it is not so 
much the desire for control over particular aspects of life that affects the sense of well-being among the elderly, but rather the expectancy of whether or not one can attain desired outcomes. Reid and ziegler state that the results of their study support the proposition that perceived control is an important factor in psychological adjustment among the elderly.

With respect to spinal cord injured persons, silver and wortman (1980b) found that although most persons with newly acquired injuries had unrealistically positive expectations about their prognosis, they did differ in how they expected this improvement to occur. As learned helplessness theory would predict, those who believed their improvement depended on their own efforts were more likely to cope well than were those who felt improvement was out of their hands. However, this relationship between expectation of control and coping effectiveness has been demonstrated only in the immediate post-injury period and the stability of the relationship over time remains to be validated.

Viewed through the lens of learned helplessness theory, social support may facilitate coping with a severe physical disability because it fosters the perception of control and thereby promotes feelings of competency and an active, coping orientation toward life. The issue of control is likely to be a very important one for the person faced with paraplegia or quadriplegia, since this person 
has lost so much control over his or her own body and physical environment. Accompanying these losses is the additional threat to control over the psychological and social environment in that this person's sense of self and role identity may be greatly disrupted. For example, Rogers and Figone (1979) found that less than one half of their sample of quadriplegics were committed to goaldirected activity, defined as the initiation of concrete activity to accomplish self-defined life goals in any number of life arenas, such as occupation, education, leisure, and self-maintenance. This lack of goal-directed activity could be interpreted as a learned helplessness response, i.e., a belief by the injured that they are incapable of effecting desired outcomes.

Significant others in the environment can help the individual regain or incrense his or her perception of control over the psychosocial and physical environment. These support persons may do this simply by assuring the individual that they are available as a stable part of the environment that the individual can count on and, in a more active way, by fostering positive internal selfattributions and encouraging direct action through statements such as "I know you can do it," "You've never been a quitter," or "Reep on trying, you're doing a little more every day." support may also operate by encouraging the individual to focus on more positive aspects of a difficult situation, thus leading the individual to 
appraise the situation as less threatening and as one that he or she can cope with. Providing accurate information may also be viewed as increasing the actual and perceived control of the individual, since reality-based information provides the basis for a problem-solving approach to the many physical and emotional difficulties associated with paraplegia and quadriplegia.

Social Comparison Theory. Nearly three decades ago, Festinger (1954) proposed a theory of social comparison processes. The underlying assumption of the theory is that there exists in humans a basic drive to evaluate their own opinions and abilities. In the absence of objective evidence (e.g., physical reality), persons will compare themselves with others to assess the validity of their views. In Festinger's words, "An opinion, belief, and attitude is 'correct,' 'valid,' and 'proper' to the extent that it is anchored in a group of people with similar beliefs, opinions, and attitudes" (1950, p. 272). Sociological counterparts to social comparison theory can be found in the work of Cooley (1956) and Mead (1934). The relevance of social comparison processes to an understanding of adjustment to late life is evident once we recognize that there is no physical reality that readily provides an answer to questions such as "HOw should I feel about my life?" and, "How happy am I?" With the possible exception of extreme cases, how we respond to or feel about a wide array of circumstances and outcomes depends on the 
opinions, beliefs, abilities, and attributes of relevant others. Who are the relevant others for the aged or, more precisely, for the physically disabled aged? This is a recurrent and pivotal question for several theories such as learned helplessness and, indeed, for several sociological theories traditionally identified with social gerontology. Social comparison theory, and a recent derivation, temporal comparison theory (Albert, 1977), suggest two possible answers to this question. One option is to identify similar others in the environment and use them as reference persons. This is reflected in corollary III(A) of social comparison theory, which states that, given a range of possible persons for comparisons, one will choose someone close to one's own ability or opinion (Festinger, 1954).

A second option is to make historical, or temporal, comparisons. This is an intraindividual comparison in which present circumstances, outcomes, abilities, etc., are compared with past circumstances, outcomes, abilities, etc. (Albert, 1977; Schulz, 1982, a and b).

To the extent that any comparison yields personally unfavorable discrepancies, individuals are likely to feel bad about themselves or their situation. Thus, for example, old persons who perceive relevant others to be considerably better off than themselves or who find the past to be better than the present are likely to experience negative affect. Positive affect should result when comparisons yield personally favorable discrepancies or 
perceived equality.

Which of the two processes dominates should have important consequences for adjustment to late life. Given the many real declines associated with old age (e.g., physical and cognitive ability, economic resources) in addition to those associated with a spinal cord injury, comparisons based on the past (particularly the preinjury period) are likely to yield personally unfavorable ciscrepancies and hence negative affective states. Alternatively, the aged spinal cord injured individual who uses her or his contemporaries as comparison others should be less likely to experience personally unfavorable discrepancies.

As an example, consider the spinal cord injured person and the types of events he or she is likely to encounter. Clearly, if such an individual compares preinjury leisure activities, physical mobility, and daily events in general with present conditions, he or she is likely to experience negative affect. However, if the same individual uses as a basis for comparison the circumstances and outcomes of similar individuals in the immediate environment (other spinal cord injured older persons), there is less likelihood of experiencing personally unfavorable discrepancies and hence negative affect. This analysis is supported by Rohrer, Adelman, Puckett, Toomey, Talbert and Johnson (1980) who report that group meetings for spinal cord injured individuals and their families are 
beneficial in decreasing feelings of anxiety, helplessness, and isolation; in increasing knowledge and understanding of spinal cord injury; and in facilitating mutual support between family members. Mann, Godfrey, and Dowd (1973) also report the beneficial effect of peer group counseling in the psychological rehabilitation of spinal cord injured persons.

The type of comparison processes older persons engage in can be inferred from some recent data reported by zemore and Eames (1979). In their study, residents of old-age homes reported no more symptoms of depression than either a group of waiting-list controls or a noninstitutionalized young group. This would be expected if individuals engage in contemporary rather than historical comparison processes. A similar inference can be derived from the large number of studies on morale and well-being in the aged (for a review of this literature, see Larson, 1978). Despite large differences in objective conditions of young, middle-age, and aged individuals, few studies report any age-related differences in self-report of well-being and morale. One interpretation of these data is that different age groups adjust their expectancies in line with the prevailing conditions for that group. Such strategies are adaptive in that they minimize disappointment, although they also tend to promote the status quo.

Further support for the view that persons may tend to make predominantly contemporary comparisons is found in 
data reported by Rogers and Figone (1979) which show that quadriplegic clients desired more contact with peer models or successful rehabilitants who were similar to themselves. There are a number of reasons why severely disabled persons may desire interaction with other disabled individuals. Contact with similar others who are coping successfully with paralysis may foster the belief and hope that one will be able to do the same; this contact may enable the individual, in attributional terms, to make positive internal attributions about his or her ability to achieve similar goals. Contact with successful models may also assist the individual in accepting that he or she is different, but equal, by deemphasizing physique as a value and emphasizing other attributes, such as personality, intellect, and interpersonal skills, as focal points of comparison with others. Finally, contact with similar others may increase perceived control by providing information about future problems and possible solutions, thus enabling the individual to rehearse for coping with future potential problems. In general, a successful model can convey that one can feel good even though one is old and handicapped. This discussion illustrates the complementary nature of learned helplessness and social comparison theories. By engaging in comparisons with others that yield personally favorable discrepancies or perceived equality, the individual is able to make attributions about herself or himself that foster a sense 
of personal control.

Mckay (1980) states that despite a disproportionately high percentage of rehabilitation counselors who are themselves disabled, the effect of counselors' physical disability on similarly disabled clients' perceptions of the counselors' social influence (attractiveness, expertness, and trustworthiness) and empathy is not understood. Mckay conducted an experiment in which 48 wheelchair-using persons (75 percent male, 87 percent spinal injured) viewed videotapes of two counselors, one disabled (wheelchaired) and one nondisabled, who had been coached to be alternately high and low in social influence and empathy. Each subject evaluated the counselors under the four experimental conditions and selected a preferred counselor from the disabled/nondisabled and high/low social influence counselors. High-influence/disabled counselors were rated significantly more desirable than high-influence/nondisabled counselors. No such preference, however, was shown for low-influence/disabled counselors, whose ineffectual behavior made them less desirable. These results are consistent with the view that contact with similar others who are coping successfully with paralysis is much desired, in that such contact facilitates positive internal attributions and an increased perception of control.

Family members and friends can also help the spinal cord injured person to make social comparisons that increase positive feelings about one's self and life 
situation. These support persons may do this by reminding the injured person of things that are positive in his or her life and by helping the injured person to realign his or her values in accordance with remaining assets. For example, such a support person may remind the injured person that he or she still has a loving family, a nice home, and full use of mental abilities. This analysis is supported by two occupational therapists (Rogers \& Figone, 1979) in their work with quadriplegic clients. These authors identify the family as crucial in providing an emotional climate conducive to adaptation and the formation of an acceptable self-image post-injury.

Exchange Theory. Exchange theory (Dowd, 1975) is a more recent entry into the social gerontology theory pool. Broadly speaking, it attempts to explain the decreased social interaction of the aged in terms of economic exchanges a' la Blau (1964), Emerson (1962, 1972), and Homans (1961). The basic assumption of all exchange theories is that interactions between individuals occur and are sustained because the rewards (e.g., money, esteem, compliance, novelty) are greater than the costs (e.g., time, boredom, anxiety). An interaction is imbalanced when one of the partners in a social exchange is unable to reciprocate the rewarding behavior of the other. According to Dowd, the aged become increasingly unable to enter into balanced exchange relationships with other groups because of the decline in power resources associated with old age. 
The imbalanced exchange ratio ultimately forces the aged to exchange compliance--a costly generalized reinforcer--for their continued sustenance. Disengagement occurs when the costs of compliance and self-respect reach a point "beyond which additional costs become prohibitive" (Dowd, 1975).

Dowd cautiously describes the aging exchange model as a "preface" to theory. This seems wise since many questions are left unanswered (Schulz, 1982a). However, the basic idea of exchange theory, that social exchange must be reasonably reciprocal in order to be maintained, is relevant to an understanding of the workings of a social support system.

Froland's (1978 a and b) research suggests that an important, necessary characteristic of the support system for the severely disabled is that the exchanges be mutual. Without some form of reciprocity, the door is left open for maladaptive relationships in which the quadriplegic or paraplegic fears alienating anyone on whom he or she must depend for the simplest functions (Mann et al., 1973). Working with cancer patients, Weisman and Worden (1975, p. 74) also noted that survival was better among patients who maintained active and "mutually responsive relationships, provided that the intensity of demands was not so extreme as to alienate people responsible for the patient's care." As exchange theory would predict, these studies illustrate the need of the disabled person to contribute something to an interaction despite her or his reduced capacity to do 
so.

\section{SUMMARY}

A study of the type proposed is felt to be important in developing the theoretical understanding basic to the formulation of policy decisions and interventions aimed at elderly spinal cord injured persons, a population likely to grow larger in coming decades. Although studies have been conducted on persors sustaining spinal cord injury, the focus has predominantly been on younger individuals. In addition, many of these studies provide descriptions of the problems of spinal cord injured persons, but do not provide a systematic theoretical base explaining why some persons adapt better than others. This research will attempt to do so.

Elderly spinal cord injured persons may be thought of as a prototype of a severely disabled group; it is hoped that knowledge gained from a study of this group can be applied to other elderly disabled groups. Elderly spinal cord injured persons undoubtedly experience many of the same problems as do younger persons; however, differences may exist in the stability of the support system of the older person due to death or health problems of friends and family. As discussed, evidence exists to support the importance of social support in facilitating coping with stressors. Thus, identification of the nature of the social support existing for the elderly disabled person is 
a focus of this research. In addition, this study will attempt to further explain what it is about "social support" that is helpful, through the use of several complementary social-psychological theories. It is hoped that this exploration will add significantly to our understanding of the processes involved in social support as a facilitator of coping with severe disability. 


\section{CHAPTER III}

\section{METHODS}

THE SAMPLE

The sample is composed of 100 spinal cord injured persons living in non-institutional community settings. Criteria for inclusion in the sample were the prestnce of paraplegia or quadriplegia, an age of 40 or over, the absence of a progressively deteriorating disease state, and agreement to participate in the study. subjects were located through agencies and institutions working wih spinal cord injured persons; namely, the portland Veterans Administration Medical Center, the oregon Paralyzed Veterans Association, and the Oregon Trail Chapter of the National Spinal Cord Injury Association. All subjects in the sample were Caucasian and predominantly (908) male. The age of subjects ranged from 40-73 with the mean age being 56 and the median age, 56.5 years. The age at time of injury ranges from 12-68, thus this sample is composed of persons who have lived with a physical disability for varying lengths of time. The mean age of injury was 35 years and the median age of injury 33 years.

The causes of spinal cord injury in this sample cover a wide range with the leading cause being vehicular 
accidents, followed by polio, other accidents including those caused by falls and participation in sports, medical problems other than polio, and penetrating wounds. Although a large proportion of the sample were veterans (758), the majority (838) of the injuries were non-service connected. The injuries sustained by this sample resulted in paraplegia (40 incomplete and 27 complete) and quadriplegia (29 incomplete and 4 complete).

The process of locating subjects for this study was time-consuming and the resulting sample of 100 persons represented considerable effort. Once persons were located and contacted for inclusion in the study, the refusal rate was very low. Four persons refused to participate, primarily for the stated reason of not being interested. All eligible persons agreeing to participate in the study were included in the sample. Two potential spinal cord injured subjects of the appropriate age group were excluded from the sample due to the existence of multiple sclerosis, a progressively deteriorating disease.

DATA COLLECTION AND HUMAN SUBJECTS PROTECTION

Data collection occurred over a nine month period from July, 1981 through March, 1982. Structured interviews of approximately one hour in duration were conducted in subjects' homes in 41 cases, in other locations such as workplace in 5 cases, and by telephone in 54 cases. Interviews were conducted by telephone when the subject 
lived outside of the greater Portland metropolitan area.

A letter explaining the nature of the research study was sent to prospective subjects requesting their participation. At the time of the interview, interviewers again explained the nature and purpose of the study and offered to answer any questions. When face to face interviews were conducted, an informed consent form was completed prior to the interview. When interviews were conducted by telephone, an informed consent form enclosed in a stamped envelope addressed to the portland state University Institute on Aging was sent to subjects.

subjects were assured that persons other than the interviewers would have access to data only in aggregate form, thus preserving the anonymity of respondents. Questionnaires were coded by number rather than by the name of the individual to further safeguard the identity of the respondent.

Sensitivity was shown to the possibility that asking people to discuss problematic situations may evoke a certain amount of anxiety. Hence, care was taken to avoid questions that would generate high levels of anxiety in the average subject. This was accomplished by carefully pretesting the research instrument to identify questions which appeared to generate respondent discomfort. In all, risk to subjects was judged to be very low. The interviews did not appear to generate anxiety in subjects and most persons expressed interest and enjoyment in participation. 
Ninety-seven subjects said they would participate again in a similar study if asked. Care was taken throughout the study to treat subjects with respect and to show approsiation for their participation in the study.

In sum, the investigator is in agreement with the National Institute on Aging's conclusions regarding the protection of elderly subjects (Rrotection of Elderly Research Subjects, U.S.D.H.E.W., 1977). Most salient to the current study of these conclusions is the distinction between research that benefits the elderly subject and that which does not, the problems of vulnerability of elderly subjects, and the potential for paternalism and stigmatization. The physical and psychological risks of participation in this study were deemed minimal and benefits to participants and society as a whole substantial. This research study was approved by the Portland Veterans Administration Medical Center and the Portland State University Committee on Human Research which are responsible for protecting the rights and welfare of human subjects.

\section{RESEARCH QUESTIONS}

Extensive data were collected in order to answer a wide range of questions regarding the characteristics of community-residing, middle-aged and elderly spinal cord injured persons. In broad terms, the questions to be addressed in this study are: 
1) What are the demographic characteristics of the sample?

2) What is the extent and nature of subjects' participation in recreational, group and community activities and services?

3) What are the health status characteristics of respondents?

4) What is the degree and nature of social support perceived by respondents?

5) What is the nature of social comparisons made by respondents?

6) What is the degree and nature of respondents' perception of control over various life situations?

7) What is the degree and nature of respondents' subjective well-being?

8) What are the correlates of subjective well-being in this sample? (Based on the review of the literature and the conceptual framework of this study, it is predicted that the variables most highly correlated with the measures of subjective well-being will be health, income, and the social-psychological variables of social support, social comparison, and perceived control.)

9) To what extent can subjective well-being be predicted by measures of perceived social support, social comparison, control and other 
social-psychological and demographic variables?

OPERATIONAL DEFINITIONS

Subjective Well-Being

The frequently studied constructs of life satisfaction, morale, and adjustment are highly interrelated and may be considered a single construct (Larson, 1978; Lohmann, 1980). Given this interpretation, these and similar constructs will be used interchangeably to denote an overall state of self-reported psychological well-being which will be called subjective well-being. Subjective well-being will be measured by the Index of Psychological Well-Being, the Life Satisfaction Index-A, and the Center for Epidemiologic studies Depression scale.

Social support

Social support is defined as a construct comprised of those mechanisms by which interpersonal relationships promote positive outcomes, such as assisting an individual to cope with stressful life events. Social support is conceptualized in this study as instrumental, affective, and cognitive in nature.

Instrumental support. Instrumental support is defined as the provision of tangible aid, whether it be financial assistance, transportation, or assistance with activities of daily living.

Affective support. Affective support is defined as 
the communication of direct positive affect; for example, feedback that one is loved, respected and "belongs."

Cegnitive support. Cognitive support is defined as the communication of information that helps the individual to negotiate her or his world. The information provided may range from the very specific "how to" variety to more subtle types enabling individuals to appraise the appropriateness of their feelings, beliefs, attitudes, and goals.

\section{Level of Spinal cord Injury}

"Level" refers to the site of the spinal cord injury. In general, the higher the injury, the greater the loss of function. Spinal cord injuries are generally categorized into two major levels: paraplegia and quadriplegia. Quadriplegia is an injury at the cervical (neck) level; paraplegia is an injury below this level in the thoracic, lumbar and sacral regions of the spinal cord. Although variations in functional ability depend on the exact nature and level of the injury, the term paraplegia is generally used to refer to the paralysis of both lower limbs. The term quadriplegia refers to the paralysis of both arms and both legs. Injuries are also categorized as complete or incomplete. Complete lesions end sensation and voluntary movement below the injury level; whereas, incomplete lesions allow some sensation and/or voluntary movement. 


\section{INSTRUMENTS}

Data were collected through use of the Elderly spinal Cord Injury Questionnaire designed for this study and three established measures of subjective well-being. The questionnaire was administered as a structured interview by skilled interviewers and took subjects approximately one hour to complete. The questionnaire was pre-tested on ten subjects by the two interviewers, both of whom were female mental health professionals.

\section{Elderly spinal cord Injury ouestionnaire}

The following are major categories of data collected in this instrument:

Demographic. Information regarding age, sex, race, marital status, children, education, religion, employment, income, and residential characteristics was obtained.

Becreational/Group Activities/Community Services. Information regarding types and numbers of recreational activities engaged in by respondents was obtained as well as data on whether these activities were individual or group-oriented. subjects were asked to describe group memberships, use of community services, and the frequency of involvement with these groups and community services.

Health status. Subjects were asked to rate their health status on a Likert-type scale; compare their health now to a year ago; and indicate the level of the spinal cord injury, age at injury, cause of injury and whether the 
injury was service-connected, i.e., incurred during service in armed forces. Questions were also asked regarding the existence of chronic health problems, hospitalization, projected physical condition, and assistance needed with activities of daily living (ADL), i.e., dressing, bathing, eating, cooking, toilet, driving a vehicle, shopping, laundry and house cleaning. A scale consisting of the nine items indicating the degree of assistance required with various activities of daily living was constructed. An SPSS Reliability Analysis Program was used to determine the internal consistency of the items. The reliability coefficient for this scale was high, Cronbach's alpha = 0.94. An attempt was made to construct an index of health status from multiple items but the alpha level of 0.56 obtained was not considered high enough to combine these items into a single scale. Thus, remaining health items were treated individually in the data analysis.

Social Network/Support. Descriptive information was obtained regarding the number of support persons and the age, sex, disability status, residence location, and relationship of each person to the subject. Questions were also asked regarding reciprocity, duration of the relationship, frequency of contact, importance of and satisfaction with each relationship, and loss of important persons in the last several years.

In order to measure perceived social support, each subject was asked to name up to five persons who were 
important sources of help, support, and guidance. After identify ing these persons, subjects were asked to indicate on a Likert-type scale how much each person helped them in a variety of ways. A social support scale was constructed of 11 items measuring instrumental, affective, and cognitive support. A total social support score was obtained by adding the ratings on the 11 items resulting in a potential range in total support scores from 0 (no support) to 275 (five persons giving very frequent support on all 11 items). Reliability analysis of the social support scale indicated a Cronbach's alpha coefficient of 0.90, indicating a high degree of internal consistency of items. The internal consistency of items lends support to the conceptual soundness of utilizing a total social support score based on the three subscales of instrumental, affective, and cognitive support. The Cronbach's alpha coefficient for each of the three subscales was as follows: instrumental support, 0.81; affective support, 0.96 ; and cognitive support, 0.95 . These reliability coefficients may be interpreted as indicating a relative homogeneity of items within each subscale. The high reliability coefficient of the total social support scale again may be interpreted as the items measuring a relatively homogeneous construct of social support or, as an alternate explanation, the possibility that subjects did not differentiate closely beween forms of social support and tended to view the support given by another person in a 
global fashion.

In addition to obtaining a total social support scale for each subject, two items measuring satisfaction with the amount and quality or cleseness of social contact with others were combined to form an index of overall satisfaction with social contact with others. The Pearson correlation coefficient between these two items was 0.68 , p $<0.001$.

Secial comparison. In order to obtain a measure of favorable/unfavorable social comparisons, a scale consisting of five items was constructed. The five items were Likert-type scales on which the individual indicated how good his/her life situation was compared to most people, others the same age, others with a similar disability, his/her life before the disability, and how good his/her life would be without the disability. The Cronbach's alpha indicating the internal consistency of items was 0.80 .

Subjects were also asked with whom they compared themselves and on what characteristics. They were also asked what things or values came to mind when they were thinking about their life situations as compared to those of others.

Control/Attributions. A scale consisting of five Likert-type items was constructed to measure perceived control. Subjects indicated to what extent they felt able to achieve or obtain what was important to them, make their 
interactions with people end up the way they expected, count on themselves to cope successfully when stressed, solve problems in their lives and to what degree they perceived the good things that happened to them as a result of their own actions. The Cronbach's alpha for this scale was 0.81 , again indicating a relatively high degree of internal consistency.

Subjects were also asked questions regarding what factors they blamed for causing their disability, the extent to which they felt they could have avoided the circumstances which caused the disability, major difficulties in their current life, the extent to which these difficulties are due to their own actions or inactions, the extent to which they perceived their disability as the worst to the best thing that could happen to them in their lifetime, and a description of any purpose or positive meaning their disability has had.

Happiness/Depression/Hope/Fears. Several questions regarding subjective well-being were asked to complement the three outcome measures to be described next. Subjects were asked to indicate on Likert-type scales how happy they were at this stage of their life, how often they felt depressed, and how hopeful they felt about their future. Subjects were also asked to describe how they coped with feelings of depression and what their greatest fears about the future were. 
Index ef Psychological Well-Being (IPWB) (Berkman, 1971)

This is an eight-item, self-report scale designed to measure mental health in a general population. Composed of both positive and negative feeling-state items, the index describes the relative strength of an individual's positive and negative feelings, rather than an absolute amount of one or the other. Negative and positive feelings scores are computed separately and combined on a matrix to form a total score of psychological well-being. For example, an individual with a negative feelings score of three and a positive feelings score of eight receives a total score of two on the scale.

$\begin{array}{ccccc} & \text { MATRIX } \\ \text { Negative } & \text { Positive } & \text { Feelings score } \\ \text { Feelings score } & 7-9 & 4-6 & 3 & 0-2 \\ 0-1 & 1 & 2 & 3 & 4 \\ 2-3 & 2 & 3 & 4 & 5 \\ 4-5 & 3 & 4 & 5 & 6 \\ 6-15 & 4 & 5 & 6 & 7\end{array}$

This method of measuring psychological well-being helps to explain why some people who seem to have a very high number of negative forces acting on them are still able to maintain a sense of well-being, while others who appear to be exposed to only a small number of negative experiences become extremely depressed. 
The items in this scale come from those used by Bradburn and Caplovitz (1965) to measure psychological well-being in their studies of happiness. For the purpose of this study, one item on the Index, "so restless you couldn't sit long in a chair," was changed to "so restless you had to move about," since persons in this study cannot get up and walk. Berkman (1971) cites a parallel association between scores on the Index of Psychological Well-Being and mental health/life stress ratings by psychiatrists in the Midtown study (Langner \& Michael, 1963) as an indication of criterion-oriented concurrent validity.

The Life satisfaction Index-A (ISIA-A) (Adams, 1969)

This is an 18 item self-report scale designed to measure subjective psychological well-being. The LSIA-A is multidimensional, composed of four factors interpreted as mood tone, zest for life, congruence between desired and achieved goals, and a fourth unnamed dimension. Adams suggests this fourth dimension represents a combination of resolution/fortitude and congruence between desired and achieved goals. The LSIA-A is identical to the LSIA developed by Neugarten, Havighurst and Tobin (1961) except for the deletion of two items from the LSIA which Adams rejected due to poor item reliability and minimal contribution to the total life satisfaction score. Inter-correlations have been demonstrated between the 
LSIA-A and other measures of life satisfaction, e.g., LSIA, .989 ; LSIZ, .952; Philadelphia Geriatric Center Morale Scale, .779; and Cavan, .799 (Lohmann, 1977). No reliability estimates are reported for the LSIA-A. However, the LSIA-A and LSIZ are highly correlated and the LSIZ has a split half reliability coefficient of .79 (Wood, Wylie, \& Sheafer, 1969). Adams concludes that the LSIA-A is composed of one major factor which he calls life satisfaction. Analysis of the data in the preient study resulted in a Cronbach's alpha of 0.76 , indicating reasonable internal consistency of items.

Center for Epidemiologic Studies--Depression Scale (CES-D) (Radloff, 1277)

This is a 20-item self-report scale designed to measure depression symptoms in the general population. The items were selected from previously validated longer scales (Beck Depression Inventory, 1961; Zung's self-Rating Scale, 1965; MMPI-Depression Scale). The CES-D is composed of four factors interpreted as depressed affect, positive affect, somatic and retarded activity, and an interpersonal factor. The CES-D scale was designed to avoid the problem characteristic of some depression scales of placing too much emphasis on somatic items which frequently characterize non-depressed older or disabled persons. Radloff (1977) reports that the internal consistency, test-retest reliability, and validity of the scale are high and correlations between the CES-D and age, social class, 
and gender are minimal. Content validity was established based on the clinical relevance of symptoms which comprise the items of the scale. Criterion-oriented validity was also established by correlations with other valid self-report depression scales (Bradburn, 1969, $I=.61$; Langner, 1962, $x=.54$; and Lubin, 1967, $I=.51$ ) and with clinical ratings of severity of depression $(r=.56)$. Construct validity was established by demonstrating a pattern of relationships with other variables. Reliability of the scale was established through test-retest procedures $(I=.54)$ and analysis of internal consistency (Cronbach's alpha $=.85$; split halves $x=.77$ ). The CES-D is not designed to be used as a clinical diagnostic tool, but is perhaps most useful in identifying "groups at risk of depression." Reliability analysis of the scale resulted in a Cronbach's alpha of 0.83 , indicating high internal consistency of items. Based on analysis of data in this study of spinal cord injured persons, the Pearson correlation coefficient between the CES-D and the LSIA-A was $-.69, \mathrm{p}<0.001$, between the CES-D and the IPWB, -.62, $p<0.001$, and between the IPWB and the LSIA-A, .73, p < 0.001 .

\section{DATA ANALYSIS PROCEDURES}

The initial steps in data analysis entailed the development of a codebook, the coding of raw data onto a Fortran coding Form, keypunching of data onto cards, and 
the storing of data on a permanent computer tape.

An extensive qualitative and quantitative analysis of the data collected in this study was carried out. The first stage of data analysis entailed obtaining frequencies and descriptive statistics on the sample. This was followed by the computation of numerous Pearson correlation coefficients to obtain a broad picture of which variables correlated significantly with each of the outcome measures of life satisfaction, psychological well-being and depression and with each other.

The next stage of analysis entailed the conducting of reliability analyses of indexes constructed to measure activities of daily living, social support, social comparison, and perceived control. Reliability analyses were also completed on the outcome measures of well-being, life satisfaction and depression. All of these reliability analyses revealed a Cronbach's alpha of 0.70 or higher indicating the internal consistency was high enough to interpret the items as measuring the same general construct.

Variables of particular interest because of their theoretical value to this study or for their contribution to past studies of subjective well-being were then analyzed by t-tests or one-way analysis of variance to look for differences in measures of subjective well-being based on group membership and to detect possible curvilinear relationships (ANOVA) likely to be obscured by Pearson 
correlation coefficients.

The final stage of data analysis involved the use of hierarchical multiple linear regression analysis to determine to what degree subjective well-being could be predicted from the social-psychological variables of particular theoretical interest (social support, social comparison, perceived control, perception of disability) and demographic variables generally considered to influence subjective well-being (health, income). The variables of health and income were entered first into the regression equation followed by the social-psychological variables to determine the additional impact of these socialpsychological variables in predicting subjective wellbeing.

The moderate size of the sample also made it possible to conduct extensive qualitative analysis of the data; for example, a description of the highest and lowest scoring subjects on the measures of subjective well-being.

All computer-assisted data analysis was conducted through use of the statistical package for the social Sciences, 2nỏ edition (Nie, Hull, Jenkins, Steinbrenner \& Bent, 1975), and SPSS Update (Hull \& Nie, 1979).

Keeping in mind that random sampling was not possible in this study, that all variables are not necessarily normally distributed, and that some variables represent ordinal level data treated as internal level data, the analysis of these data with parametric statistics is 
nonetheless viewed as appropriate, in line with statistical procedures currently used in social science research, and as meeting the assumptions of parametric tests to a degree compatible with the purposes of this study. In support of this approach to statistical analysis, Kerlinger (1973, p. 287) states that

Unless there is good evidence to believe that populations are rather seriously non-normal and that variances are heterogeneous, it is usually unwise to use a nonparametric statistical test in place of a parametric one. The -eason for this is that parametric tests are alinost always more powerful than nonparametric tests.

Kerlinger also quotes Anderson (1961, p. 315) as stating, "It was concluded that parametric procedures are the standard tools of psychological statistics, although nonparametric procedures are useful minor techniques." 


\section{CHAPTER IV}

\section{FINDINGS}

The data are analyzed by the nine research questions identified previously. QUESTION 1: WHAT ARE THE DEMOGRAPHIC CHARACTERISTICS OF
THE SAMPLE?

A typical demographic profile of a subject in this sample is a 56 year old Caucasian male, married with two children. He is a veteran, has a high school diploma, is currently unemployed, perceives himself as moderately religious and claims a Protestant affiliation. His income is approximately $\$ 10,000$ a year, drawn primarily from Social security and other disability insurance. He is moderately satisfied with his income and lives in his own well-maintained home in an urban setting with his spouse. His monthly mortgage payment is relatively low, approximately $\$ 150$ per month and he lives in relative comfort.

\section{Demographic Characteristics of Respondents}

Race, Gender and Age. All subjects in the sample were Caucasian and predominantly (90\%) male. The current age of subjects ranged from 40 to 73 with the mean age being 56 and the median age, 56.5 years. The largest 
percentage of respondents (458) were 50-59 years of age.

Marital status. The majority (728) of subjects were currently married or living as married (18). Eight percent were never married, 17 percent were divorced, and 2 percent were widowed. Among those widowed or divorced, 11 incurred this status over seven years ago, four within the last 4-7 years and four within the last $1-3$ years. Thus, most of those widowed or divorced were not adjusting to a recent loss of marital partner.

children. A majority (848) of the subjects had at least one child. The mean number of children was 2.5 . Approximately two-thirds of those subjects had their children before the occurrence of the spinal cord injury.

Household composition. The most prevalent living situation for subjects was with a spouse. Almost a third (27\%) of the respondents also had a child still living in the home. The incidence of other persons such as parents, siblings, friends and paid care givers in the home was small. Fourteen percent of the respondents lived alone. Empleyment status. The majority of the respondents (74\%) were currently unemployed. of the 26 percent employed, 22 persons were employed full-time and four part-time. Those employed identified a variety of occupations, but it was interesting that half of those employed were professional persons. This may indicate a high degree of career commitment among professional persons and/or that professional-type jobs frequently do not 
require a large degree of physical mobility. Other jobs identified by respondents were sales, management, clerical, craftsman, and laborer. Of those persons working, all but two rated job satisfaction $4-5$ on a 1-5 Likert-type scale with 5 being very satisfied. The remaining two persons rated their job satisfaction as moderate.

Income. The yearly income of respondents ranged from less than $\$ 2500$ to over $\$ 20,000$. The median income fell within the $\$ 10,000$ to $\$ 15,000$ bracket. Twenty-five percent of the respondents reported yearly incomes of over $\$ 20,000$. The major sources of income identified by subjects were Social Security, disability insurance, employment of respondent or spouse, pension/retirement funds and investments. Thirty percent of the respondents were moderately satisfied with their income, 27 percent were somewhat or very dissatisfied, and 43 percent were somewhat or very satisfied with their income.

Education. The educational level of respondents ranged from less than high school (178) to the possession of graduate degrees $(78)$. The greatest percentage (318) of respondents possessed a high school diploma as their highest educational achievement.

Religiesity. The highest percentage (358) of respondents described themselves as moderately religious, while 33 percent viewed themselves as not very/not at all religious and 32 percent as somewhat/very religious. Forty-nine percent of the respondents identified themselves 
as Protestant, followed by 21 percent claiming no religious affiliation, 16 percent Catholic, 9 percent other, and 5 percent Mormon.

Residence Type and Location. Fifty-one percent of the subjects lived in an urban area, 31 percent in a suburban area or small town, and 18 percent in a rural area. Most of the subjects (858) lived in their own homes; 10 percent lived in apartments, 4 percent in mobile homes, and $I$ percent in condominiums. Eighty-eight percent of the respondents owned or were purchasing their residences. Monthly mortgage or rent payments varied widely, ranging from nothing (218) to over $\$ 300$ (218).

\section{QUESTION 2: WHAT IS THE EXTENT AND NATURE OF SUBJECTS' PARTICIPATION IN RECREATIONAL, GROUP, AND COMMUNITY ACTIVITIES AND SERVICES?}

Subjects identified a wide variety of recreational activities and hobbies they engaged in. These activities ranged from quiet individual activities such as reading and watching TV to outdoors activities with others such as fishing and traveling. Fifty-two percent of the subjects indicated they usually engaged in individual types of recreation, 8 percent in group activities and 40 percent in a combination of individual and group activities.

On the whole, subjects in this study were not active members of groups. Those who were active in groups mentioned a number of organizations such as the Elks, Kiwanis, Paralyzed Veterans' Association, Amateur Radio 
Club, church groups, Lions, American Legion, and the National spinal Cord Injury Foundation. Thirty-nine percent of the subjects stated they belonged to no groups, 27 percent to one group, 23 percent to two groups, and 11 percent to three or more groups. In regard to participation in these groups, 50 percent stated they never participated in a group, 12 percent participated less than once a month, 28 percent once or twice a month, and 10 percent once a week or more.

Persons in this study were even less involved with community agencies and services. Eighty-five percent said they didn't use any community services or agencies at any time, 13 percent used one agency, 1 percent used two agencies, and 1 percent used three agencies. Of the 15 percent using community agencies, 5 percent used them less than once a month, 4 percent once or twice a month, 2 percent once a week, and 4 percent several times a week. Examples of community agencies or services used were senior centers, Meals on Wheels, The Lift, Upjohn Nursing Service, Visiting Nurses' Association, Loaves and Fishes, and Home Health Care.

The relatively low degree of participation by these subjects in organized groups and community programs has implications for those persons planning services for elderly spinal cord injured persons. A thorough assessment of the needs of this population and the factors which may influence utilization of services (such as transportation, 
cost, and types of services provided) is indicated before investing resources in programs.

QUESTION 3: WHAT ARE THE HEALTH STATUS CHARACTERISTICS OF RESPONDENTS?

subjects' responses to the question, "All things considered, how would you rate your health status right now?", ranged from poor to excellent. The greatest percentage (348) of subjects rated their health status as moderate ( 3 on a 1 to 5 Likert-type scale). Seven percent of the subjects perceived their health as poor, 18 percent as fair, 30 percent as good, and 11 percent as excellent. Fifty-five percent of the subjects felt their health status now was the same as it was one year ago, 18 percent felt their health was better now, and 27 percent thought it was worse now. In regard to projected health status, 60 percent of the subjects felt their health would be the same in the next year, 16 percent felt it would improve, and 24 percent felt it would get worse.

In regard to the level of injury, 40 percent of the subjects were classified as paraplegia, incomplete; 27 percent paraplegia, complete; 29 percent quadriplegia, incomplete; and 4 percent quadriplegia, complete. The age at injury ranged from 12 to 68 with the mean age at injury being 35.4 years; the mode was 20.0 and the median age was 33.2 years. The age at injury in this sample tended to be older than that cited in the literature; Trieschmann (1980) 
cites the mean age of injury at 28.5 years, the mode at 20.0 and the median age of injury 23.0 using a large data base from the National spinal Cord Injury Model systems Conference proceedings (1978). The older age at injury in this study is most likely explained by the exclusion of persons under the age of 40 in this sample.

The major cause of injury (328) was vehicular accidents involving both automobiles and motorcycles, followed by polio (27 ), other assorted accidents (158), falls ( $8 \%)$, penetrating wounds $(6 \%)$, other disease processes $(68)$, tumors $(48)$, and sports injuries (28). Eighty-three percent of these injuries were non-service connected, meaning that most persons in this sample were not receiving additional benefits associated with a service-connected disability.

Fifty-seven percent of the subjects indicated they had no chronic health problems other than their spinal cord injury. Among the chronic health problems identified by the remaining 43 percent of the sample were the following: hypertension, kidney infection and disease, hypotension, diabetes, arthritis, emphysema and a variety of cardiovascular problems. Many of the chronic health problems mentioned are among those associated with spinal cord injury, particularly renal disease and related hypertension (Gunby, 1981). Thirty-five percent of the respondents had been hospitalized in the last year. of those hospitalized, ten were hospitalized for less than one 
week, five for one to two weeks, ten for three to four weeks and ten for over one month.

QUESTION 4: WHAT IS THE DEGREE AND NATURE OF SOCIAL SUPPORT PERCEIVED BY RESPONDENTS?

Number of Support Persons

Subjects in this study were asked to name persons who were important sources of help or support to them. The relatively few subjects (148) who named more than five persons who were important sources of help or support were asked to list the five persons who were the most important to them. The mean number of support persons identified was 2.3, the mode 1.0 and the median, 1.9. It was interesting that the largest number of subjects (4l8) named only one support person. The small number of support persons identified by many respondents makes them vulnerable to the potential loss of these persons through illness or death.

Who Provides Support

Individuals identified as support persons typically lived with respondents or within a tri-county area. Subjects named very few support persons who lived outside the tri-county area. Almost all of the support persons named were people the subjects had known for over five years. Subjects viewed these interpersonal relationships as long-term and stable. In almost all cases, individuals who were identified as support persons knew each other. Spouses and children were the most important sources 
of help and support for subjects. Seventy-two percent of the respondents named spouses and 38 percent named children as important support persons. Other sources of support in descending order of frequency were friends, siblings, parents, other relatives, neighbors, professional helpers, and co-workers.

It was interesting that out of all the support persons named (231) by the 100 subjects in this study, only 11 of the total number of support persons were disabled. It was expected that severely disabled persons would have a desire or need for support from others with similar disabilities. The verbal responses of subjects seemed to indicate, however, that this was not particularly important at this time in their lives. Perhaps it is important to have contact with similarly disabled persons at a point soon after injury in order to redefine one's personal and social identity, but less important as time goes by. Most persons in this study did have access to organizations such as the Paralyzed Veterans Association and the National Spinal cord Injury Foundation, thus the availability of similarly disabled persons did not appear to be a major factor in subjects' responses.

\section{Erequency of contact}

Subjects in this sample see the support persons frequently; eighty-four percent of respondents' contacts with support persons were "several times a week or daily," 
I4 percent were several times a month, and 2 percent were less than once a month.

Importance of support Persons

The support persons are very important to respondents. Ninety-two percent of the respondents viewed their relationships with support persons as being very important, 7 percent as moderately important, and I percent as not important.

\section{Satisfaction with Social support}

Respondents were satisfied with their relationships with support persons for the most part. Ninety percent of the respondents were very satisfied with these relationships, 8 percent were moderately satisfied and 2 percent were not satisfied. Subjects were also asked, "In general, how satisfied are you with the amount of social contact you have with others?" and "with the quality or cleseness of the social contact you have with others?" sixty-eight percent of the subjects indicated high satisfaction, 22 percent moderate satisfaction, and 10 percent low satisfaction with the amount of social contact with others. Following a similar pattern, 70 percent indicated high satisfaction, 20 percent moderate satisfaction, and 10 percent low satisfaction with the quality of social contact with others. The Pearson correlation coefficient between satisfaction with the amount and satisfaction with the quality of social contact 
was $\underline{r}=0.68, \underline{p}<.001$, indicating a relatively strong positive relationship. These data suggest that one component of the perceived quality of a relationship is the frequency or amount of contact between the parties.

The Pearson correlation coefficients between "satisfaction with the amount and quality of the social contact with others" and the actual social support scale score, although in the expected direction, were surprisingly low. Tise correlation coefficient between satisfaction with the amount of social contact and the social support scale score was $\underline{I}=0.22, \underline{p}<.014$ and between satisfaction with the quality of social contact and the social support scale score, $\boldsymbol{x}=0.25, \boldsymbol{p}<.006$. In interpreting these correlations it must be remembered, though, that the social support scale score is based on support persons named, whereas, the measures of satisfaction with the overall amount and quality of social contact are based on a broader range of relationships. It is certainly possible for someone to have a strong personal support system, be satisfied with that system, and still not be satisfied with the amount and quality of social contact with others in general.

\section{Beciprecity}

It was thought that subjects in this study might be somewhat vulnerable to unbalanced exchanges with those in their support network due to the needs their physical 
disability might impose. In actuality, relationships were viewed by the respondents as reciprocal the majority of the time. For the first support person named, usually the spouse, respondents viewed the relationship as reciprocal (helping each other about the same) in 58 instances, as the other person helping them more in 38 instances, and the respondent helping the other person more in three instances. The remaining subject had no support person. For subsequent persons named as supports, the same pattern emerged but with relationships being even more frequently identified as reciprocal; for example, for the second person named as a support, 22 were viewed as reciprocal relationships, eight as the other helping the subject more, and eight as the subject helping the other more. statistical analysis of relationship reciprocity by relationship satisfaction revealed no significant results. Reciprocity was likewise not correlated highly with either satisfaction with the amount $(\boldsymbol{I}=0.21, p<.02)$ or quality $(\underline{I}=0.13, \underline{p}<.09)$ of social contact. There are undoubtedly many factors which influence the expectation of reciprocity in a relationship including the relative ages, role positions, and health status of the participants. Most persons in this study did not express difficulty regarding the issue of reciprocity and as noted previously reported high satisfaction and high stability in their relationships with significant others. It would be interesting in future study to investigate che issue of 
reciprocity from the viewpoint of the spouses of spinal cord injured persons.

\section{Conceptualization of support}

As described previously, social support was conceptualized as being instrumental, affective, and cognitive in nature. For the most part, subjects did not seem to differentiate strongly between these types of support; i.e., on a 1-5 Likert-type scale they tended to classify a given support person as a 3, 4, or 5 "across the board." The degree to which persons differentiated between particular types of support given of course varied, but it appeared that many persons tended to view someone else in a more global fashion as being supportive or not. It is, of course, also quite possible that many persons in fact do give support in a "global" fashion, i.e., they provide material assistance, affection and love, and information and advice. The Pearson correlation coefficients between the three types of social support were thus high; between instrumental and affective support $(\underline{x}=0.81, p<.001)$, between instrumental and cognitive support $(\Sigma=.86, p<$ $.001)$, and between affective and cognitive support $(x=$ $0.95, p<.001)$.

Reliability analyses of each of these subscales of the social support scale revealed a Cronbach's alpha of 0.81 for the instrumental support scale, 0.96 for the affective support scale, and 0.95 for the cognitive support 
scale. All of these coefficients indicate a high degree of internal consistency of items within each of the subscales. Looking at these three subscales together, a reliability analysis of the total social support scale resulted in a Cronbach's alpha of 0.90, again indicating high internal consistency. The high internal consistency of items in the social support scale and high Pearson $I$ coefficients between the three subscales lend support to the conceptualization of instrumental, affective and cognitive support as comprising one basic construct, social support.

\section{Socjal support scores}

Social support was viewed in this study as being both qualitative and quantitative in nature; thus scores on the social support scale reflect a combination of the number of support persons named and the quality of support received from those persons. Thus, a subject who names two support persons and perceives them as providing very frequent support in many categories may receive the same total social support score as another subject who names four persons and perceives them as providing a moderate amount of support. For each of the 11 items on the social support scale, the subject indicates to what degree each support person named helps them. Subjects rate the degree of help received on a 1-5 Likert-type scale with 1 being "not at all," 2 "rarely," 3 "on some occasions," 4 "often," and 5 "very frequently." Thus, the potential score on the scale 
may range from zero if no support persons are named to 275 if the subject names 5 persons who help him very frequently on all 11 items. The social support scale scores ranged in this sample from zero to 247. The mean social support score was 92.94, the mode 49.00 , and the median 83.50 .

QUESTION 5: WHAT IS THE NATURE OF THE SOCIAL COMPARISONS MADE BY RESPONDENTS?

In order to create a set for asking questions about social comparison, subjects were asked to think about their overall life situation and rate their life situation on a 1-10 Likert-type scale with 10 being "the greatest." Responses to this question ranged from 1 to 10 ; the mean score was 6.6 , the mode 7.0 , and the median 7.0 .

Subjects were then asked to describe with whom they compared themselves to decide how good their life situation was. Subjects had difficulty relating to this question and many stated they didn't compare themselves with other people. This response was not surprising to the interviewers in view of a prevalent cultural norm which says something to the effect of "If you're secure in yourself you shouldn't need to compare yourself with other people." with some explanation by interviewers that we all compare ourselves with others even though we're not always aware of it, subjects were able to relate somewhat better to this question. It was expected that many respondents would compare themselves to other disabled persons, since 
social comparison theory (Festinger, 1954) would predict a need to evaluate the self in relationship to similar others. OnIy 25 percent of the subjects said that they compared themselves with other disabled persons. Sixteen percent said that they compared themselves with nondisabled persons and 59 percent said they didn't compare themselves with any particular group of persons, "just people in general." It was expected that persons who compared their life situation to those of other disabled persons would have a greater sense of subjective well-being than those comparing their life situation to nondisabled persons. one way analysis of variance, however, showed no significant differences in measures of subjective well-being based on comparison groups. Contrasts between each of the three comparison groups (disabled, nondisabled, no particular group) likewise showed no significant differences in subjective well-being. It is difficult to interpret these findings in view of the difficulty subjects had in recognizing or being aware of the comparison processes they probably used.

Subjects were also asked to describe what characteristics, things, or values came to their mind when thinking about their life situation and how good it was. The most frequently mentioned things or values were family and friends, followed by mobility and independence, health, finances, work/productivity, and several persons mentioning personality, intellect and pain. The importance of family 
and friends shown here and previously in the discussion of social support may perhaps be most accurately interpreted as a reflection of the particular needs and values of a severely disabled population and also as a reflection of the general cultural value placed on family by persons of the age group represented in this sample.

A scale consisting of 5 Likert-type items was constructed to obtain a measure of the favorable/ unfavorabie nature of the inter- and intra-personal comparisons made by this group. The 5 items ask subjects to rate how good their current life situation is in relationship to "most people," "others the same age," "others with a similar disability," "their life before the disability," and a projection of their current life "if they didn't have the disability." It is interesting that in all comparisons with other people, the mean response is on the favorable side; whereas, in regard to intrapersonal comparisons the mean response is on the unfavorable side. It seems that many persons in this sample are able to see their own life situations favorably as compared to others, but still acknowledge that their own life situation could be better now without the disability and was perhaps better before the disability. It is also interesting that in comparisons with other people, subjects rate their own life situations most favorably when the other has a similar disability.

Considering the social comparison scale as a whole, 
possible scores range from 5 to 25 , the higher the score the more favorable the comparison. The mean score on the scale was 14.9 , the mode 12.0 , and the median 14.7 . Reliability analysis of the scale resulted in a Cronbach's alpha of 0.80 , indicating a high degree of internal consistency among scale items.

To summarize, then, a "typical person" in this sample tends to view his or her own life situation as about the same or a little better than that of other persons in general, others his own age, and others with a similar disability. This "typical person" views his current life situation as somewhat worse than before the disability and believes his current life situation would be somewhat or much better if he didn't have a disability. In thinking about his life situation, family and friends were mentioned as foremost in his mind.

QUESTION 6: WHAT IS THE DEGREE AND NATURE OF RESPONDENTS' PERCEPTION OF CONTROL OVER VARIOUS LIFE SITUATIONS?

subjects were asked to what extent they felt their lives were controlled by themselves or other factors. Subjects on the whole reported a high sense of control over their lives.

A scale consisting of 5 Likert-type items was construcied to measure the extent of perceived control over various life situations. Scores on the scale ranged from 5 (indicating no perception of control) to 25 (indicating a 
perception of complete control). The mean score was 19.0 , the mode 20.0, and the median score 19.7. Reliability analysis of the scale resulted in a Cronbach's alpha of 0.81 , indicating a relatively high degree of internal consistency among items. Scores on this scale indicate that 72 percent of the subjects perceive a relatively high degree of control over their ability to "achieve or obtain what is important to them," to "make their interactions with others end up the way they expect," to "cope successfully when stressed," to "solve problems," and to "view the good things that happen to them as a result of their own actions." Another 17 percent of the sample perceived themselves as having a moderate perception of control over these things and only 11 percent of the subjects perceived themselves as having a low perception of control.

Subjects were also asked whether they felt they could have avoided incurring the disability and what factor(s) they blamed for causing the disability. These questions are particularly interesting in view of research by Bulman and Wortman (1977) regarding attribution of blame by victims of severe accidents. These researchers concluded from their data that those who coped the best blamed themselves but felt the injury was unavoidable; whereas, individuals who coped the worst blamed others, showed more regret, and felt they could have avoided the injury. The majority of persons in this current study did not blame 
themselves for causing their disability; fifty-seven percent of the subjects did not blame themselves at all, 4 percent only slightly, 9 percent moderately, 9 percent somewhat, and 21 percent blamed themselves very much. Those who did blame themselves tended to give examples such as carelessness resulting in a vehicular accident or failure to take polio vaccine resulting in paralysis.

The majority of persons in this sample did not feel they could have avoided the disability; fifty-six percent felt there was nothing they could have done and only 19 percent felt they could have completely avoided the disability. As would be expected, those who blamed themselves tended to be those who felt they could have avoided the disability, Pearson's $\underline{x}=0.72, \underline{p}<.001$.

In summary, the "typical person" in this sample has a relatively high perception of control over various life situations, does not tend to blame himself for causing the disability, and does not believe that he could have avoided incurring the disability.

QUESTION 7 : WHAT IS THE DEGREE AND NATURE OF RESPONDENTS' SUBJECTIVE WELL-BEING?

In addition to the three scales measuring psychological well-being, life satisfaction, and depression, a number of individual questions relevant to subjective well-being were asked. The most frequent response to the question, "What are the major difficulties 
in your life at this time?" was dependency and immobility (38\% of subjects), followed by health, finances, relationships with others, and pain. Approximately one-quarter of the sample said they had no major difficulties, while others mentioned multiple difficulties. subjects were asked several questions regarding their perception of and attitude toward their disability. Responses to the question, "Considering the best and worst things that could happen to you in your lifetime, where does your disability fit into the scale?" showed that 41 percent of the subjects viewed their disability as neither the worst nor the best thing that could happen to them. Fifty-four percent of the subjects viewed their disability as the worst or almost the worst thing that could happen to them and 5 percent of the subjects viewed their disability as the best or almost the best thing that could happen to them. It is relatively easy to imagine how one would perceive paralysis as the "worst thing that could happen," but what about those persons who say it is "the best thing that could happen?" Perhaps the response of one such person gives some insight into this question: "Before, I was drifting: since then I have gone to school and my outlook on life is changed drastically toward the positive."

Subjects were also asked whether their disability had any purpose or positive meaning in their life. A majority of subjects (648) said that there had been some purpose or 
positive meaning. The most frequently mentioned types of meaning were those related to personal growth such as an "increased awareness of self," "becoming a better person," and "value change" and those related to seeing other people as more important. Less frequently mentioned responses were more "patience anad tolerance," "being more careful now," "using my head-vs-brawn," "increased importance of God," and "acquiring new skills and hobbies." It appears that ovel time many spinal cord injured persons go though a process of recognizing their values and perceptions of themselves in order to cope with their new status as a disabled person. This reorganization process most likely entails for many such persons a search for positive meaning or purpose in their disability in order to fully accept and integrate this new element into their lives. The ability to attribute positive meaning or purpose to the disability most probably enhances a perception of control over how one feels about one's self and life situation; i.e., one is not doomed to feel miserable because of the disability; one has a choice of how to feel. The incurring of a severe injury may also be perceived by many as a close brush with death, accompanied by a clear realization of human vulnerability. In other words, a severe trauma such as paraplegia or quadriplegia may make one "stop and think what life is really about," and thus lead to dramatic value and attitude changes.

Many physically able persons may have a hard time 
imagining that they could be happy if paralyzed from the waist down. In response to the question, "How happy are you now (not at this moment, but at this stage of your life)?", subjects in this study appeared relatively happy. Sixty-one percent of the subjects indicated a high level of happiness, 31 percent a moderate level, and only 8 percent a low level of happiness. Again, this suggests an ability to develop a view of life and self that is positive despite the existence of potentially devastating life stressors (Lazarus 1977).

Although some subjects in this study (158) indicated that they were frequently depressed, a majority of subjects indicated a low (48\%) to moderate (37\%) frequency of depression in response to the question, "How often do you feel depressed?" In describing how they coped with the feeling of depression, subjects most frequently mentioned thinking positively and engaging in some activity followed by reading, TV, music, and talking to someone. Less frequently mentioned ways of coping were sleeping, crying, screaming, arguing, complaining, praying and drinking or drug-taking.

Responses to the question, "In general, how hopeful do you feel about your future?", indicated that 47 percent of the subjects had a high degree of hope, 30 percent a moderate degree, and 23 percent a low degree of hope about the future. Variables that were correlated with hope at a significance level of .001 or better and with a Pearson $x$ 
of .3 or higher are shown in Table II. These correlations suggest that persons who are younger, employed, require little assistance with activities of daily living, and who make favorable social comparisons, perceive that they have control over various life situations, view their relationships with others as reciprocal, and who view their disability in a somewhat positive light have more hope about their future than do persons not exhibiting these characteristics. As would be expected, the perception of hope was positively correlated with psychological well-being, life satisfaction, and the absence of depression.

subjects identified a variety of fears about the future. The fear of having an inadequate income was the most frequently mentioned fear ( 328 of subjects), followed by fears of deteriorating health (258), dependency on others (218), losing others and loneliness (128), death (88), going to a nursing home (48) and pain (28).

The last part of the questionnaire consisted of the outcome measures of subjective well-being. The Index of Psychological Well-Being (IPWB) is scored from 1 to 7 representing a balance of positive and negative feelings. A score of one represents a high level of psychological well-being. Utilizing a probability sample of 6,928 adults from a general population, Berkman's (1971) study resulted in a distribution of scores resembling that in this study (see Table III). The persons in Berkman's study scored 
TABLE II

PEARSON CORRELATIONS BETWEEN HOPE ${ }^{a}$ AND SELECTED PREDICTOR VARIABLES

\begin{tabular}{lc}
\hline Variable & Pearson $\underline{\underline{ }}^{*}$ \\
\hline Age & -.35 \\
Employed & .40 \\
Assistance with ADL & -.35 \\
Social Comparison & .52 \\
Perceived Control & .44 \\
Reciprocity & .35 \\
Life Satisfaction (LSIA-A) & .46 \\
Psychological Well-Being (IPWB) & -.54 \\
Depression (CES-D; & .31 \\
Disability Perception & .31 \\
Positive Meaning of Disability & \\
\hline
\end{tabular}


TABLE III

COMPARATIVE DISTRIBUTION OF SCORES ON THE

INDEX OF PSYCHOLOGICAL WELL-BEING

\begin{tabular}{|c|c|c|c|c|c|}
\hline \multirow{2}{*}{\multicolumn{2}{|c|}{ Scale Score }} & \multicolumn{2}{|c|}{ Berkman (1971) } & \multicolumn{2}{|c|}{ Spinal Cord Injury Study } \\
\hline & & \multicolumn{2}{|c|}{ Percentage of Sample } & \multicolumn{2}{|c|}{ Percentage of Sample } \\
\hline 1 & High Well-Being & & 6.9 & & 3 \\
\hline 2 & & & 14.9 & & 7 \\
\hline 3 & & & 22.5 & & 23 \\
\hline 4 & & & 22.3 & & 31 \\
\hline 5 & & & 20.5 & & 25 \\
\hline 6 & & & 9.4 & & 8 \\
\hline \multirow{5}{*}{\multicolumn{2}{|c|}{7 Low Well-Being }} & & 3.5 & & 3 \\
\hline & & Total & 100 & & LOO \\
\hline & & Mean & 3.77 & Mean & 4.04 \\
\hline & & Mode & 3.00 & Mode & 4.00 \\
\hline & & & & Median & 4.05 \\
\hline
\end{tabular}


slightly lower on the scale, thus indicating slightly higher psychological well-being than the spinal cord injured persons in this study. One might have expected the spinal cord injured sample to exhibit a much lower level of psychological well-being than the general population but this was not the case.

The Life Satisfaction Index-A (LSIA-A) yields a score ranging from 0 to 18 with 18 being the most positive response. Scores on this scale ranged from 0 to 18 with a mean score of 10.76 , a mode of 9.0 , and a median score of 10.88. These scores were compared with those of Adams (1969) utilizing the LSIA (a 20 item scale from which the LSIA-A was derived) and those of Harris and Associates (1975) using the 18 item version as in this study (see Table IV). The study by Adams (1969) was based on a sample of 508 persons, aged 65 and over, and residing in small towns. The study by Harris and Associates (1975) was based on an in-depth survey of a cross-section of the American public aged 18 and over. The Harris sample was composed of 4,254 persons; 3,624 of whom were 40 and over and 2,797 of whom were 65 and older.

The scores of spinal cord injured persons in this study do reflect lower levels of life satisfaction than older persons in general and the general adult public as reported by Adams (1969) and Harris and Associates (1975). Over 50 percent of the spinal cord injured persons in this study gave responses indicating dissatisfaction on 5 of the 
TABLE IV

MEAN SCORES ON THE LSIA AND LSIA-A OF SELECTED SAMPLES

\begin{tabular}{|c|c|c|c|c|c|}
\hline & $\begin{array}{c}\text { LSIA } \\
(\text { Adams, 1969) a }\end{array}$ & \multicolumn{3}{|c|}{$\begin{array}{c}\text { LSIA-A } \\
(\text { Harris, 1975) }\end{array}$} & $\begin{array}{l}\text { LSIA-A } \\
\text { (Spinal Cord } \\
\text { Injury study) }\end{array}$ \\
\hline Age of subjects & $65+$ yrs. & $18-64$ yrs. & $65+y r s$. & $\begin{array}{l}\text { Total } \\
\text { Public }\end{array}$ & $40+y$ ys. \\
\hline Mean Score & 12.5 & 13.35 & 12.2 & 13.2 & 10.76 \\
\hline Median Score & - & 14.15 & 13.0 & 14.0 & 10.88 \\
\hline Mode & - & - & - & - & 9.0 \\
\hline
\end{tabular}

ascores can range from 0 to 20 .

bscores can range from 0 to 18. High scores indicate high levels of life satisfaction. 
18 items on the LSIA-A. Sixty-six percent indicated that they were not as happy now as when they were younger, these were not the best years of their lives (738), their lives could be happier than they are now (788), they would change their past if they could (638), and the lot of the average person is getting worse, not better (51\%). The reasons subjects gave for some of these responses were related to their disability; for example, some persons volunteered the information that the part of their past they would change would be their injury.

Comparing the responses of spinal cord injured persons to those of other persons on the same 5 items, Harris and Associates (1975) report that 44 percent of those over 65 were not as happy now as when younger, 68 percent felt these were not the best years of their lives, 45 percent felt their lives could be happier, 38 percent would change their past lives, and 34 percent felt the lot of the average person was getting worse. Persons in these two samples scored similarly to each other on most of the remaining items. One exception was that only 58 percent of the spinal cord injured persons felt they had gotten pretty much what they expected out of life compared to 82 percert of the over 65 year old Harris sample. One interesting observation was that a majority of persons in both samples felt they "made a good appearance compared to other people their age" (spinal cord sample, 758; Harris, 838). One might expect that the spinal cord injured persons, in 
particular, might feel inferior to other persons in regard to appearance. One person who said he didn't feel he made as good an appearance as others his age said that "if other people in the study said they did, they're kidding themselves!"

The Center for Epidemiologic studies-Depression scale (CES-D) yields a score of 0 to 60 with 60 being the most depressed response. Subjects are given a list of ways they may have felt or behaved during the past week and are asked to indicate how often they felt or behaved in each of the ways. Scores on this scale ranged from 0 to 37 with a mean score of 9.74 , a mode of 3.0 , and a median score of 7.5 . The mean score of subjects in this sample is similar to that of a probability sample of 2,514 persons from the general population aged 18 and over in a study conducted by Radloff (1977). Radioff also reports mean scores on the CES-D for an inpatient psychiatric sample of 70 persons and for a sample of 35 persons admitted to outpatient treatment for severe depression (see Table $V$ ). The mean score and percentage of scores at or above 16 for spinal cord injured persons in this study are only slightly higher than the scores of the general population studied by Radloff. This finding may be interpreted as an indication that this group of disabled persons is not particularly "at risk" of depression or in need of treatment.

There were, however, six individuals scoring above the mean of the inpatient group in Radloff's study. Three 
TABLE V

MEAN SCORES ON THE CES-D OF SELECTED SAMPLES

\begin{tabular}{lcccc}
\hline & Radloff (1977) & $\begin{array}{l}\text { Spinal Cord } \\
\text { Injury Study }\end{array}$ \\
& $\begin{array}{l}\text { General } \\
\text { Population 18+ }\end{array}$ & $\begin{array}{l}\text { Inpatient } \\
\text { Psychiatric }\end{array}$ & $\begin{array}{l}\text { Outpatient } \\
\text { Psychiatric }\end{array}$ & \\
$\begin{array}{l}\text { Mean Score } \\
\begin{array}{l}\text { Percentage of } \\
\text { scores at or } \\
\text { above } 16\end{array}\end{array}$ & 9.25 & 24.42 & 39.11 & 9.74 \\
\hline
\end{tabular}

Note. Scores can range from 0 to 60 . High scores indicate high levels of depression. 
of these individuals had scores in the $30^{\prime} \mathrm{s}$, not far below the mean of the severely depressed outpatient sample in Radloff's study. of these three persons, one was a paraplegic and reported no support person whatsoever. This person impressed the interviewer as being extremely isolated, bitter, and suspicious of people. The other two persons with high depression scores were quadriplegic and both were married. One of these persons required complete assistance with activities of daily living, was in constant pain, frequently cried during the interview, and asked the interviewer to get a gun and kill him several times during the interview. At one point he said he was interested only in getting rid of the pain. The other individual also required complete assistance with activities of daily living. He stated that he constantly had to come up with things to occupy his mind; otherwise he would dwell on his physical condition and want to kill himself. Suggestions for help were offered to these very depressed persons regarding resources they might wish to call for assistance.

\section{QUESTION 8: WHAT ARE THE CORRELATES OF SUBJECTIVE WELL-BEING IN THIS SAMPLE?}

This survey research study examined a wide variety of variables in relationship to subjective well-being. The relationship between the three outcome scales and the four individual items measuring outcome were also examined (Table VI). As seen in Table VI, the highest correlation 
TABLE VI

CORRELATIONS AMONG SEVEN MEASURES OF SUBJECTIVE WELL-BEING

\begin{tabular}{|c|c|c|c|c|c|c|c|}
\hline Variable & IPWB & $\operatorname{LSIA}-\mathrm{A}$ & CES-D & $\begin{array}{l}\text { How Good } \\
\text { is Life? }\end{array}$ & Happy? & Depressed? & Hope ful? \\
\hline IPWB & $1.00 *$ & .73 & -.62 & .60 & .57 & .38 & .46 \\
\hline LSIA-A & - & 1.00 & -.69 & .72 & .62 & .45 & .57 \\
\hline CES-D & - & - & 1.00 & -.60 & -.54 & .43 & -.54 \\
\hline $\begin{array}{l}\text { How good } \\
\text { is life? }\end{array}$ & - & - & - & 1.00 & 3 & .49 & .51 \\
\hline Happy? & - & - & - & - & 1.00 & .40 & .39 \\
\hline Depressed? & - & - & - & - & - & 1.00 & -.42 \\
\hline Hope ful? & - & - & - & - & - & - & 1.00 \\
\hline
\end{tabular}

${ }^{*} \underline{p}<.001$ for all correlations. 
is between the Index of Psychological Well-Being and the Life Satisfaction Index $-A(x=.73)$ followed by the correlation between the LSIA-A and the single item, "Overall, how good would you say your life situation is on a 1-10 scale with 10 being the greatest?" $(\boldsymbol{L}=.72)$. This single item question is one frequently used in clinical and other situations where it may not be expedient to administer a longer scale.

Many variables considered in this study showed a positive correlation with the measures of subjective well-being. Those independent variables with a Pearson correlation coefficient of $I=.3$ or higher are shown in descending order of significance in Table VII. The pattern of correlations is very similar on the three measures of subjective well-being and particularly on the IPWB and the LSIA-A. As predicted, the variables accounting for the greatest amount of variance in the outcome measures are social comparison, control, social support, and health. It was also predicted that reciprocity and income would be correlated highly with measures of subjective well-being. Reciprocity was correlated with the LSIA-A ( $\boldsymbol{E}=.34$, $\mathrm{p}<$ $.001)$ and with the IPWB $(\underline{I}=.20, \mathrm{p}<.02)$ and CES-D ( $\mathbf{L}=$ $-.26, g<.004)$ at somewhat lower levels. The level of perceived reciprocity was expected to be positively related to subjective well-being in that the person who views him or herself as both giving and receiving in relationships is likely to make favorable social comparisons about his or 
TABLE VII

MAJOR CORRELATES OF THREE MEASURES OF SUBJECTIVE WELL-BEING (IPWB, LSIA-A, CES-D)

\begin{tabular}{|c|c|c|c|c|c|}
\hline IPWB & & LSIA-A & & CES-D & \\
\hline & $\underline{\mathbf{r}}$ & & $\underline{\mathbf{r}}$ & & $\underline{\mathbf{r}}$ \\
\hline Social comparison & $.61 *$ & Social comparison & .74 & Perceived control & -.56 \\
\hline $\begin{array}{l}\text { Satisfaction with } \\
\text { quality of social }\end{array}$ & & Perceived control & .52 & Social comparison & -.56 \\
\hline contact & .49 & $\begin{array}{l}\text { Satisfaction with } \\
\text { amount of social }\end{array}$ & & Health & -.49 \\
\hline Perceived control & .49 & contact & & $\begin{array}{l}\text { Satisfaction with } \\
\text { amount of social }\end{array}$ & \\
\hline Health & .43 & Health & .47 & contact & -.45 \\
\hline $\begin{array}{l}\text { Satisfaction with } \\
\text { amount of social } \\
\text { contact }\end{array}$ & .43 & $\begin{array}{l}\text { Cognitive support } \\
\text { subscale }\end{array}$ & .46 & $\begin{array}{l}\text { Satisfaction with } \\
\text { quality of social } \\
\text { contact }\end{array}$ & -.44 \\
\hline $\begin{array}{l}\text { Social support } \\
\text { Cognitive support } \\
\text { subscale }\end{array}$ & .42 & $\begin{array}{l}\text { Satisfaction with } \\
\text { quality of social } \\
\text { contact }\end{array}$ & .42 & $\begin{array}{l}\text { Cognitive support } \\
\text { subscale }\end{array}$ & -.32 \\
\hline $\begin{array}{l}\text { Affective support } \\
\text { subscale }\end{array}$ & .40 & $\begin{array}{l}\text { Affective support } \\
\text { subscale }\end{array}$ & .42 & & \\
\hline $\begin{array}{l}\text { Instrumental } \\
\text { support subscale }\end{array}$ & .34 & $\begin{array}{l}\text { Disability } \\
\text { perception }\end{array}$ & .40 & & \\
\hline
\end{tabular}


TABLE VII (Continued)

\begin{tabular}{llll}
\hline \multicolumn{1}{c}{ IPWB } & \multicolumn{1}{c}{ LSIA-A } & CES-D \\
\hline & $\underline{r}$ & $\underline{r}$ & $\underline{r}$ \\
Religious & .31 & $\begin{array}{l}\text { Instrumental } \\
\text { support }\end{array}$ & .39 \\
$\begin{array}{l}\text { Positive meaning } \\
\text { of disability }\end{array}$ & .30 & $\begin{array}{l}\text { Positive meaning } \\
\text { of disability }\end{array}$ & .37 \\
$\begin{array}{l}\text { Disability } \\
\text { perception }\end{array}$ & .30 & Education & .36 \\
& Assistance with ADL & -.35 \\
& Reciprocity & .34 \\
& Employed & .33 \\
\hline
\end{tabular}

${ }^{*} \underline{p}<.001$ for all correlations. 
her interpersonal assets and to perceive capability or control in this realm. These correlations with subjective well-being were in the expected direction, but reciprocity does not appear to differentiate highly between persons reporting different levels of well-being.

Income had a surprisingly low relationship to the measures of subjective well-being (IPWB $\mathrm{I}=.21, \mathfrak{p}<.02$; LSIA-A $x=.18, \mathrm{p}<.04 ;$ CES-D $x=-.08, \mathrm{p}<.23)$. One-way analysis of variance revealed a significant between-groups difference on one outcome measure only, the IPWB (E ratio = $3.66, d f=2$ and $88, p<.03)$. The low contribution of income to variability on measures of subjective well-being can perhaps be attributed to the fact that although income levels varied widely in this sample, most of the subjects had comfortable living arrangements with relatively low expenses. Even subjects who reported low incomes did not appear to live in discomfort. Another possibility is that some subjects may have under-reported income due to a fear that their economic benefits could somehow be affected.

The correlations between the independent variables and the outcome measures for the most part, however, came out as expected. The order of importance of the independent variables differs somewhat on the three measures of subjective well-being, but as was proposed within the conceptual framework of the study, social comparison, perceived control, social support, and health are the variables most consistently correlated at the 
highest levels with subjective well-being. It was especially interesting that the variable of perceived control was correlated higher than any other independent variable with the outcome measure of depression. This finding is supportive of the theory of learned helplessness (Seligman, 1975) which predicts that depression is the result of perceived noncontingency (lack of control) between personal efforts and the attainment of desired outcomes.

In addition to the variables already noted, the attribution of positive meaning to the disability and the perception of "the relative badness" of the disability were correlated with the IPWB and the ISIA-A with Pearson $I$ coefficients above .3 (see Table VII). Thus, persons who were able to attribute purpose or positive meaning to their disability and who viewed their disability on the more positive end of the "worst to best thing that could happen" continuum, tended to report higher levels of subjective well-being than other persons.

The perception of self as a religious person was correlated positively $(\underline{r}=.31)$ with the IPWB. A higher level of education $(I=.36)$ and being employed $(\Sigma=.33)$ were correlated positively with the ISIA-A. The degree of assistance required with activities of daily living was negatively correlated with the LSIA-A $(x=-.35)$ indicating that persons requiring more assistance indicated less life satisfaction. 
other variables of interest in regard to their relationship with the measures of subjective well-being (but with correlation coefficients below.30) were age, age at injury, blaming self for the disability, and percepicion of the ability to have avoided disability (Table VIII). Thus, there was a slight tendency for persons who were younger, incurred their disability at a younger age, blamed themselves for their disability, and who felt they could have avoided the disability to report higher subjective well-being. The findings regarding blame and the ability to have avoided the injury are interesting in view of the findings by Bulman and wortman (1977) that victims of severe accidents who coped the best blamed themselves but felt the injury was unavoidable. As noted previously, blaming oneself and the perception of the ability to have avoided the disability are highly correlated ( $\boldsymbol{L}=.72, \mathfrak{e}<$ $.001)$ in this study.

To supplement the correlational findings, one-way analysis of variance was completed for a number of variables. There were no significant between-groups differences (significance level of .05) on the three outcome measures on the variables of age, level of injury, perceived ability to have avoided the disability, and residence location. Likewise, two-tailed t-tests showed no significant differences on outcome measures based on gender or marital status. Inspection of the data indicated no pattern of differences in well-being based on 
TABLE VIII

PEARSON CORRELATION COEFFICIENTS FOR AGE,

AGE AT INJURY, BLAMING SELF, PERCEIVED

AVOIDABILITY OF DISABILITY AND

THREE MEASURES OF WELL-BEING

\begin{tabular}{|c|c|c|c|c|}
\hline Variable & IPWB & ISIA-A & & CES-D \\
\hline & $\underline{\mathbf{r}}$ & $\underline{\mathbf{r}}$ & & $\underline{\mathbf{r}}$ \\
\hline Age & $p<. .04$ & $p<-.02$ & $\underline{\mathrm{p}}$ & $\begin{array}{l}.18 \\
<.03\end{array}$ \\
\hline Age at injury & 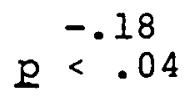 & 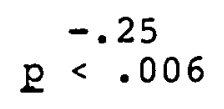 & $\mathrm{p}$ & $\begin{array}{l}.14 \\
<.09\end{array}$ \\
\hline Blaming self & $p<.13$ & $p<.01$ & $\mathrm{p}$ & $\begin{array}{l}-.25 \\
<.006\end{array}$ \\
\hline $\begin{array}{l}\text { Avoidability } \\
\text { of disability }\end{array}$ & 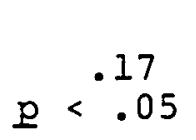 & $p<.01$ & $\mathrm{p}$ & $\begin{array}{l}-.22 \\
<.02\end{array}$ \\
\hline
\end{tabular}


veteran/non-veteran status.

Significant between-groups differences on outcome measures were found for perceived health status, level of social support, social comparison, perceived control, satisfaction with social contact, blaming self for the disability, and perception of the disability "from the worst to best thing that could happen." Two-tailed t-tests also yielded significant differences on outcome measures hased on attribution of positive meaning to the disability and employment status (see Table IX).

In addition to statistical analysis, it was thought interesting and of value to examine the profiles of those with the lowest and highest levels of subjective well-being as measured in this study. The five highest and the five lowest "scoring" subjects are similar in that none is employed. Most subjects in both groups were married; one person in the high well-being group and two in the low group were divorced. High scorers tended to be younger, ranging in age from 45-55 compared to 54-67 in the low well-being group. Four of the five in the high well-being group had some college, while three of the low scorers completed high school and two less than high school as did the fifth high scorer. The income levels of the high group tended to be higher $(\$ 5001-7500$ to 20,000 and over) than that of the low group $(\$ 2500$ to $10,001-15,000)$ although income levels overlapped substantially in the two groups. Individuals with high levels of well-being perceived their 
TABLE IX

SUMMARY RESULTS OF ONE-WAY ANALYSIS OF VARIANCE AND TWO-TAILED T-TESTS ON SELECTED OUTCOME MEASURES

\begin{tabular}{|c|c|c|c|c|c|c|c|c|c|c|c|c|}
\hline \multirow[t]{2}{*}{ Variable } & \multicolumn{4}{|c|}{ IPWB } & \multicolumn{4}{|c|}{ LSI $A-A$} & \multicolumn{4}{|c|}{ CES-D } \\
\hline & $\mathrm{df}$ & MS & $\mathbf{F}$ & $p$ & $\mathrm{df}$ & MS & $\mathbf{F}$ & p & $\mathrm{df}$ & MS & $\mathbf{F}$ & $\mathbf{p}$ \\
\hline $\begin{array}{l}\frac{\text { Health }}{\text { Between groups }} \\
\text { Within groups }\end{array}$ & $\begin{array}{r}2 \\
97\end{array}$ & $\begin{array}{r}14.2 \\
1.4\end{array}$ & 10.3 & .001 & $\begin{array}{r}2 \\
97\end{array}$ & $\begin{array}{r}124.3 \\
10.8\end{array}$ & 11.5 & .001 & $\begin{array}{r}2 \\
97\end{array}$ & $\begin{array}{r}655.2 \\
58.6\end{array}$ & 11.2 & .001 \\
\hline $\begin{array}{l}\text { Social supporta } \\
\text { Between groups } \\
\text { Within groups }\end{array}$ & $\begin{array}{r}2 \\
97\end{array}$ & $\begin{array}{r}26.0 \\
1.1\end{array}$ & 23.0 & .001 & $\begin{array}{r}2 \\
97\end{array}$ & $\begin{array}{r}204.2 \\
9.2\end{array}$ & 22.3 & .001 & $\begin{array}{r}2 \\
97\end{array}$ & $\begin{array}{r}686.1 \\
57.9\end{array}$ & 11.8 & .001 \\
\hline 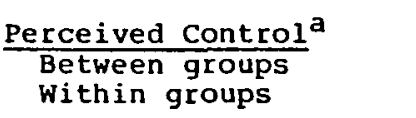 & $\begin{array}{r}2 \\
97\end{array}$ & $\begin{array}{r}11.4 \\
1.4\end{array}$ & 7.9 & .001 & $\begin{array}{r}2 \\
97\end{array}$ & $\begin{array}{r}132.9 \\
10.6\end{array}$ & 12.5 & .001 & $\begin{array}{r}2 \\
97\end{array}$ & $\begin{array}{r}849.4 \\
54.6\end{array}$ & 15.6 & .001 \\
\hline $\begin{array}{l}\text { Satisfaction with } \\
\text { Social Contact } \\
\text { Between groups } \\
\text { Within groups }\end{array}$ & $\begin{array}{r}2 \\
97\end{array}$ & $\begin{array}{r}15.8 \\
1.3\end{array}$ & 11.8 & .001 & $\begin{array}{r}2 \\
97\end{array}$ & $\begin{array}{r}128.5 \\
10.7\end{array}$ & 12.0 & .001 & $\begin{array}{r}2 \\
97\end{array}$ & $\begin{array}{r}471.8 \\
62.4\end{array}$ & 7.6 & .001 \\
\hline 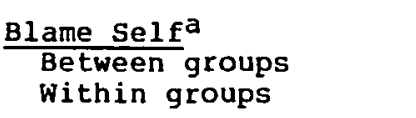 & $\begin{array}{r}2 \\
97\end{array}$ & $\begin{array}{l}7.2 \\
1.5\end{array}$ & 4.8 & .01 & $\begin{array}{r}2 \\
97\end{array}$ & $\begin{array}{l}66.9 \\
11.9\end{array}$ & 5.6 & .005 & $\begin{array}{r}2 \\
97\end{array}$ & $\begin{array}{r}215.1 \\
67.7\end{array}$ & 3.2 & .05 \\
\hline $\begin{array}{l}\text { Disability Perceptiona } \\
\text { Between groups } \\
\text { Within groups }\end{array}$ & $\begin{array}{r}2 \\
97\end{array}$ & $\begin{array}{r}10.9 \\
1.4\end{array}$ & 7.5 & .001 & $\begin{array}{r}2 \\
97\end{array}$ & $\begin{array}{l}81.0 \\
11.7\end{array}$ & 6.9 & .002 & & Not Sig & ificant & \\
\hline 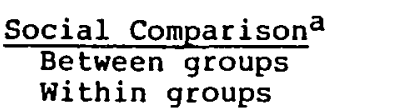 & $\begin{array}{r}2 \\
97\end{array}$ & $\begin{array}{r}28.6 \\
1.1\end{array}$ & 26.4 & .001 & $\begin{array}{r}2 \\
97\end{array}$ & $\begin{array}{r}298.4 \\
7.2\end{array}$ & 41.4 & .001 & $\begin{array}{r}2 \\
97\end{array}$ & $\begin{array}{r}991.4 \\
51.7\end{array}$ & 19.2 & .001 \\
\hline
\end{tabular}

Continued 
TABLE IX (Continued)

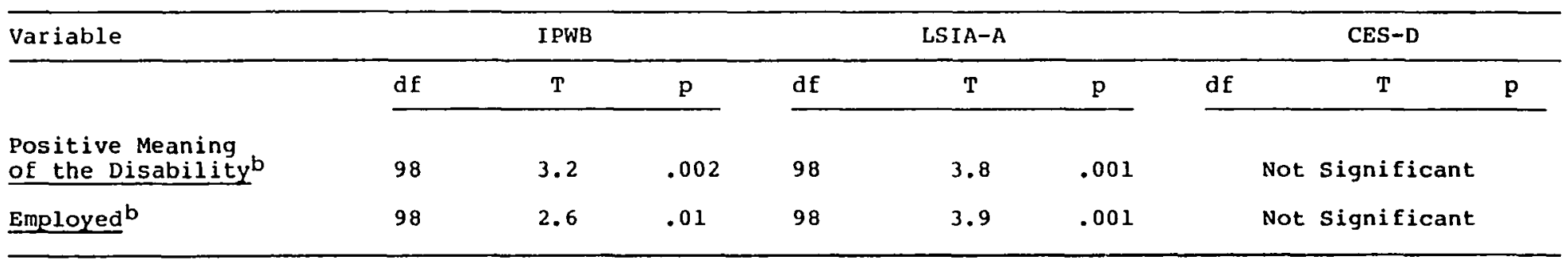

asubjects were divided into three groups (low, medium, high) of approximately equal size.

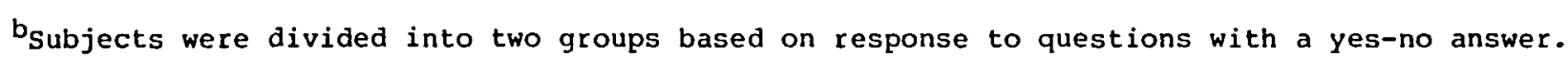


health status as being moderate to high compared to low to moderate within the low group. The high group tended to have lower levels of injury (four paraplegic, one quadriplegic) than the low group (two paraplegic, three quadriplegic). Those with high well-being perceived more social support; their scores on the social support scale ranged from 110-247 compared to a range of 0-50 among the low scorers. High scorers rated their life situation on a 1-10 scale from 7-10, compared to a range of $1-5$ among the low scorers of whom three persons gave a rating of "I" indicating great dissatisfaction. Those with high well-being were more satisfied with their social contact with others, rating this as moderate to high compared to a low to moderate rating by low scorers. High scorers made more favorable social comparisons (score range 17-19/possible score 25) than did low scorers (5-9). High scorers also perceived more control (20-24/possible score 25) than did low scorers (5-20). Perceptions of the disability as ranging from the "worst to the best" thing that could happen were interesting. Among the five highest scorers, ratings ranged from 1 to 5 with three persons giving a moderate rating of 3 (on a $1-5$ scale). All five of the lowest scoring individuals gave ratings of "I" indicating they perceived their disability to be the worst thing that could happen to them in their lifetime. 
QUESTION 9: TO WHAT EXTENT CAN SUBJECTIVE WELL-BEING BE PREDICTED BY MEASURES OF PERCEIVED SOCIAL SUPPORT, SOCIAL COMPARISON, CONTROL AND OTHER SOCIALPSYCHOLOGICAL AND DEMOGRAPHIC VARIABLES?

Multiple linear regression analysis was conducted for each of the three measures of subjective well-being with health status entered first and income level second in order to control for their contribution to the prediction of well-being. The remainder of the independent variables were entered on step number three. These variables are social comparison, control, social support, satisfaction with the amount and quality of social contact, perception of the disability, and attribution of positive meaning to the disability. As seen in Tables $X, X I$, and XII, the independent variables studied accounted for approximately 56 percent of the variance in scores on the IPWB, almost 74 percent of the variance in scores on the LSIA-A, and 56 percent of the variance in scores on the CES-D. Looking at the Beta weights as indicators of the approximate change in the dependent variable due to change in the independent variable with other variables held constant, social comparison appears to account for the greatest amount of variance in the measures of subjective well-being. The apparent importance of the other independent variables varies among the three outcome measures of subjective well-being.

Correlation coefficients between the variables entered in these regression analyses are shown in Table XIII. 
TABLE X

MULTIPLE LINEAR REGRESSION ANALYSIS OF PREDICTOR VARIABLES ON IPWB

\begin{tabular}{|c|c|c|c|c|c|}
\hline Independent Variables & Multiple $\mathrm{R}$ & R Square & RSQ Change & BETA & $F$ \\
\hline Health & .420 & .177 & .177 & .157 & $3.19 *$ \\
\hline Income & .458 & .210 & .033 & .013 & .026 \\
\hline Social Comparison & .646 & .418 & .208 & .282 & $7.10 *$ \\
\hline Perceived Control & .677 & .458 & .040 & .120 & 1.81 \\
\hline $\begin{array}{l}\text { Perception of } \\
\text { Disability }\end{array}$ & .681 & .463 & .005 & .054 & .428 \\
\hline Social Support & .714 & .510 & .047 & .216 & $6.97^{*}$ \\
\hline $\begin{array}{l}\text { Satisfaction with } \\
\text { Social Contact }\end{array}$ & .743 & .552 & .042 & .222 & $6.93 *$ \\
\hline $\begin{array}{l}\text { Positive Meaning } \\
\text { of Disability }\end{array}$ & .748 & .560 & .008 & .103 & 1.57 \\
\hline
\end{tabular}

$$
{ }^{*} p<.01
$$


TABLE XI

MULTIPLE LINEAR REGRESSION ANALYSIS OF PREDICTOR VARIABLES ON LSIA-A

\begin{tabular}{|c|c|c|c|c|c|}
\hline Independent Variables & Multiple R & R Square & RSQ Change & BETA & $\mathrm{F}$ \\
\hline Health & .452 & .204 & .204 & .120 & $3.15 *$ \\
\hline Income & .476 & .226 & .022 & .113 & $3.22 *$ \\
\hline $\begin{array}{l}\text { Positive Meaning } \\
\text { of Disability }\end{array}$ & .530 & .281 & .054 & .042 & .449 \\
\hline Social Comparison & .806 & .649 & .368 & .560 & $47.19 *$ \\
\hline Perceived Control & .823 & .677 & .028 & .105 & 2.32 \\
\hline Social Support & .847 & .717 & .040 & .209 & $10.92 *$ \\
\hline $\begin{array}{l}\text { Satisfaction with } \\
\text { Social Contact }\end{array}$ & .855 & .731 & .014 & .125 & $3.72 *$ \\
\hline $\begin{array}{l}\text { Perception of } \\
\text { Disability }\end{array}$ & .859 & .738 & .007 & .093 & 2.18 \\
\hline
\end{tabular}

${ }^{*} \mathrm{p}<.01$ 
TABLE XII

MULTIPLE LINEAR REGRESSION ANALYSIS OF PREDICTOR VARIABLES ON CES-D

\begin{tabular}{|c|c|c|c|c|c|}
\hline Independent Variables & Multiple $\mathrm{R}$ & $\mathrm{R}$ Square & RSQ Change & BETA & $\mathrm{F}$ \\
\hline Health & .488 & .239 & .239 & .204 & $5.45 *$ \\
\hline Income & .490 & .240 & .002 & .144 & $3.13^{*}$ \\
\hline $\begin{array}{l}\text { Positive Meaning } \\
\text { of Disability }\end{array}$ & .494 & .244 & .004 & .040 & .241 \\
\hline Social Comparison & .658 & .433 & .189 & .368 & $12.23^{*}$ \\
\hline Perceived Control & .714 & .510 & .077 & .249 & $7.80 *$ \\
\hline Social Support & .725 & .525 & .015 & .111 & 1.84 \\
\hline $\begin{array}{l}\text { Satisfaction with } \\
\text { Social Contact }\end{array}$ & .747 & .558 & .033 & .216 & $6.67^{\star}$ \\
\hline $\begin{array}{l}\text { Perception of } \\
\text { Disability }\end{array}$ & .751 & .564 & .006 & .084 & 1.05 \\
\hline
\end{tabular}

$$
{ }^{*} \mathrm{p}<.01
$$


TABLE XIII

INTERCORRELATIONS AMONG ALL VARIABLES IN THE MULTIPLE LINEAR REGRESSION ANALYSES

\begin{tabular}{|c|c|c|c|c|c|c|c|c|c|c|c|}
\hline & IPWB & LSIA-A & CES-D & $\begin{array}{l}\text { Social } \\
\text { Compar- } \\
\text { ison }\end{array}$ & $\begin{array}{l}\text { Perceived } \\
\text { Control }\end{array}$ & Health & Income & $\begin{array}{l}\text { Social } \\
\text { Support }\end{array}$ & $\begin{array}{l}\text { Satisfaction } \\
\text { with Social } \\
\text { Contact }\end{array}$ & $\begin{array}{l}\text { Disability } \\
\text { Perception }\end{array}$ & $\begin{array}{l}\text { Positive } \\
\text { Meaning of } \\
\text { Disability }\end{array}$ \\
\hline & $\underline{r}$ & $\underline{\mathbf{r}}$ & $\underline{\mathbf{r}}$ & $\underline{\mathbf{r}}$ & $\underline{\mathbf{r}}$ & $\underline{r}$ & $\underline{\mathbf{r}}$ & $\underline{\mathbf{r}}$ & $\underline{\mathbf{r}}$ & $\underline{x}$ & $\underline{r}$ \\
\hline I PWB & 1.00 & $\begin{array}{l}.74 \\
\star \star \star\end{array}$ & -.61 & $\begin{array}{l}.62 \\
\star \star \star\end{array}$ & $\begin{array}{l}.50 \\
\star \star \star\end{array}$ & .42 & .21 & $: 42$ & $: 50$ & $: 36$ & $: 32$ \\
\hline LSIA-A & & 1.00 & -.69 & $\begin{array}{l}.78 \\
\star \star \star\end{array}$ & $\begin{array}{l}.53 \\
\star \star \star\end{array}$ & $: 45$ & .18 & $: 46$ & $: 48$ & .42 & $: 36$ \\
\hline CES - D & & & 1.00 & -.58 & -.57 & -.49 & -.08 & -.31 & -.51 & -.20 & -.19 \\
\hline $\begin{array}{l}\text { Social } \\
\text { Comparison }\end{array}$ & & & & 1.00 & $\begin{array}{l}.47 \\
\star \star \star\end{array}$ & .42 & $\underset{\star * \star}{.39}$ & .32 & $\begin{array}{l}.37 \\
\star \star \star\end{array}$ & $\underset{\star \star * \star}{.39}$ & $\begin{array}{l}: 39 \\
\vdots \star \star\end{array}$ \\
\hline $\begin{array}{l}\text { Perceived } \\
\text { Control }\end{array}$ & & & & & 1.00 & $\begin{array}{l}.39 \\
\star \star \star\end{array}$ & .17 & $\begin{array}{l}: 30 \\
\star * \star\end{array}$ & $\begin{array}{l}.39 \\
\star \star \star\end{array}$ & .23 & .18 \\
\hline Health & & & & & & 1.00 & .07 & -.002 & .30 & .16 & .25 \\
\hline Income & & & & & & & 1.00 & .15 & .06 & .01 & .21 \\
\hline $\begin{array}{l}\text { Social } \\
\text { Support }\end{array}$ & & & & & & & & 1.00 & .23 & .14 & .22 \\
\hline $\begin{array}{l}\text { Satisfactior } \\
\text { with Social } \\
\text { Contact }\end{array}$ & & & & & & & & & 1.00 & .24 & .08 \\
\hline $\begin{array}{l}\text { Disability } \\
\text { Perception }\end{array}$ & & & & & & & & & & 1.00 & .24 \\
\hline
\end{tabular}


TABLE XIII (Continued)

\begin{tabular}{|c|c|c|c|c|c|c|c|c|c|c|c|}
\hline & IPWB & LSIA-A & CES-D & $\begin{array}{l}\text { Social } \\
\text { Compar- } \\
\text { ison }\end{array}$ & $\begin{array}{l}\text { Perceived } \\
\text { Control }\end{array}$ & Health & Income & $\begin{array}{l}\text { Social } \\
\text { Support }\end{array}$ & $\begin{array}{l}\text { Satisfaction } \\
\text { with Social } \\
\text { Contact }\end{array}$ & $\begin{array}{l}\text { Disability } \\
\text { Perception }\end{array}$ & $\begin{array}{l}\text { Positive } \\
\text { Meaning of } \\
\text { Disability }\end{array}$ \\
\hline & $\underline{\mathbf{r}}$ & $\underline{r}$ & $\underline{\mathbf{r}}$ & $\underline{\mathbf{r}}$ & $\underline{r}$ & $\underline{\mathbf{r}}$ & $\underline{\mathbf{r}}$ & $\underline{\mathbf{r}}$ & $\underline{r}$ & $\underline{\mathbf{r}}$ & $\underline{\mathbf{r}}$ \\
\hline $\begin{array}{l}\text { Positive } \\
\text { Meaning of } \\
\text { Disability }\end{array}$ & & & & & & & & & & & 1.00 \\
\hline${ }^{\star} p<.05$ & & & & & & & & & & & \\
\hline${ }^{\star \star} \mathrm{p}<.01$ & & & & & & & & & & & \\
\hline$\star \star \star * p<.001$ & & & & & & & & & & & \\
\hline
\end{tabular}


Correlations between independent variables and outcome measures were previously discussed, but it is of interest here to note correlations between several independent variables. As seen in Table XIII, the independent variables are correlated positively except for a slight negative correlation beween health status and the social support score. There appears to be a slight tendency for social support to increase as health status decreases. The highest correlations between independent variables are between social comparison and control $(r=.47)$, social comparison and health $(I=.42)$, social comparison and income $(\boldsymbol{L}=.39)$, control and health $(\boldsymbol{L}=.39)$, control and satisfaction with social contact $(\underline{I}=.39)$, social comparison and perception of disability $(\boldsymbol{r}=.39)$, social comparison and positive meaning of the disability $(\boldsymbol{I}=$ .39), social comparison and satisfaction with social contact $(\boldsymbol{r}=.37)$, social support and social comparison ( $\boldsymbol{r}$ $=.32)$, health and satisfaction with social contact ( ${ }=$ $.30)$, and social support and control $(\Sigma=.30)$. Although these correlations do not necessarily represent causal relationships, they do support some possible causal interpretations. The correlations between social comparison and other independent variables such as health, income, and perception of the disability may indicate that these variables are frequently used as part of the comparison process. Correlations between social support measures and social comparison and control measures are 
106

supportive of the view that social support fosters favorable social comparisons and a perception of control. Correlations between social comparison and control may indicate that a perception of control fosters favorable social comparisons and/or that favorable social comparisons foster perception of control. A model incorporating these possible relationships is proposed in the conclusions of this report. 
CHAPTER V

CONCLUSIONS

OVERVIEW OF THE STUDY

Advances in health care science are enabling greater numbers of spinal cord injured persons to live increasingly into old age. Persons sustaining severe spinal corà injuries face numerous adaptation problems. As those persons grow older, there may be additional problems in coping due to stressors associated with old age, such as decreasing health and income and loss of friends and family members. A considerable amount of research in social gerontology has been aimed at finding ways for maximizing optimal levels of wellness in older persons. The purpose of this study was to determine those factors that contribute to the psychological well-being and life satisfaction of middle-aged and elderly community-residing spinal cord injured persons.

one hundred spinal cord injured persons ranging in age from 40 to 73 were interviewed through use of the Elderly Spinal Cord Injury Questionnaire designed for this study and three established measures of subjective well-being; the Index of Psychological Well-Being (Berkman 1971), the Life Satisfaction Index-A (Adams 1969), and the 
Center for Epidemiologic Studies Depression Scale (Radloff 1977). An extensive data base was collected in order to answer a wide range of questions regarding the characteristics of respondents. The major questions addressed in this study were:

1) What are the demographic characteristics of the sample?

2) What is the extent and nature of subjects' participition in recreational, group and community activities and services?

3) What are the health status characteristics of respondents?

4) What is the degree and nature of social support perceived by respondents?

5) What is the nature of the social comparisons made by respondents?

6) What is the degree and nature of respondents' perception of control over various life situations?

7) What is the degree and nature of respondents' subjective well-being?

8) What are the correlates of subjective well-being in this sample?

9) To what extent can subjective well-being be predicted by measures of perceived social support, social comparison, control and other social-psychological and demographic variables? 
Qualitative and quantitative analysis of the data collected in this study was completed. In addition to the computation of frequencies and measures of control tendency and variation, the data were analyzed primarily by Pearson correlation and multiple linear regression techniques. other statistical techniques employed were two-tailed t-tests, one-way analysis of variance, and computation of Cronbacin's alpha and Kendall's tau c.

\section{MAJOR FINDINGS}

In general, the spinal cord injured persons in this study reported a degree of well-being that was slightly lower than that reported in studies of nondisabled populations on the same outcome measures of psychological well-being, life satisfaction and depression. One might have expected the spinal cord injured sample to exhibit a much lower level of well-being than the general population but this was not the case. The majority of subjects in this study appeared able to form a perception of life and self that was relatively positive despite the existence of a severe physical disability.

The independent variables explaining the greatest overall variance in the measures of subjective well-being were social comparison, perceived control, two measures of social support (a raw score indicating both quality and quantity of support and a Likert-type measure of satisfaction with the quality and quantity of social 
contact), and perceived health status. Thus, persons who reported high levels of well-being compared themselves favorably with others, had a high perception of control over various life situations, reported a high degree of social support, were very satisfied with the quantity and quality of support they received, and perceived their health status as good. These "good copers" also perceived their disability in a more positive manner than did subjects indicating lower levels of well-being; they saw positive meaning in their disability and did not view their disability as the worst thing that could happen to them.

In addition, persons reporting high well-being tended to have higher incomes, more education, to be employed, and to be more religious than those indicating lower levels of well-being. The severity of the spinal cord injury was not correlated highly with subjective well-being, although there was a tendency for persons with greater disabilities to report lower levels of well-being. Although correlations were not high, persons who were younger and who incurred their disability at a younger age also tended to report higher levels of well-being.

In general, subjects in this study had small, but stable, interpersonal support systems which were very important and satisfying to them. Many subjects, however, appeared vulnerable to the potential loss of support persons; forty-one percent of the respondents named only one support person, who was usually a spouse. It was 
interesting that relatively few of the respondents identified other disabled individuals as support persons. It was expected that severely disabled persons might have a desire or need for support from others with similar disabilities. Perhaps it is important to have contact with similarly disabled peisons at a point soon after injury in order to redefine one's personal and social identity, but less important for such contact on an ongoing basis.

One finding in this study that was contradictory to a finding in the literature regarded the issue of the perceived avoidability of the injury and the attribution of blame for the injury. Bulman and wortman (1977) concluded from their data that victims of severe accidents who coped the best blamed themselves and felt the injury was unavoidable. This finding by Bulman and wortman (1977) was surprising in view of the positive correlation beween self-blame and perceived avoidability in their study. As in the Bulman and wortman (1977) study, self blame was positively correlated with perceived avoidability and with good coping in this study of spinal cord injured persons. However, unlike the Bulman and wortman (1977) study, the data reported here indicate a positive correlation between perceived avoidability and good coping. This positive correlation between perceived avoidability and well-being is supportive of the perspective that the ability to view a negative outcome as the result of avoidable or preventable factors reflects a perception of control. 
It is difficult to compare the findings in these two studies since different measures of well-being and different populations were used. The 29 subjects in the Bulman and wortman (1977) study were younger and still hospitalized within a year post-injury; whereas, subjects in this study lived in the community and were as many as 42 years post-injury. However, one possibility is that the perception that "one could not have avoided the injury" may serve is a good defense to recently injured persons; such persons may have difficulty accepting the fact that they could have avoided this severe, permanent injury. As time goes by, however, perhaps this defense is not needed and it may be a sign of ego strength to be able to acknowledge one's role in causing an avoidable injury.

\section{PREDICTORS OF WELL-BEING: A CAUSAL MODEL}

While the non-experimental design of this study does not purport to confirm causal relationships among variables, the extensive analysis of relationships among variables does suggest a causal model of well-being which could be further tested (see Figure 1). As supported by the conceptual framework and data analysis in this study, the major predictor variables comprising this model are social support, social comparison, and perceived control. Health status, socioeconomic status, and the culture and environment in which one lives are also viewed as influencing well-being. 


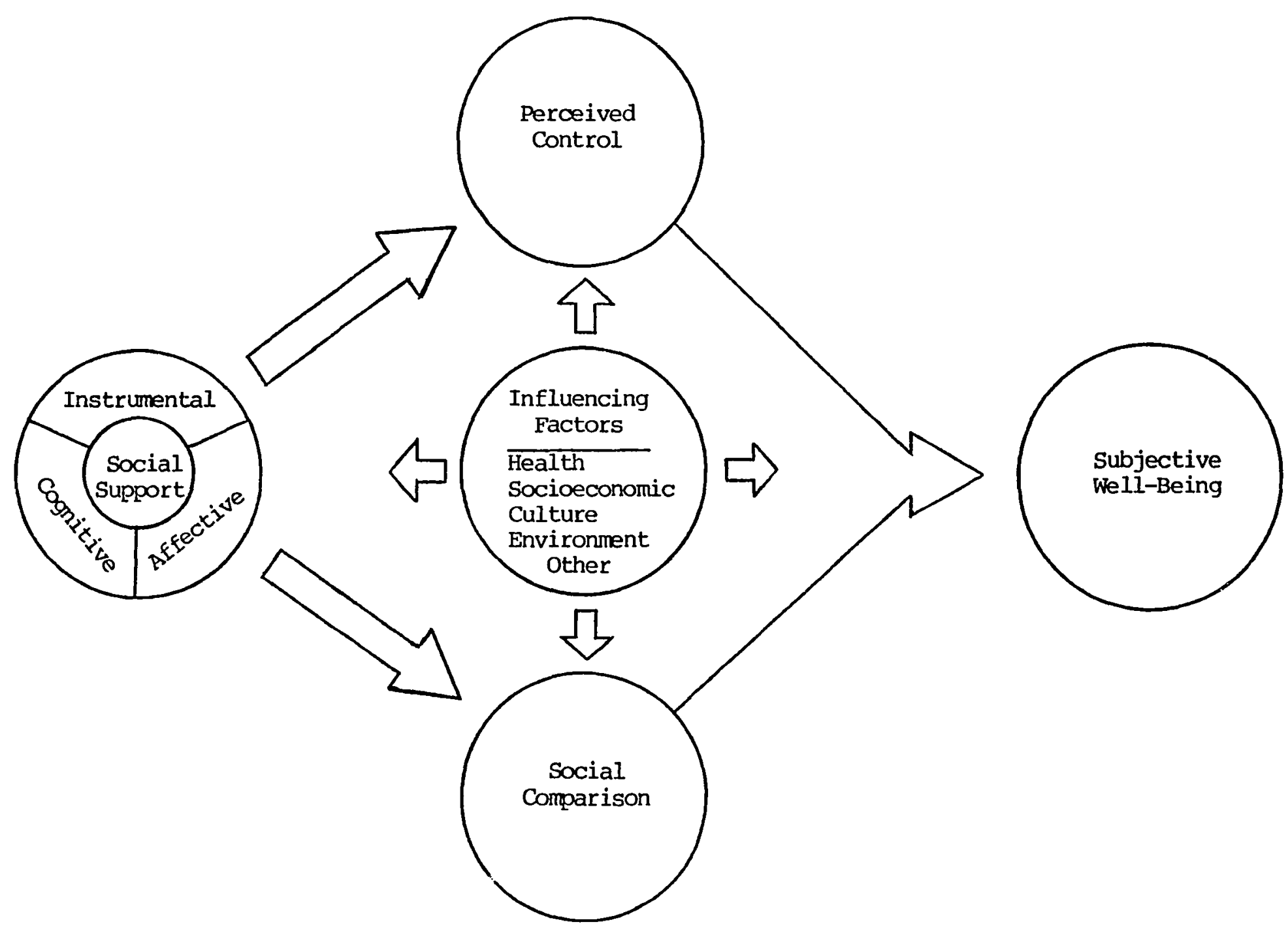

Figure 1. Social psychological model of subjective well-being. 
More specifically, this model suggests that social support fosters (1) feelings of competency in meeting environmental demands and thereby the perception of control and (2) the making of favorable intra- and interpersonal social comparisons. In addition to social support, this model views the perception of control and social comparisons as being influenced by factors such as health status, socioeconomic status, and the culture and environment in which one lives. These influencing factors may also have an impact on the type and extent of social support provided.

The extent to which an individual perceives control over his or her internal and external environment and the favorable or unfavorable nature of social comparisons made are viewed in this model as determining the extent of the individual's subjective well-being. This model also acknowledges some direct influence on subjective well-being by factors such as health, socioeconomic status, culture and environment. Social support may also have some direct influence on subjective well-being not necessarily channeled through the perspectives of control and social comparison.

IMPLICATIONS OF THE MODEL FOR RESEARCH AND PRACTICE

This model has implications for both research and practice. The conceptualization of social support as being instrumental, affective, and cognitive in nature was useful 
in this study and future reseachers may wish to use and build upon the social support scale utilized in this study. Likewise, the scales measuring perceived control and social comparison provide a good basis for further application in research. Studies testing the usefulness of the proposed model with various populations would be desirable. In addition to survey studies such as this one, studies of a longitudinal nature could also lend credence to the interpretations in this study. A longitudinal study could show possible changes in subjective well-being as the quantity and quality of social support fluctuated over time. An experimental design in which independent variables were manipulated would be difficult to conduct due to the impractical and unethical nature of manipulating variables such as social support. Thus, the causal nature of the relationships among the variables under study may have to be largely inferred from extensive descriptive and correlational data.

This model also has valuable implications for clinical application. The model as proposed provides direction for the assessment of existing or potential risk factors for individuals or population aggregates. For example, the professional or family helper would be directed by this model to assess levels of social support, perceived control, and the nature of social comparison processes. The model also provides direction for clinical intervention; for example, the model would direct the 
helping person to focus on promoting a perception of control and the making of favorable social comparisons by the spinal cord injured person.

Examples of the types of interventions suggested by this study include the following:

1) Assist spinal cord injured persons to build and maintain stable, intimate sources of social support by a) enhancing awareness in the injured person of the importance of social support and b) encouraging the development of contingency plans for the maintenance of future support.

2) Promote the active participation of family members (or equivalent others) in the ongoing rehabilitation process in order to enhance the helper's ability to a) reinforce an acceptable self-image in the injured person, b) foster independence and feelings of competency in the injured person, and c) develop reciprocal relationships with the injured person.

3) Foster the active participation of spinal cord injured persons in all aspects of the ongoing rehabilitation process in order to enhance feelings of competency and mastery over the environment; this may be accomplished by encouraging the spinal cord injured person to engage in problem-solving, decision-making, and in reasonably challenging activities. 
4) Assist spinal cord injured persons to re-organize their value systems in ways that emphasize remaining assets in order to facilitate favorable social comparisons; this can be accomplished through verbal and nonverbal interactions with professional workers, family members, and other injured persons who project a favorable view of "life post-injury."

5) Assist spinal cord injured persons to focus on ways that they can make use of remaining physical, intellectual, and social assets, rather than concentrating on lost abilities.

6) Develop programs to facilitate the ongoing participation of spinal cord injured persons in vocational and avocational pursuits, thus enhancing the injured person's sense of competency and sense of contribution to society.

7) Develop educational programs for professional workers and family members (or equivalent others) of spinal cord injured persons which will foster understanding of the importance and functions of social support in promoting the psychological well-being and life satisfaction of older cord injured persons.

\section{SUMMARY}

As the absolute number and proportion of elderly 
persons increase in the next few decades, the number of elderly spinal cord injured persons will increase as well. As is the case with other frail elderly persons, it is likely that the survival of this group in community settings is largely dependent on the availability of social support. In order to facilitate "residing in the community" as a viable option for this group, this study has attempted to identify those factors associated with subjective well-being and effective coping. A model was proposed to explain the processes through which social support and other variables facilitate subjective well-being and effective coping. This model, and the theories inherent in it, will hopefully provide an essential context within which research can be conducted and social programs and individual interventions implemerted and evaluated. 


\section{REFERENCES}

Abramson, A. J. Modern concepts of management of the patient with spinal cord injury. Archives of Physical Medicine and Rehabilitation, 1967, 48, 113121 .

Abramson, L. Y., Seligman, E. P., \& Teasdale, J. D. Learned helplessness in humans: Critique and reformulation. Journal of Abnormal Psychology, 1978, 87, 49-74.

Adams: D. Analysis of a life satisfaction inaex. Journal of Gerontology, $1969,24(4), 470-474$.

Adams, D. Correlates of satisfaction among the elderly. The Gerontologist, Winter 1971, pp. 64-68 (Pt. 2).

Aguilera, D., \& Messick, J. Crisis intervention--Theory and methodology. St. Louis: C. V. Mosby Co., 1974.

Albert S. Temporal comparison theory. Psychological Review, $1977,84,485-503$.

Anderson, N. Scales and statistics: Parametric and nonparametric. Psychological Bulletin, 1961, 58, 305-316.

Bachman, L. Spinal cord injury committee. Pennsylvania Medicine, 1978, 31, 31-54.

Beck, A., Ward, C., Mendelson, M., Mock, J., \& Erbaugh, J. An inventory for measuring depression. Archives of General Psychiatry, 1961, 4, 561-571.

Berkman, L., \& syme, s. Social networks, host resistance, and mortality: A nine year followup study of Alameda County residents. American Journal of Epidemiology, $1979,109(2), 186-204$.

Berkman, P. Measurement of mental health in a general population survey. American Journal of Epidemiology, $1971,24(2), 105-111$.

Blau, P. M. Exchange and Power in social I.ife. New York: John wiley and Sons, 1964. 
Bradburn, N., \& Caplovitz, D. Reports on happiness. Chicago: Aldine Publishing Co., 1965.

Brandt, P., \& Weinert, C. The PRQ--A social support measure. Nursing Research, 1981, 30(5), 277-280.

Bull, C., \& AuCoin, J. Voluntary association participation and life satisfaction: A replication note. Journal of Gerontology, 1975, 30(1), 73-76.

Bulman, R., \& Wortman, C. Attributions of blame and coping in the "real world": Severe accident victims react to their lot. Journal of Personality and social Psychology, 1977, 35(5), 351-363.

Burgess, A. W., \& Holmstrom, L. L. Recovery from rape and prior life stress. Research in Nursing and Health, $1978,1,165-174$.

Caplan, G. Support systems and community mental health. New York: Behavioral Publications, 1974.

Caplan, R. D. Social support, person-environment fit, and coping. In L. Furman \& J. Gordis (Eds.), Mental health and the economy. Kalamazoo, Michigan: W. E. Upjohn Institute for Employment Research, 1979.

Carey, R. Emotional adjustment in terminal patients: A quantitative approach. Journal of counseling Psychology, $1974,21,433-439$.

Cassel, J. Social science in epidemiology: Psychosocial processes and "stress" theoretical formulation. In E. L. Struening \& M. Guentag (Eds.), Handbook of Evaluative Research (Vol. 1). Beverly Hills, Ca.: Sage Publications, 1975.

Clayton, P. J., Halikas, J. A., \& Maurice, W. L. The depression of widowhood. British Journal of Psychiatry, 1972, 120, 71-78.

Coates, D., Wortman, C., and Abbey, A. Reactions to victims. In I. Frieze, D. Baratal, \& J. Carroll (Eds.), New approaches to social problems. San Francisco: Jossey-Boss, 1979.

Cobb, S. Social support as a moderator of life stress. Psychosomatic Medicine, 1976, 38, 300-314.

Cobb, S., \& Kasl, S. Termination: The consequences of job 10s5. (Publication \# LR 77-224). Washington, D.C.: DHEW (NIOSH), 1977. 
Coelho, G., Hamburg, D., \& Adams, J. (Eds.). Coping and adaptation. New York: Basic Books, Inc., 1974.

Cohen, S.: \& McRay: Go Social support, stress and the buffer hypothesis: Theoretical and empirical issues. Unpublished paper, 1980.

Cooley, C. H. Human Nature and the Secial order. Glencoe, Ill.: Free Press, 1956.

Coyne, J. Depression and the response of others. Jeurnal of Abnormal Psychology, 1976, 85(2), 186-193.

Cronenwett, L., \& Kunst-Wilson, W. Stress, social support, and the transition to fatherhood. Nursing Research, $1981,30(4), 196-201$.

Cumming, E., \& Henry, w. Growing old. New York: Basic Books, 1961 .

Deloach, C., \& Greer, B. Adjustment to severe physical disability, a metamorphosis. New York: McGraw-Hill, 1981 .

DeVivo, M., Fine, P., \& Stover, S. The prevalence of SCI: A re-estimation based on life tables. Model systems' SCI Digest, Winter 1979, 1, 3-11.

Dowd, J. Aging as exchange: A preface to theory. Journal of Gerentology, 1975, 30, 584-594.

Edwards, J., \& Rlemmack, D. Correlates of life satisfaction: A reexamination. Journal of Gerontology, $1973,28,497-502$.

Emerson, R. Power-dependence relations. American Sociolegical Review, 1962, 27, 31-41.

Emerson, R. Exchange theory, parts 1 and 2. In $J$. Berger \& M. Zelditch (Eds.), Sociological theories in pregress (Vol. 2). Boston: Houghton-Mifflin, 1972 .

Festinger, L. A theory of social comparison processes. Human Relations, 1954, 1, 117-140.

Festinger, L. Informal social communication. Psychological Review, 1950, 57, 271-282.

Fine, P. Spinal cord injury: An epidemiologic perspective. Paraplegia, 1979-80, 17, 237-250.

Frielich, M. Vocational and avocational adjustment: A 
followup study of discharged paraplegic and quadriplegic veterans (Doctoral dissertation, Rutgers University, 1977) . Dissertation Abstracts International, 1977, 37(12), 7682-A. (University MicroFilms No. DBJ77-13461)

Froland, C. Improving the social adjustment of mental health clients: The case for social support netwerks. Unpublished doctoral dissertation, University of California, Berkeley, 1978a.

Froland, c. Social support and social adjustment: Implications for mental health professionals. Networks for Helping. Proceedings of the Conference on Networks, Portland state University, Portland, Oregon, November 1-2, 1978b, 31-56.

Geis, H. The problems of personal worth in the physically disabled patient. Rehabilitation literature, 1972, $33(2), 34-39$.

George, L. The impact of personality and social status factors upon activity level and psychological well-being. Journal of Gerontology, 1978, 33(6), 840-847.

Gore, S. The influence of social support and related vari= ables in ameliorating the consequences of job loss

(Doctoral dissertation, University of Pennsylvania, 1973). Dissertation Abstracts International, 1973, 34(8), 5330-A. (University Microfilms No. 74-02416)

Graney, M. Happiness and social participation in aging. Journal of Gerontology, 1975, 30, 701-706.

Gunby, P. New focus on spinal cord injury. Journal of the American Medical Association, 1981, 245(12), 12011206 .

Gunther, M. S. Emotional aspects. In D. Rage (Ed.), spinal cord injuries. Springfield, Mass.: Charles C. Thomas, 1969 .

Guttman, L. Spinal cord injuries--comprehensive management and research. Oxford, England: Blackwell Scientific Publications, 1976.

Harris, L. \& Associates. The myth and reality of aging in America. Washington, D.C.: The National Council on Aging, 1975.

Harris, P., Patel, S., Greer, W., \& Naughton, J. 
Psychological and social reactions to acute spinal paralysis. International Journal of Paraplegia, $1973,11,132-136$.

Heller, $R$. The effects of social support: Prevention and treatment implications. In A. P. Goldstein \& F. H. Ranfer (Eds.), Maximizing treatment gains: Transfer enhancement in psychotherapy. New York: Academic Press, 1979.

Hirsch, B. J. Natural support systems and coping with major life changes. American Journal of community Psychology, 1980, 8(2), 153-166.

Homans, G. Social behavior: Its elementary forms. New York: Harcourt, Brace \& World, 1961.

Hull, C., \& Nie, N. SPSS update. New York: McGraw-Hill, 1979.

Jamison, R. R., Wellisch, D. K., \& Pasnau, R. 0. Psychosocial aspects of mastectomy: The woman's perspective. American Journal of Psychiatry, 1978, $135,432-436$.

Kemp, B., \& Vash, C. Productivity after injury in a sample of spinal cord injured persons: a pilot study. Journal of Chronic Disease, 1971, 24, 259-275.

Kerlinger, F. Foundation of behavioral research (2nd ed.). New York: Holt, Rinehart, \& Winston, 1973.

Kerr, W., \& Thompson, M. Acceptance of disability at sudden onset in paraplegia. Paraplegia, 1972, 10, 94-102.

Kimball, C. P. Psychological responses to the experience of open-heart surgery. American Journal of Psychiatry, 1969, 126, 96-107.

Langer, E., \& Rodin, J. The effects of chronic and enhanced personal responsibility for the aged: A fixed experiment in an institutional setting. Journal of Personality and Social Psychology, 1976, 34, 191-198.

Langner, T. A twenty-two item screening scale of psychiatric symptoms indicating impairment. Journal of Health and Human Behavior, 1962, 3, 269-276.

Langner, T., \& Michael, S. Life stress and mental health. Glencoe, Ill.: Free Press, 1963. 
Larson, R. Thirty years of research on the subjective well-being of older Americans. Journal of Gerontology, 1978, 33(1), 109-125.

Lawton, M. The dimensions of morale. In D. Rent, R. Rastenbaum, \& S. Sherwood (Eds.), Research, planning, and action for the elderly. New York: Behavioral Publications, 1972 .

Lawton, M., \& Cohen, J. The generality of housing impact on the well-being of older people. Journal of Gerontology, 1974, 22(2), 194-204.

Lazarus, R. Cognitive and coping processes in emotion. In A. Monat \& R. Lazarus (Eds.), Stress and coping. New York: Columbia University Press, 1977.

Lemon, B., Bengtson, V., \& Peterson, J. An exploration of the activity theory of aging: Activity types and life satisfaction among in-movers to a retirement community. Journal of Gerontology, 1972, 27, 511523 .

Lewinsohn, P. Clinical and theoretical aspects of depression. In $\mathrm{K}$. Calhoun, H. Adams, \& $\mathrm{R}$. Mitchell (Eds.), Innovative treatment methods in psychopatholegy. New York: Wiley, 1974 .

Litman, T. An analysis of the sociological factors affecting the rehabilitation of physically handicapped patients. Archives of Physical Medicine and Rehabilitation, 1964, 45, 9-16.

Litwak, E. Research patterns in the health of the elderly: The community mental health center. In E. F. Borgatta \& N. G. McCluskey (Eds.), Aging and Society. Beverly Hills, Ca.: Sage Publications, 1979.

Lohmann, N. Correlation of life satisfaction, morale and adjustment measures. Journal of Gerontology, 1977, $32(1), 73-75$.

Lohmann, N. Life satisfaction research in aging: Implications for policy development. In N. Datan \& $N$. Lohmann (Eds.), Transitions of aging. New York: Academic Press, 1980.

Lubin, B. Manual for the depression objective checklists. San Diego: Educational and Industrial Testing Service, 1967.

MacElveen-Hoehn, P., \& Smith-DiJulio, K. Social network 
behavior in long term illness: Preliminary analysis. Networks for helping. Proceedings of the Conference on Networks, Portland state university, Portland, Oregon, Nov. 1-2, 1978, 67-91.

Maddison, D., \& Walker, W. L. Factors affecting the outcome of conjugal bereavement. British Journal of Rsychiatry, 1967, 113, 1057-1067.

Mann, W., Godfrey, M., \& Dowd, E. The use of group counseling procedures in the rehabilitation of spinal cord injured patients. The American Journal of eccupational Therapy, 1973, 22(2), 73-77.

MCKay, J. The effect of rehabilitation counselor disability status on similarly disabled clients' perceptions of counselor social influence and empathy (Doctoral dissertaion, Florida State University, 1980). Dissertation Abstracts International, 1980, 40(9), 4898A. (University Microfilms No. DEMBO07488 )

Mead, G. H. Mind, Self, and Society. Chicago: University of Chicago Press, 1934.

Milhouse, R. Emotional adjustments to spinal cord injury. National Resource Directory. Newton upper Falls, Mass.: National Spinal Cord Injury Foundation, 1979.

Murawski, B., Penman, D., \& Schmitt, M. Social support in health and illness: The concept and its measurement. Cancer Nursing, October 1978, pp. 365-371.

National Spinal Cord Injury Model Systems" Conference: Proceedings. Phoenix, Az.: National Spinal Cord Injury Data Research Center, 1978.

Neugarten, B., Havighurst, R., \& Tobin, S. The measurement of life satisfaction. Journal of Gerontology, 1961, $16,134-143$.

Nie, N., Hull, C., Jenkins, J.., Steinbrenner, K., \& Bent, D. Statistical package for the social sciences (2nd ed.). New York: McGraw-Hill, 1975.

Norbeck, J., Lindsey, A., \& Carrieri, V. The development of an instrument to measure social support. Nursing Research, 1981, 30(5), 264-269.

Palmore, E., \& Rivett, V. Change in life satisfaction: A longitudinal study of persons aged 46-70. Journal of Gerontolegy, 1977, 32(3), 311-316. 
Palmore, E., \& Luikart, C., Jr. Health and social factors related to life satisfaction. Health and social Behavior, 1972, 13, 68-80.

Peterson, D., King, P., \& Davis, $R$. Age and lifestyle adjustment as a result of amputation. Presented at the annual meeting of the Gerontological society, Dallas, Texas, Nov. 16-20, 1978.

Petrus, J., \& Balaban, A. Special psychiatric problems of the paraplegic, American Journal of Psychiatry, $1953,109,693-695$.

Pihlblad, C., Adams, D. Widowhood, social participation, and life satisfaction. Aging and Human Development, $1972,3,323-330$.

Pinneau, S. Effects of social support on psychological and physiological strains (Doctoral dissertation, University of Michigan, 1976). Dissertation Abstracts International, 1976, 36(10), 5359B. (University Microfilms No. DAH76-09491)

Protection of Elderly Research Subjects, U.S.D.H.E.W., 1977 .

Radloff, L. The CES-D scale: A self-report depression scale for research in the general population. Applied Psychological Measurement, 1977, 1, 385-401.

Reid, D., \& zeigler, M. Validity and stability of a new desired control measure pertaining to psychological adjustment of the elderly. Journal of Gerontology, $1980,35(3), 395-402$.

Rodin, J., \& Langer, E. Long-term effects of a controlrelevant intervention with the institutionalized aged. Journal of Personality and Social Psychology, $1977,35,897-902$.

Roessler, R., \& Bolton, B. Psychosocial adjustment to disability. Baltimore: University Park Press, 1978.

Rogers, J., \& Figone, J. Psychosocial parameters in treating the person with quadriplegia. The American Journal of Occupational Therapy, 1979, 33(7), 432439.

Rohrer, K., Adelman, B., Puckett, J., Toomey, B., Talbert, D., \& Johnson, E. Rehabilitation in spinal cord injury: Use of a patient-family group. Archives of Physical Medicine and Rehabilitation, 1980, 61, 225229. 
Schulz, R. Aging, health and theoretical social gerontology: Where are we and where should we go? In $M$. R. Eiser (Ed.), Social nsychology and behavioral medicine. New York: John Wiley, 1982a.

Schulz, R. Emotionality and aging. In K. Blankstein \& J. Polivy (Eds.), Advances in the study of communication and affect (Vol. 7). New York: Plenum Press, $1982 \mathrm{~b}$.

Schulz, R. Psychology of death, dying, and bereavement. Reading, Mass.: Addison-Wesley, 1978.

Schulz, R. The effects of control and predictability on the psychological and physical well-being of the institutionalized aged. Journal of Personality and Social Psychology, 1976, 33, 563-573.

Schulz, R., \& Hanusa, B. Environmental influences on the effectiveness of control and competence enhancing interventions. In L. C. Perlmutter \& R. A. Monty (Eds.), Choice and perceived control. New York: Lawrence Erlbaum Associates, 1979.

Schulz, R., \& Hanusa, B. Experimental social psychology: A social psychological perspective. Journal of social Issues, $1980,36,30-47$.

Schulz, R., \& Hanusa, B. Long-term effects of predictability and control enhancing interventions: Findings and ethical issues. Journal of Personality and Social Psychology, 1978, 36, 1194-1201.

Seligman, M. Helplessness: on depression, development and death. San Francisco: W. H. Freeman, 1975.

Seymour, G. Activity level, the sense of personal autonomy and life satisfaction in old age (Doctoral dissertation, Boston University Graduate School, 1972). Dissertation Abstracts International, 1972, $33(5)$, 2331B-2332B. (University Microfilms No. $72-25326)$

Silver, R., \& Wortman, C. Coping with undesirable life events. In J. Garber \& M. E. P. Seligman (Eds.), Human helplessness. New York: Academic Press, $1980 a$.

Silver, R., \& Wortman, C. Expectations of control and coping with permanent paralysis. Paper presented at symposium on "Issues of control in Health," APA Convention, Montreal, Canada, September 1980b. 
Spreitzer, E., \& Snyder, E. Correlates of life satisfaction. Journal of Gerontology, 1974, 29(4), 454-458.

Thompson, G. Work versus leisure roles: An investigation of morale among employed and retired men. Journal of Gerontology, 1973, 18(3), 339-344.

Thorn, I., Von Salzer, C., \& Fromme, A. Psychological aspects of the paraplegic patient. Medical Clinics of North America, 1946, 3Q, 473.

Trieschmann, R. B. Spinal cord injuries: Psychological, social and vocational adjustment. New York: Pergamon Press, 1980.

Tucker, S. The psychology of spinal cord injury: Patient-staff interaction. Rehabilitation Literature, $1980,41(5-6), 114-121 ; 160$.

Vachon, M. L. S., Lyall, W. A., Rogers, J., Formo, A., Freedman, K., Cochrane, J., \& Freeman, S. The use of group meetings with cancer patients and their families. In J. Tache', H. Selye, \& S. B. Day (Eds.), Cancer, stress and death. New York: Plenum, 1979 .

Vargo, J. Some psychological effects of physical disability. American Journal of Occupational Therapy, $1978,32,31-34$.

Veroff, J., Douvan, E., \& Kulka, R. The inner American: A self-portrait from 1257 to 1976. New York: Basic Books, 1981.

Walker, K. N., MacBride, A., \& Vachon, M. L. S. Social support networks and the crisis of bereavement. Social Science and Medicine, 1977, 11, 35-41.

Watson, N. Pattern of spinal cord injury in the elderly. Paraplegia, 1976, 14, 36-40.

Weisman, A. D. Early diagnosis of vulnerability in cancer patients. American Journal of the Medical Sciences, $1976,271,187-196$.

Weisman, A. D., \& Worden, J. W. Psychological analysis of cancer deaths. Omega, 1975, 6, 61-75.

Weller, D., \& Miller, P. Emotional reactions of patient, family and staff in acute-care period of spinal cord injury. Social Work in Health Care, Summer 1977, 367-379 (Pt. 1). 
Wood, V., Wylie, M., \& Sheafer, B. An analysis of a short self-report measure of life satisfaction: Correlation with rater judgments. Journal of Gerontology, $1969,24,465-469$.

Wortman, C. B., \& Dunkel-Schetter, C. Interpersonal relationships and cancer: A theoretical analysis. Journal of Social Issues, $1979,35,120-155$.

Wright, B. A. Physical disability: A psychological approach. New York: Harper and Row, 1960.

Zemore, R., \& Eames, N. Psychic and somatic symptoms of depression among young adults, institutionalized aged, and noninstitutionalized aged. Journal of Gerontology, 1979, 34, 716-722.

Zung, $W$. A self-rating depression scale. Archives of General Psychiatry, 1965, 12, 63-70. 
APPENDIX A

ELDERLY SPINAL CORD INJURY QUESTIONNAIRE 
Interviewer

Respondent Code

Date

Elderly Spinal Cord Injury Questionnaire

First, let me thank you for agreeing to talk to us. He are very interested in learning more about persons with spinal cord injuries as they grow older. I have a number of questions to ask you, so please let me know if you need to stop or rest.

A. Demographics

1. Age

2.

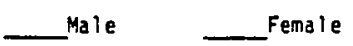

3. Race (ask only if not obvious)

$\begin{array}{ll}\text { Hispanic origin } & \text { Astan American } \\ - \text { Black } & \text { Hhite } \\ - \text { Otfue American } & \text { Other }\end{array}$

4A. Marital Status

$\begin{array}{ll}\text { Oivorced } & \text { Never Married } \\ \text { Separated } & \text { Widowed }\end{array}$ Ling as Married

4B. If widowed, divorced or separated; how Iong?

Less than one year
$1-3$ years
4-7 years

over 7 years

5. Chilaren

Age

Gender

No. Cnildren

Child 1

Child 12

Child $* 3$

Child is

Chitd $\$ 5$

$\begin{array}{lll}\square & F \\ \square & M & F \\ \square & F \\ M & F \\ M & F\end{array}$

5. What is the highest level of education completed?

L_Less than higi: echoo?

High Sehool

Vocational training

Associate degree
Baccalaureate degree

Graduate degree

other

7A. Would you describe yourself as a religious person?

$\begin{array}{lllll}1 & 2 & 3 & 4 & 5 \\ \text { iot at all } & & & & \begin{array}{l}\text { Very } \\ \text { Religious }\end{array} \\ \text { Religious }\end{array}$


78. What is your religious affiliation, if any?

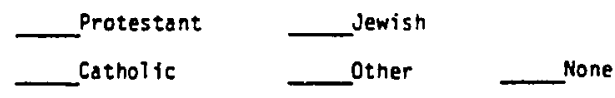

GA. Are you employed?

No (If no, skip to question 9)
Yes Part-time rull-time

8B. If employed, what is your occupation?

SC. If employed, how satisfied are you with your job?

\begin{tabular}{|c|c|c|c|c|}
\hline 1 & 2 & 3 & 4 & 5 \\
\hline $\begin{array}{l}\text { Not at } \\
\text { al }\end{array}$ & & & & $\begin{array}{l}\text { Very } \\
\text { satisfied }\end{array}$ \\
\hline
\end{tabular}

9A. Can you tell me into which of these categories your yearly income falls?

$\begin{array}{rr}\$ 0-2500 & \$ \$ 0,001-15,000 \\ \$ 2501-5000 & \$ 15,001-20,000 \\ \$ 5001-7500 & \$ 20,001 \text { and over } \\ \$ \$ & \text { Refused to answer }\end{array}$

9R. What are the sources of your income? (eg. job, socid security, pensions, disability)

list in order of largest to smallest source of income:

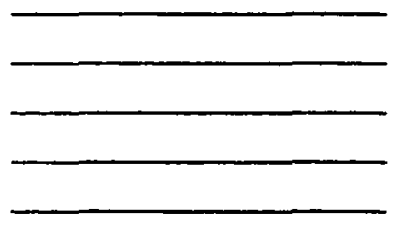

$Q C$. How satisfied are you with your income?

\begin{tabular}{|c|c|c|c|c|}
\hline 1 & 2 & 3 & 4 & 5 \\
\hline $\begin{array}{l}\text { Not at all } \\
\text { satisfied }\end{array}$ & & & & $\begin{array}{l}\text { Very } \\
\text { satisfied }\end{array}$ \\
\hline
\end{tabular}

8. Recreattonal/Group Activities/Community Services

104. What recreational activities andfor hobbies do you participate in? List:

10B. Are these activities?

Individual

Group

Combination of above 
11A. Are you a menber of any group that meets together regularly?

118. If yes, describe group(s) Meets less Once or Once a Several times Almost

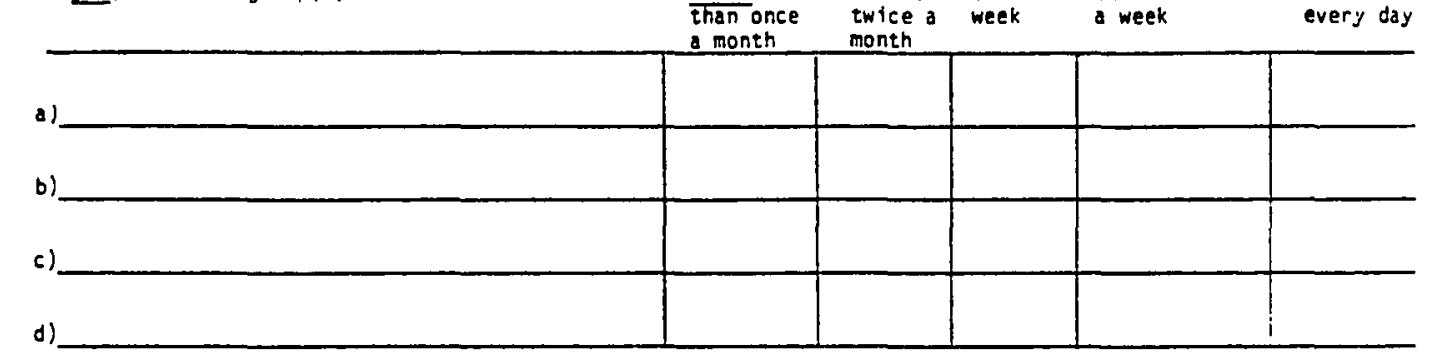

12. What community services or agencies do you tend to use on an ongoing basis?

\begin{tabular}{|c|c|c|c|c|c|}
\hline Name of service/agency & $\begin{array}{l}\text { Use less than } \\
\text { once a ronth }\end{array}$ & $\begin{array}{l}\text { Once or } \\
\text { twice o } \\
\text { month }\end{array}$ & $\begin{array}{l}\text { Cnce a } \\
\text { week. }\end{array}$ & $\begin{array}{l}\text { Several } \\
\text { t'mes a week }\end{array}$ & $\begin{array}{l}\text { Alriost } \\
\text { every dav }\end{array}$ \\
\hline \multicolumn{6}{|l|}{ a) } \\
\hline \multicolumn{6}{|l|}{ b) } \\
\hline \multicolumn{6}{|l|}{ c) } \\
\hline \multicolumn{6}{|l|}{ d) } \\
\hline e) & & & & & \\
\hline
\end{tabular}

\section{Residential Characteristics}

13A. Residential status (Interviewer observation)

_urban Suburban Rural

13B. Type of residence

House
Apartment
Condominium
Hobile home

$13 r$. _Lwn residence

130. Condition of kesidence (Interviewer judgement)

(Interviewer: Explain that you're asking item in because weire interested in how much it costs for elderiy cord injured persons to live)

$1 C A$. Pbnthly rent/mortoage paynent?

IKB. lonthly expenses for utilities, heatinn, ghone, etc.

14.. Do you pay housing costs yourseif? Yes _. Yo Share costs

140. If no, who heips you gay this expense? 
15A. Not courting yourself, how many persons live in this house/apartment/room, etc., with you?

15B How are they related to you?

$\begin{array}{ll}\text { Respondent only } & \text { Sibling(s) } \\ \text { Spouse } & \text { Other relative } \\ \text { Children } & \text { Priend }\end{array}$

D. Healen Status

15R. All things considered, how would you rate your health status right now?

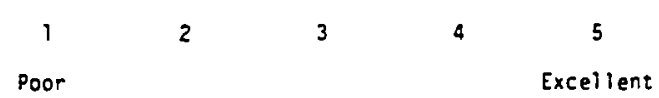

168. Compared to a year ago, is your health: (a) Better

(b) Worse (c) Same

17A. What is the nature of your spinal cord injury?
Level of lesion
Complete
Incomplete

178. How old were you when the spind cord injury cccurred?

17c. What was the cause of the injury?

Describe:

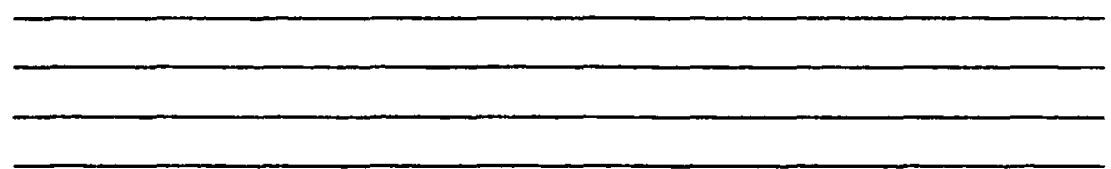

170.

Service-connested Non-service connected

13. Do you have any other chronic health problems: (If no answer, probe: es. diabetes, heart consition, high blood pressure)

Describe:

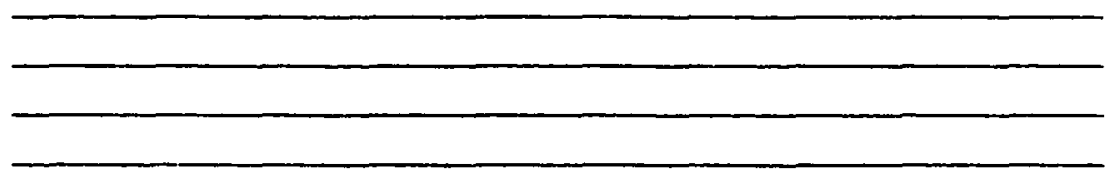

19A. Have you been hospitalized in the past year? (a) No

(b) Yes

19B. If yes, for how long?

20. No you feel your present physical condition may/is likely to:

Get better in the next year

Stay the same in the next year.

Get worse in the next year 
21. How much assistance do you need with the following activities?

\begin{tabular}{l|l|l|l|l} 
& $\begin{array}{c}\text { No assistance } \\
0\end{array}$ & $\begin{array}{c}\text { Occassonal } \\
\text { assistance } \\
\text { (a) Dressing }\end{array}$ & $\begin{array}{l}\text { Frequent } \\
\text { Assistance } \\
2\end{array}$ & $\begin{array}{l}\text { Complete } \\
\text { Assistance } \\
3\end{array}$ \\
\hline (b) Bathing & & & & \\
(c) Eating & & & & \\
\hline (d) Cooking & & & & \\
\hline (e) Toilet & & & & \\
\hline (f) Oriving venicle & & & & \\
(g) Shooping & & & & \\
\hline (b) Laundry & & & & \\
(i) House Cleaning & & & & \\
\hline
\end{tabular}

\section{E. Social Ne:work/Support}

(22-31) Instructions:

I would like you to list those persons who are in some way significant to you at this time in your life. Please include on this list anyone who is an important source of help, support, or guidance to you. These persons may inciude relatives, friends, neighbors, co-workers, church or club members, or professional workers. After listing these people, I'd like to ask you some questions about these persons and your relationshtp with them.

(Interviewer instructions:

List the first names of the persons here. If the interviewee names more than five persons, ask them to look at these names and indicate which five are the most important to them. Ask the social support questions for these five persons.) List first names:

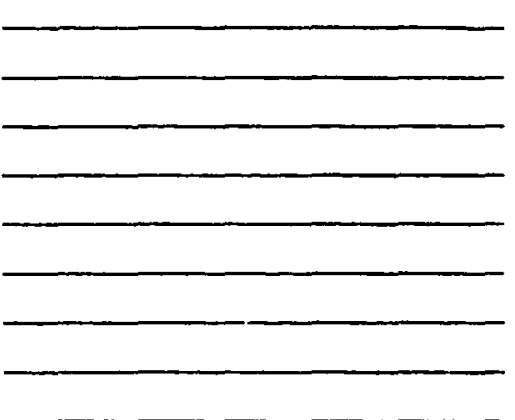




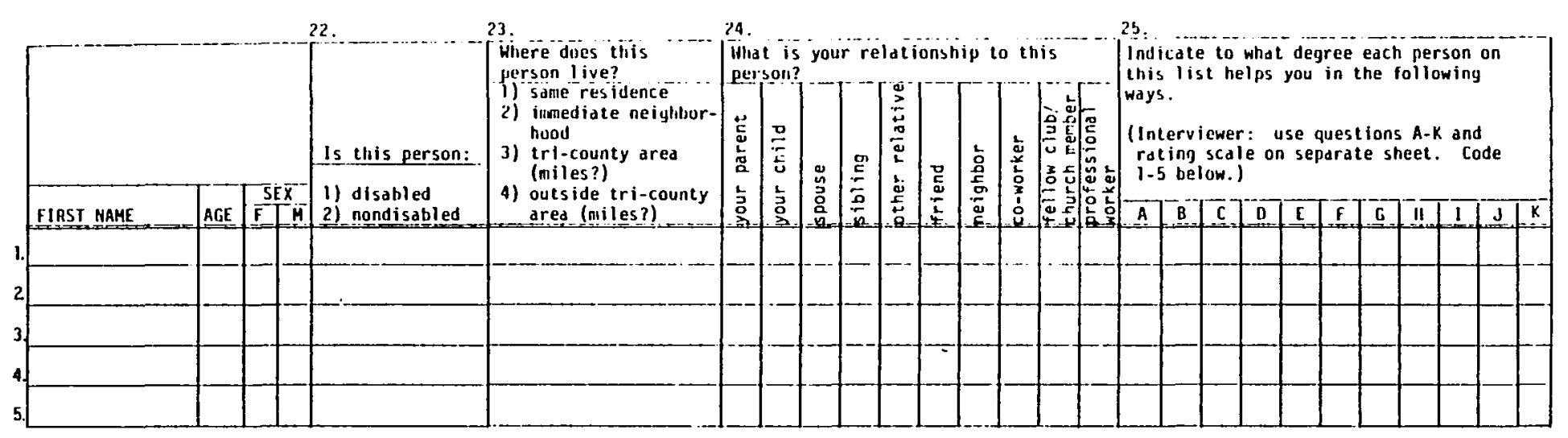

FOR USE IN QUESTION 25:

Indicate the degree to which each person on this list helps you in the folluwing ways:

\begin{tabular}{|c|c|c|c|c|c|c|}
\hline \multirow{2}{*}{\multicolumn{2}{|c|}{ Wist helps you in the following ways: }} & \multirow{2}{*}{$\frac{1}{1}$} & \multirow{2}{*}{ Rurely } & \multirow{2}{*}{$\begin{array}{l}\text { On soae } \\
\text { Occassions } \\
3\end{array}$} & \multirow{2}{*}{ often } & \multirow{2}{*}{ 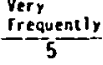 } \\
\hline & & & & & & \\
\hline$\underset{w}{\vec{E}}$ & $\begin{array}{l}\text { A) Assist with things such as cleaning. shop- } \\
\text { ping, transportation, repairs or even } \\
\text { loaning money. }\end{array}$ & & & & & \\
\hline 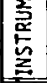 & $\begin{array}{l}\text { B) Maxe sure, you get enough rest, nutrition, } \\
\text { exercise, and just take care of yourself. } \\
\text { in general. }\end{array}$ & & & & & \\
\hline & $\begin{array}{l}\text { C) Shuw genuine concern and interest in your } \\
\text { feel ings and worries. }\end{array}$ & & & & & \\
\hline 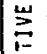 & $\begin{array}{l}\text { D) Inciude you in what they do, make you } \\
\text { feel you belong. }\end{array}$ & & & & & \\
\hline 总 & $\begin{array}{l}\text { E) Let you know you are important to them. } \\
\text { make you feel cared for and loved. }\end{array}$ & & & & & \\
\hline & $\begin{array}{l}\text { If there when you need them for support; } \\
\text { know you can count on them. }\end{array}$ & & & & & \\
\hline & $\begin{array}{l}\text { G) Give you information or advice; helo to } \\
\text { give you sume ideds or answers in dedl. } \\
\text { ing with jroblens. }\end{array}$ & & & & & \\
\hline 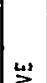 & $\begin{array}{l}\text { 1) Set things in a positive way make your } \\
\text { problesns seen smaller or remind you of } \\
\text { things you have to be happy dbout. }\end{array}$ & & & & & \\
\hline 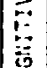 & $\begin{array}{l}\text { 1) llave the sane or sinilar problemis as } \\
\text { you do; you discuss similar concerns with }\end{array}$ & & & & & \\
\hline 8 & $\begin{array}{l}\text { 3) Poine out your strengthis give you con- } \\
\text { fidence to deal with stresstul things in } \\
\text { your tife. }\end{array}$ & & & & & \\
\hline & 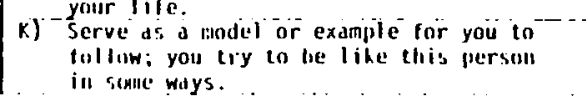 & & & & & \\
\hline
\end{tabular}




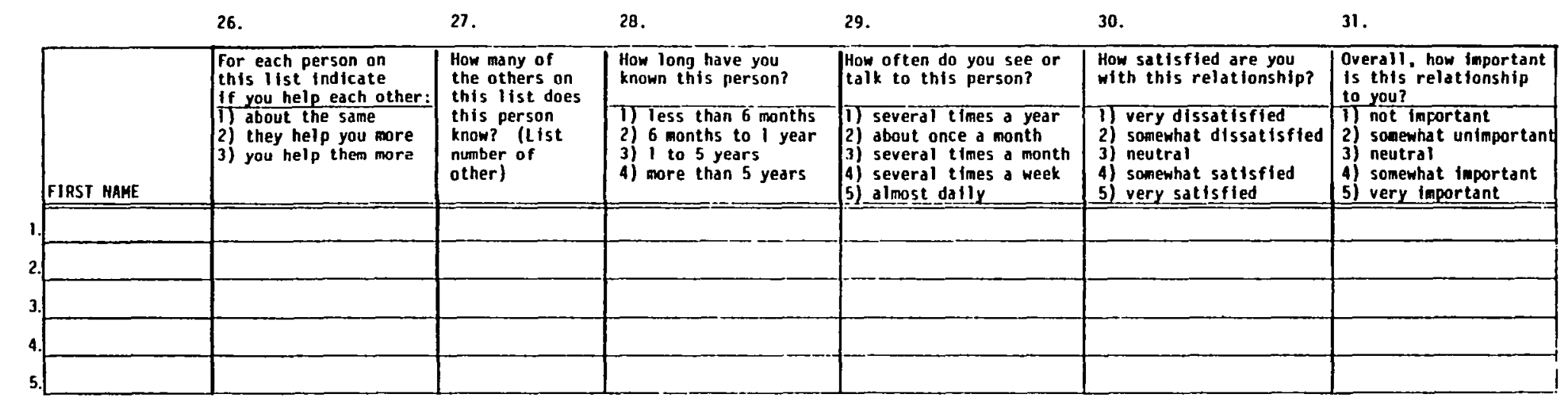


32A. In general, how satisfied are you with the amount of social contact you have with others?

$\begin{array}{lllll}1 & 2 & 3 & 4 & 5 \\ \text { Not at all } & & & & \begin{array}{l}\text { Very } \\ \text { satisfied }\end{array}\end{array}$

32B. In general, now satisfied are you with the gualtty or closeness of the soctal contact you have with others?

$\begin{array}{lllll}1 & 2 & 3 & 4 & 5 \\ \text { Not at all } & & & & \begin{array}{l}\text { Very } \\ \text { Satisfied }\end{array}\end{array}$

3jA. Are there persons who were very important to you that you've lost contact with in the last several years? (e.g. through death, moving away)

No

Yes

336. Describe:

F. Social Comparison

34. Overall, how good would you say your life sttuation is on a 1-10 scale with lo being "the greatest."

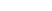

35. Who do you compare yourself with to dectde this? Describe:

Probe: Is there any particular group of person you find yourself most frequently comparing yourself and your iffe situation to? Describe:

35. On what characteristics (e.g. appearance, skllis, intellect, personality) do you find yourself comparing your life situation with others? Describe: 
37A. Compared with most peoole (e.g.. the "average American"). haw good is your current life situation? Worse than most Horse than some

Same as most

Better than some

Better than most

37B. Compared with others your age, how good is your life situation?

Horse than most

Horse than some

Same as most

Getter than some

Better than most

376. Compared with others with a similar disability, how good is your current 1 ife situation? Worse than most

Worse than some

Same as most

Better than some

Better than most

372. Compared to your life before your disability, how good is your current life situation?

Much worse now

Somewha: worse now

about the same

Somewhat better now Much better now

37. How goof do you think your current iffe would be if you didn't have the disability?

Much worse

Somewhat worse

About the same

Somewhat better

Much better

I. What :hings or values come to your mind when you're thinking about your life situation? Tescrite: 
39A. In general, to what extent do you feel your life is controlled by the following factors?

\begin{tabular}{l|l|l|l|l|l}
\multicolumn{1}{c|}{} & Not it all & 2 & 3 & & Very much \\
\hline d) Self & & & & & 5 \\
\hline b) Other people & & & & & \\
\hline c) Luck, chance & & & & & \\
\hline d) God & & & & & \\
\hline e) Oener & & & & & \\
\hline
\end{tabular}

398. In general, to what extent do you feel that you can achieve or obtain what is important to you?

$\begin{array}{ccccc}1 & 2 & 3 & 4 & 5 \\ \text { Not at } & & & & \text { Completely } \\ \text { all } & & & & \end{array}$

39c. In general, to what extent do you feel that you can make your interactions with people end up the way you expect them to?

$\begin{array}{ccccc}1 & 2 & 3 & 4 & 5 \\ \begin{array}{c}\text { Not at } \\ \text { all }\end{array} & & & & \text { Compietely }\end{array}$

390. Overall, to what degree do you feel you can count on yourself to cope successfuliy when you're stressed?

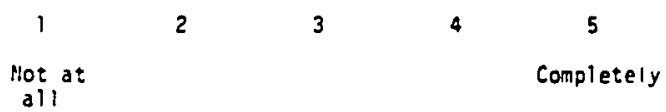

39E. In generai, to what degree do you feel able to solve problems in your life?

$\begin{array}{ccccc}1 & 2 & 3 & 4 & 5 \\ \text { Not at } & & & & \text { Completely } \\ \text { il } & & & & \end{array}$

39F. In general, to what degree ore the good things that happen to you largeiy your own doing:

$\begin{array}{ccccc}1 & 2 & 3 & 4 & 5 \\ \text { Not at } & & & & \text { Completely } \\ \text { ali } & & & & \text { Con }\end{array}$

4DA. To what exten: do you blame each of the following factors for causing your disability?

\begin{tabular}{|c|c|c|c|c|c|}
\hline & Not at all & 2 & 3 & 4 & $\begin{array}{l}\text { Very muen } \\
\end{array}$ \\
\hline 2) Self & & & & & \\
\hline D) oiner people & & & & & \\
\hline c) Chance, luck & & & & & \\
\hline d) God & & & & & \\
\hline e) Other & 1 & & & & \\
\hline
\end{tabular}

48?. To what extent do you belfeve you could have avoided what happened causing your disability?

$\begin{array}{ccccc}? & 2 & 3 & 4 & 5 \\ \text { Not at } & & & & \text { Completely } \\ \text { all } & & & & \end{array}$


41A. What are the major difficulties in your life at this time? Describe:

418. In general, to what extent do you believe present difficulties in your life are due to your own actions or inactions?

$\begin{array}{ccccc}1 & 2 & 3 & 4 & 5 \\ \text { Not at ail } & & & & \text { Compietely }\end{array}$

424. Considering the best and worst things that could happen to you in your lifetime, where does your disability fit into the scale?

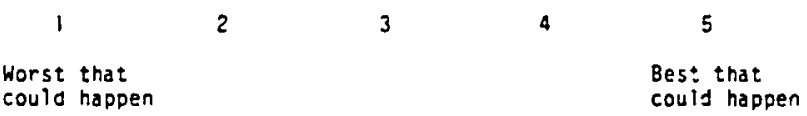

428. Has there been any purpose or positve meaning that your disability has had in your life?

No

Yes___ Describe:

43. How happy are you now (not at this moment, but at this stage of your life)?

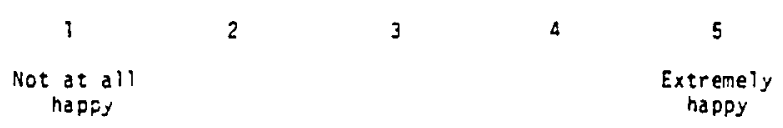

:A. How of:en do you feel depressed?

$\begin{array}{ccccc}1 & 2 & 3 & 4 & b \\ \begin{array}{l}\text { Very } \\ \text { Often }\end{array} & \text { Often } & \text { Sometimes } & \text { Occasionaliy } & \text { Never }\end{array}$

44B. When you feel depressed, what do you do to cope with that feeling? Describe:

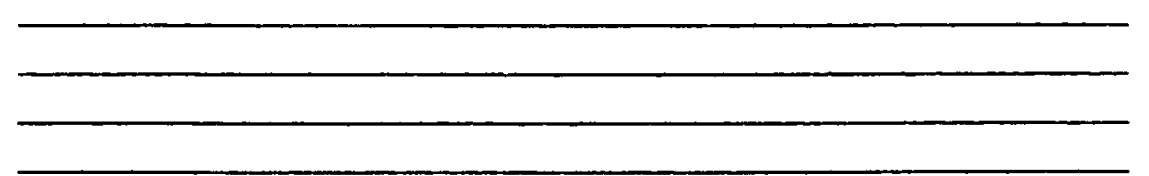

45A. In general, how hopeful do you feel about your future? (Probe: e.g. how good do you think things

will be in a month or even a year from now?!

\begin{tabular}{|c|c|c|c|c|}
\hline 1 & 2 & 3 & 4 & 5 \\
\hline $\begin{array}{l}\text { Hot ot } \\
\text { dll hopeful }\end{array}$ & & & & $\begin{array}{l}\text { Very } \\
\text { hepeful }\end{array}$ \\
\hline
\end{tabular}

453. What are your greatest fears about the future? Describe: 
I. Index of Psychologica! Well-Being

Instructions: Here is a list that describes some of the ways people feel at different times. How often do you feel each of these ways?

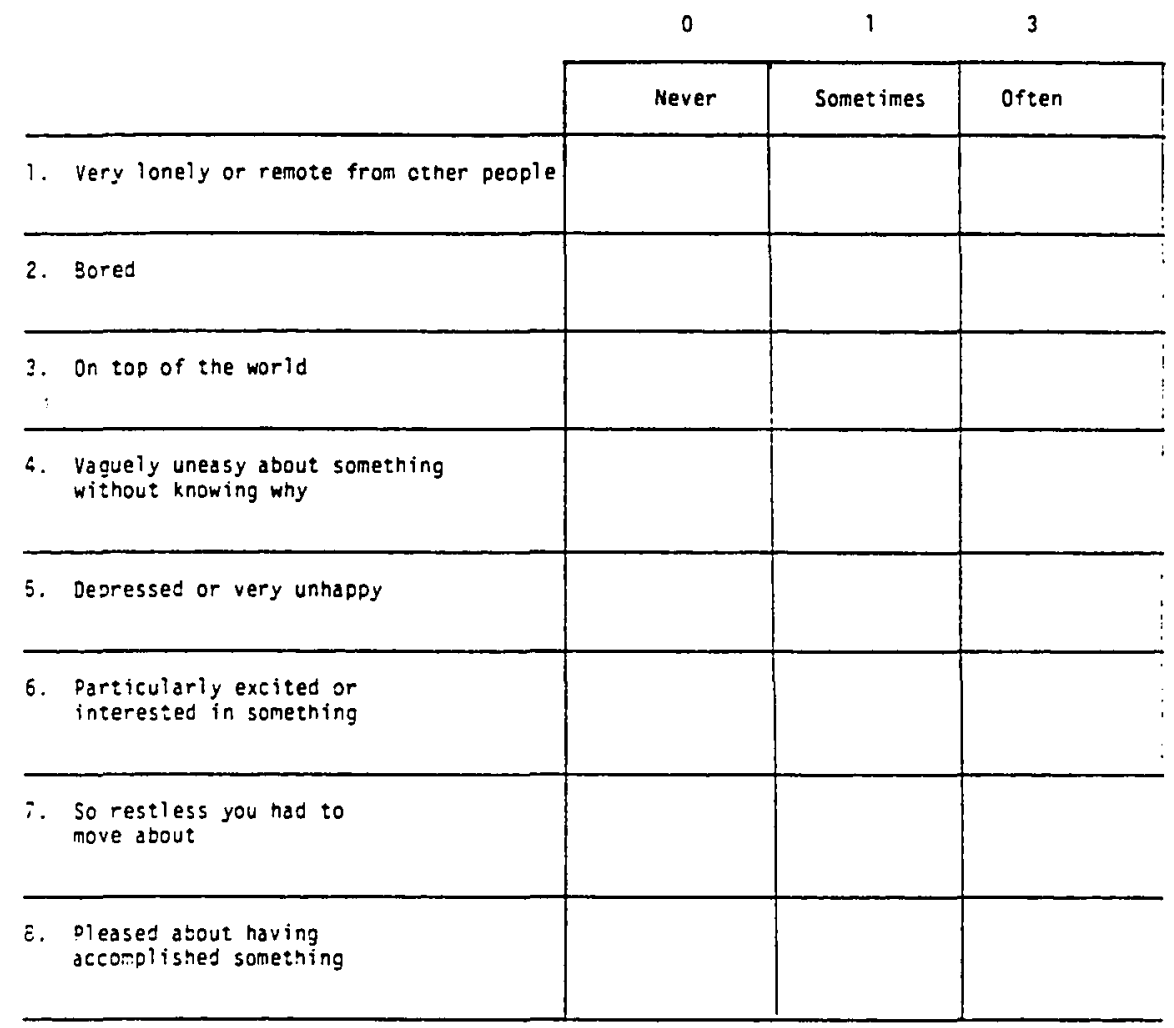

46A. Negative feelings score $(0-15)$

468. Positive feelings score

$$
\text { (0-9) }
$$

45C. Balance of positive and negative feelings score

$$
\begin{array}{cc}
\text { (1) - } & 7 \text { ) } \\
\text { positive - negative }
\end{array}
$$


J. The Modified Life Satisfaction Index A (LSIA-A)

Instructions: Indicate whether you agree or disagree with the following statements:

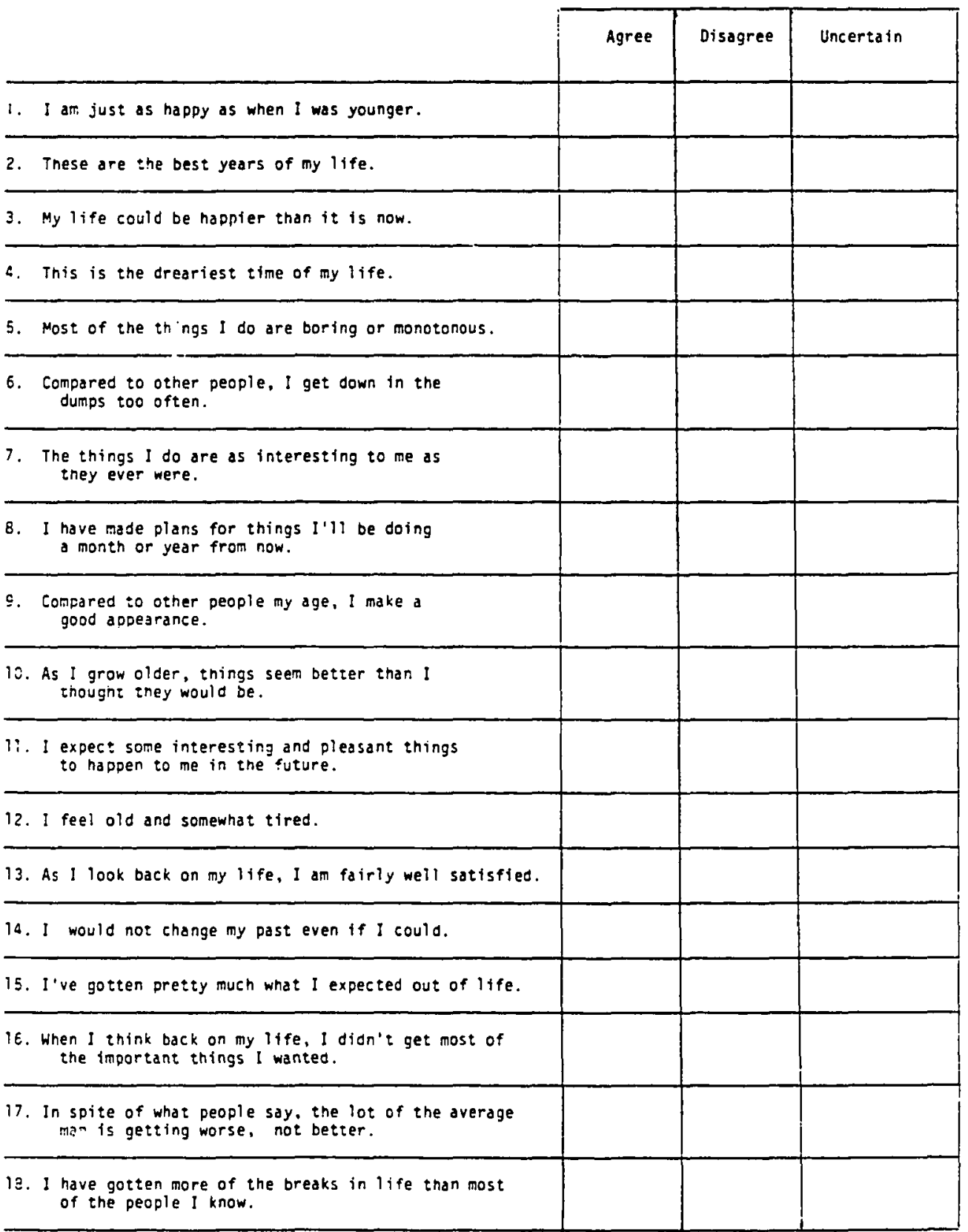

47. Score:

One (1) point affirmative (satisfied) response.

(0................. 18)

unsafisfied satisfied 
K. CES-D SCale

Instructions: This is a list of the ways you might have felt or behaved.

Please tell me how often you have felt this way during

the past week.

\begin{tabular}{|c|c|c|c|c|}
\hline During the past week: & $\begin{array}{c}\text { Rareiy or } \\
\text { none of } \\
\text { the time } \\
\text { Lessthan } 1 \text { Day }\end{array}$ & $\begin{array}{l}\text { Some or a } \\
\text { little of } \\
\text { the time } \\
1-2 \text { Days }\end{array}$ & $\begin{array}{l}\text { Occasionally } \\
\text { or a moder- } \\
\text { a te amount } \\
\text { of the time } \\
3-4 \text { Oays }\end{array}$ & $\begin{array}{l}\text { Most or all } \\
\text { of the time } \\
5-7 \text { Days }\end{array}$ \\
\hline \multicolumn{5}{|l|}{$\begin{array}{l}\text { 1. I was bothered oy things that usually don't } \\
\text { bother me. }(0-3)\end{array}$} \\
\hline \multicolumn{5}{|l|}{$\begin{array}{l}\text { 2. I did not feel like eating, my appetite } \\
\text { was poor. }(0-3)\end{array}$} \\
\hline \multicolumn{5}{|l|}{$\begin{array}{l}\text { 3. I felt that I could not shake off the blues even } \\
\text { with help from my family or friends. }(0-3)\end{array}$} \\
\hline \multicolumn{5}{|l|}{$\begin{array}{l}\text { 4. I felt that I was just as good as other people. } \\
(3-0)\end{array}$} \\
\hline \multicolumn{5}{|l|}{$\begin{array}{l}\text { 5. : had trouble keeping my mine on what I was } \\
\text { doing. }(0-3)\end{array}$} \\
\hline \multicolumn{5}{|l|}{ 5. I felt depressed. $(0-3)$} \\
\hline \multicolumn{5}{|l|}{$\begin{array}{l}\text { 7. I feit tha: everytning I did was an effort. } \\
(0-3)\end{array}$} \\
\hline \multicolumn{5}{|l|}{ e. I fel: hopeful about the future. $(3-0)$} \\
\hline \multicolumn{5}{|l|}{ 9. I thought my life had been a failure. $(0-3)$} \\
\hline \multicolumn{5}{|l|}{ 10. I felt fearful. $(0-3)$} \\
\hline \multicolumn{5}{|l|}{ 11. My sleep was restless. $(0-3)$} \\
\hline \multicolumn{5}{|l|}{ 12. I was happy. $(0-3)$} \\
\hline \multicolumn{5}{|l|}{ 13. I talked less than usual. $(0-3)$} \\
\hline \multicolumn{5}{|l|}{ 14. I fele lonely. $(0-3)$} \\
\hline \multicolumn{5}{|l|}{ 15. People were unfriendly. $(0-3)$} \\
\hline \multicolumn{5}{|l|}{ 16. I enjoyed life. $(3-0)$} \\
\hline \multicolumn{5}{|l|}{ 17. I had erjing spells. $(0-3)$} \\
\hline \multicolumn{5}{|l|}{ ic. I felt sad. $(0-3)$} \\
\hline \multicolumn{5}{|l|}{ 19. I felt that people oislike me. $(0-3)$} \\
\hline 20. I could not get "going." (0-3) & & & & \\
\hline
\end{tabular}

Scoring Instructions:

Score eact. item on a 0.3

scale with 3 being a

48. Score:

cepressed response)

$(0-60)$

non-depressed - depressed 
L.

49. How difficult was it to answer these questions?

$\begin{array}{lllll}1 & 2 & 3 & 4 & 5 \\ \text { Not at } & & & & \text { Very } \\ \text { alifficult } & & & & \text { difficult } \\ \text { difficul } & & \end{array}$

5c. Would you be willing to participate in this study again at a future time?

Yes

No

Observer Notes: (Cognitive and affective state, appearance, behavior) 
APPENDIX B

CLIENT INTERVIEW CODEBOOK 


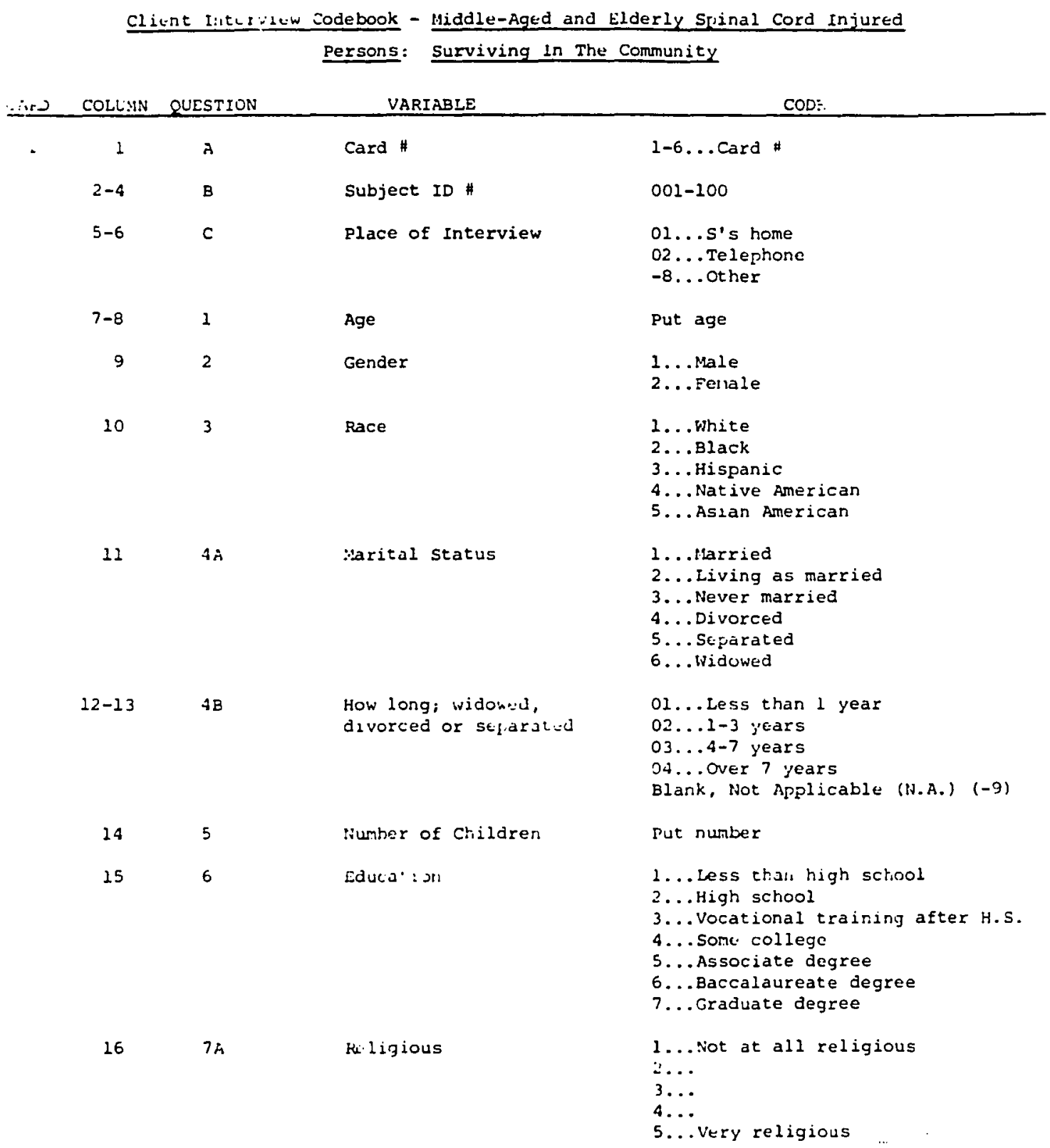


Page 2

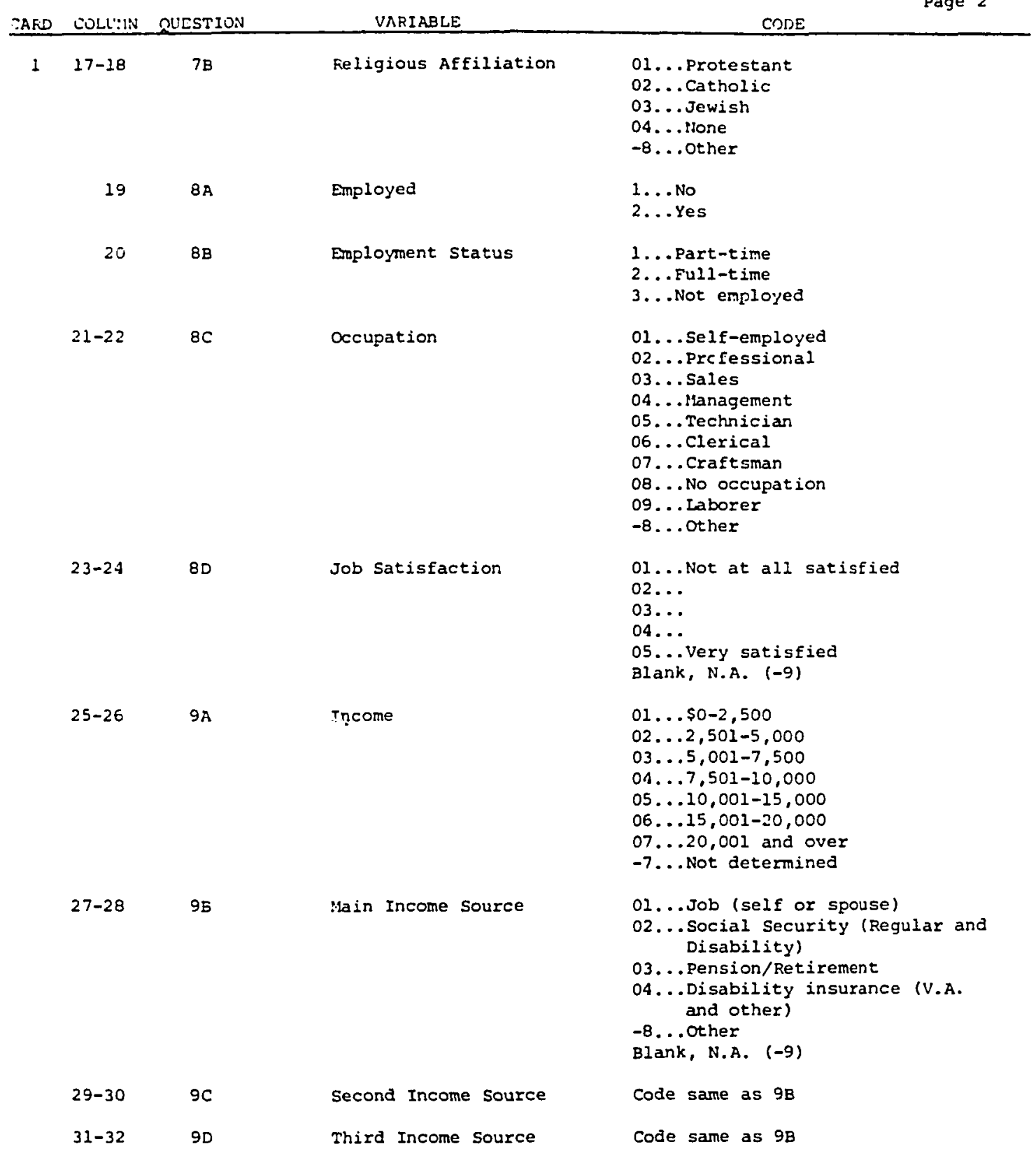


Page 3

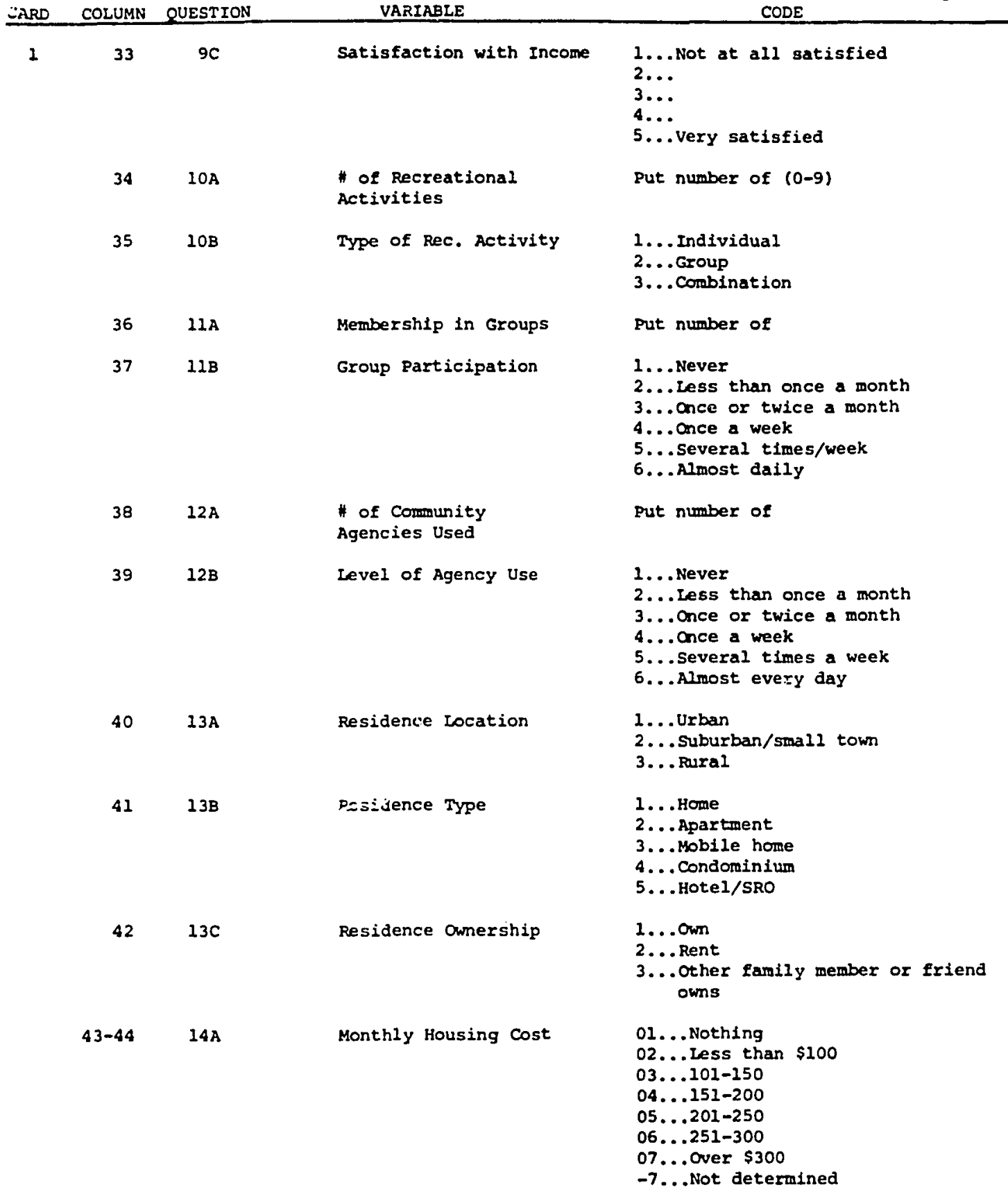




\begin{tabular}{|c|c|c|c|c|}
\hline CARD & COLUMN & QUESTION & VARIABLE & CODE \\
\hline \multirow[t]{11}{*}{1} & $45-46$ & $14 \mathrm{~B}$ & Monthly Housing Expenses & $\begin{array}{l}01 \ldots \text { Less than } \$ 100 \\
02 \ldots 101-150 \\
03 \ldots 151-200 \\
04 \ldots 201-250 \\
05 \ldots 251-300 \\
06 \ldots \text { over } \$ 300 \\
-7 \ldots \text {. Not determined }\end{array}$ \\
\hline & $47-48$ & $15 \mathrm{~A}$ & " Persons/dwelling & Put number $(01-10)$ \\
\hline & & $15 B$ & $\begin{array}{l}\text { Type Relationship/ } \\
\text { Persons Dwelling }\end{array}$ & $\begin{array}{l}\text { 01... Respondent only } \\
02 . . \text { Spouse }\end{array}$ \\
\hline & $\begin{array}{l}49-50 \\
51-52 \\
53-54\end{array}$ & $\begin{array}{l}\text { a) } \\
\text { b) } \\
\text { c) }\end{array}$ & & $\begin{array}{l}\text { 03... Child } \\
04 \ldots \text {. Parent } \\
05 \ldots \text {... Sibling } \\
06 \ldots \text {. other relative } \\
07 \ldots \text {. Friend } \\
\text { 08...Paid caregiver } \\
\text {-8...0ther } \\
\text { Blank, N.A. }(-9)\end{array}$ \\
\hline & 55 & $16 \mathrm{~A}$ & Health Status & $\begin{array}{l}1 \ldots \text { Poor } \\
2 \ldots \\
3 \ldots \\
4 \ldots \\
5 \ldots \text { Excellent }\end{array}$ \\
\hline & 56 & $26 B$ & $\begin{array}{l}\text { Health of./ } \\
\text { one year ago }\end{array}$ & $\begin{array}{l}\text { 1...Better } \\
2 \ldots \text { Worse } \\
\text { 3... Same }\end{array}$ \\
\hline & $57-58$ & $17 \mathrm{~A}$ & $\begin{array}{l}\text { Categorical/ } \\
\text { Level Infury }\end{array}$ & $\begin{array}{l}\text { 01... Paraplegia, incomplete } \\
\text { 02... Paraplegia, complete } \\
03 . . \text {. Muadrlplegia, incomplete } \\
04 \ldots \text {. Quadriplegia, complete } \\
-8 \ldots \text {. Other } \\
-7 . . \text {. Not determined }\end{array}$ \\
\hline & $59-60$ & 178 & Age at Injury & Put age \\
\hline & $61-62$ & $17 \mathrm{C}$ & Cause of Injury & $\begin{array}{l}\text { 01... Vetricular accident } \\
02 \ldots \text {. Fall } \\
03 \ldots \text {. Sports } \\
04 \ldots \text {. Polio } \\
\text { 05... Penetrating wound } \\
06 \ldots \text { Tumor } \\
07 \ldots \text {. Disease other than polio } \\
08 \ldots \text {. Other accident } \\
-8 \ldots \text {. Othex }\end{array}$ \\
\hline & 63 & 170 & Service-Connected & $\begin{array}{l}\text { 1...Service-connected } \\
2 \text {... Nonservice-connected }\end{array}$ \\
\hline & 64 & 28 & Chronic Health Problems & $\begin{array}{l}1 \ldots \text { No } \\
2 \ldots \text { Yes }\end{array}$ \\
\hline
\end{tabular}




\begin{tabular}{|c|c|c|c|c|}
\hline SRD & COLUMN & QUESTION & VARIABLE & CODE \\
\hline \multirow[t]{13}{*}{1} & 65 & $19 A$ & Hospitalized Past Year & $\begin{array}{l}1 \ldots \text { No } \\
2 \ldots \text { Yes }\end{array}$ \\
\hline & 66 & $19 B$ & Length/Hospitalization & $\begin{array}{l}\text { 1... Not hospitalized } \\
2 \ldots \text {. Less than } 1 \text { week } \\
3 \ldots 1-2 \text { weeks } \\
4 \ldots 3-1 \text { weeks } \\
5 \ldots \text {. over } 1 \text { month }\end{array}$ \\
\hline & 67 & 20 & Profected Health & $\begin{array}{l}\text { 1... Get better } \\
2 \ldots \text { Stay same } \\
3 . . \text {. Get worse }\end{array}$ \\
\hline & 68 & $21 \mathrm{~A}$ & Dressing & $\begin{array}{l}\text { 1... No assistance } \\
2 \ldots \text {.ccasional assistance } \\
3 \ldots \text { Frequent assistance } \\
4 \ldots \text { Complete assistance }\end{array}$ \\
\hline & 69 & 218 & Bathing & Same as $21 \mathrm{~A}$ \\
\hline & 70 & $21 C$ & Eating & Sane as 21A \\
\hline & 72 & 210 & Cooking & Same as 21A \\
\hline & 72 & $21 \mathrm{E}$ & Toilet & Same as 21A \\
\hline & 73 & $21 F$ & Driving & Same as 21A \\
\hline & 74 & $21 \mathrm{G}$ & Shopping & Same as 21A \\
\hline & 75 & $21 \mathrm{H}$ & Laundry & Same as 21A \\
\hline & 76 & $21 I$ & Housecleaning & Same as 2IA \\
\hline & 77 & $21 A-I$ & Overall Assistance & $\begin{array}{l}1 \ldots \text { Low }(1-1.9) \\
2 \ldots \text { Moderate }(2.0-2.9) \\
3 \ldots \text { High }(3.0-4)\end{array}$ \\
\hline \multirow[t]{5}{*}{2} & 1 & A & Card \# & $1-6 \ldots$ Card \\
\hline & $2-4$ & $\mathbf{B}$ & Subject ID \# & $001-100$ \\
\hline & 5 & 22 & Number/Support Persons & Put $0-5$ \\
\hline & $\begin{array}{c}6-7 \\
8-9 \\
10-11 \\
12-13 \\
14-15\end{array}$ & $\begin{array}{r}22 A(1) \\
(2) \\
(3) \\
(4) \\
(5)\end{array}$ & $\begin{array}{c}\text { Age/Support Person } \\
\text { " } \\
\text { " }\end{array}$ & $\begin{array}{l}\text { Put age } \\
\text { ox } \\
\text { Blank, N.A. (-9) }\end{array}$ \\
\hline & $\begin{array}{l}16-17 \\
18-19 \\
20-21 \\
22-23 \\
24-25\end{array}$ & $\begin{array}{r}22 \mathrm{~B}(1) \\
(2) \\
(3) \\
(4) \\
(5)\end{array}$ & Gender & $\begin{array}{l}\text { 01... Male } \\
\text { 02...Female } \\
\text { Blank, N.A. (-9) }\end{array}$ \\
\hline
\end{tabular}




\begin{tabular}{|c|c|c|c|c|}
\hline CAND. & COLUMN & QUESTION & VARIABLE & CODE \\
\hline \multirow[t]{6}{*}{2} & $\begin{array}{l}26-27 \\
28-29 \\
30-31 \\
32-33 \\
34-35\end{array}$ & $\begin{array}{r}22 c(1) \\
(2) \\
(3) \\
(4) \\
(5)\end{array}$ & Disability status & $\begin{array}{l}\text { 01... Disabled } \\
\text { 02... Nondisabled } \\
\text { Blank, N.A. (-9) }\end{array}$ \\
\hline & $\begin{array}{l}36-37 \\
38-39 \\
40-41 \\
42-43 \\
44-45\end{array}$ & $\begin{array}{r}23(1) \\
(2) \\
(3) \\
(4) \\
(5)\end{array}$ & Proximity & $\begin{array}{l}\text { 01... Same residence } \\
02 \ldots \text { Imediate neighborhood } \\
03 \ldots \text { Tri-county area } \\
04 \ldots \text { outside tri-county area } \\
\text { Blank, N.A. (-9) }\end{array}$ \\
\hline & $\begin{array}{l}46-47 \\
48-49 \\
50-51 \\
52-53 \\
54-55\end{array}$ & $\begin{array}{r}24(1) \\
(2) \\
(3) \\
(4) \\
(5)\end{array}$ & Relationship & 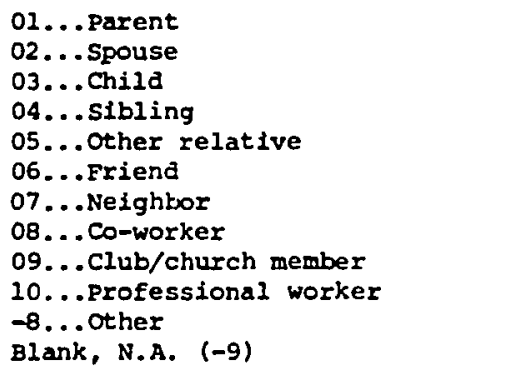 \\
\hline & $\begin{array}{l}56-57 \\
58-59 \\
60-61 \\
62-63 \\
64-65\end{array}$ & $\begin{array}{r}25 A(1) \\
(2) \\
(3) \\
(4) \\
(5)\end{array}$ & $\begin{array}{l}\text { Instrumental support/ } \\
\text { Assistance }\end{array}$ & $\begin{array}{l}01 \ldots \text {. Not at all } \\
02 \ldots \text {. Rarely } \\
03 \ldots \text {. On some occasions } \\
04 \ldots \text {. Often } \\
05 \ldots . \text { Very frequently } \\
\text { Blank, N.A. }(-9)\end{array}$ \\
\hline & $\begin{array}{l}66-67 \\
68-69 \\
70-71 \\
72-73 \\
74-75\end{array}$ & $\begin{array}{r}25 B(1) \\
(2) \\
(3) \\
(4) \\
(5)\end{array}$ & $\begin{array}{l}\text { Instrumental support/ } \\
\text { Care of self }\end{array}$ & Code same as $25 \mathrm{~A}$ \\
\hline & $76-77$ & $25 A+B$ & $\begin{array}{l}\text { Total Instrumental } \\
\text { Support }\end{array}$ & Put total $(00-50)$ \\
\hline \multirow[t]{4}{*}{3} & 1 & A & Card \# & $1-6 \ldots$ Card \# \\
\hline & $2-4$ & B & Subject ID & $001-100$ \\
\hline & $\begin{array}{l}5-6 \\
7-8 \\
9-10 \\
11-12 \\
13-14\end{array}$ & $\begin{array}{r}25 c(1) \\
(2) \\
(3) \\
(4) \\
(5)\end{array}$ & $\begin{array}{l}\text { Affective support/ } \\
\text { Concern }\end{array}$ & $\begin{array}{l}01 \ldots \text {. Not at all } \\
02 \ldots \text { Rarely } \\
03 \ldots \text {. on some occasions } \\
04 \ldots \text {. Often } \\
05 \ldots \text { Very frequently } \\
\text { Blanx, N.A. }(-9)\end{array}$ \\
\hline & $\begin{array}{l}15-16 \\
17-18 \\
19-20 \\
21-22 \\
23-24\end{array}$ & $\begin{array}{r}25 D(2) \\
(2) \\
(3) \\
(4) \\
(5)\end{array}$ & $\begin{array}{l}\text { Affective Support/ } \\
\text { Inclusion }\end{array}$ & Code same as $25 \mathrm{C}$ \\
\hline
\end{tabular}


Page 7

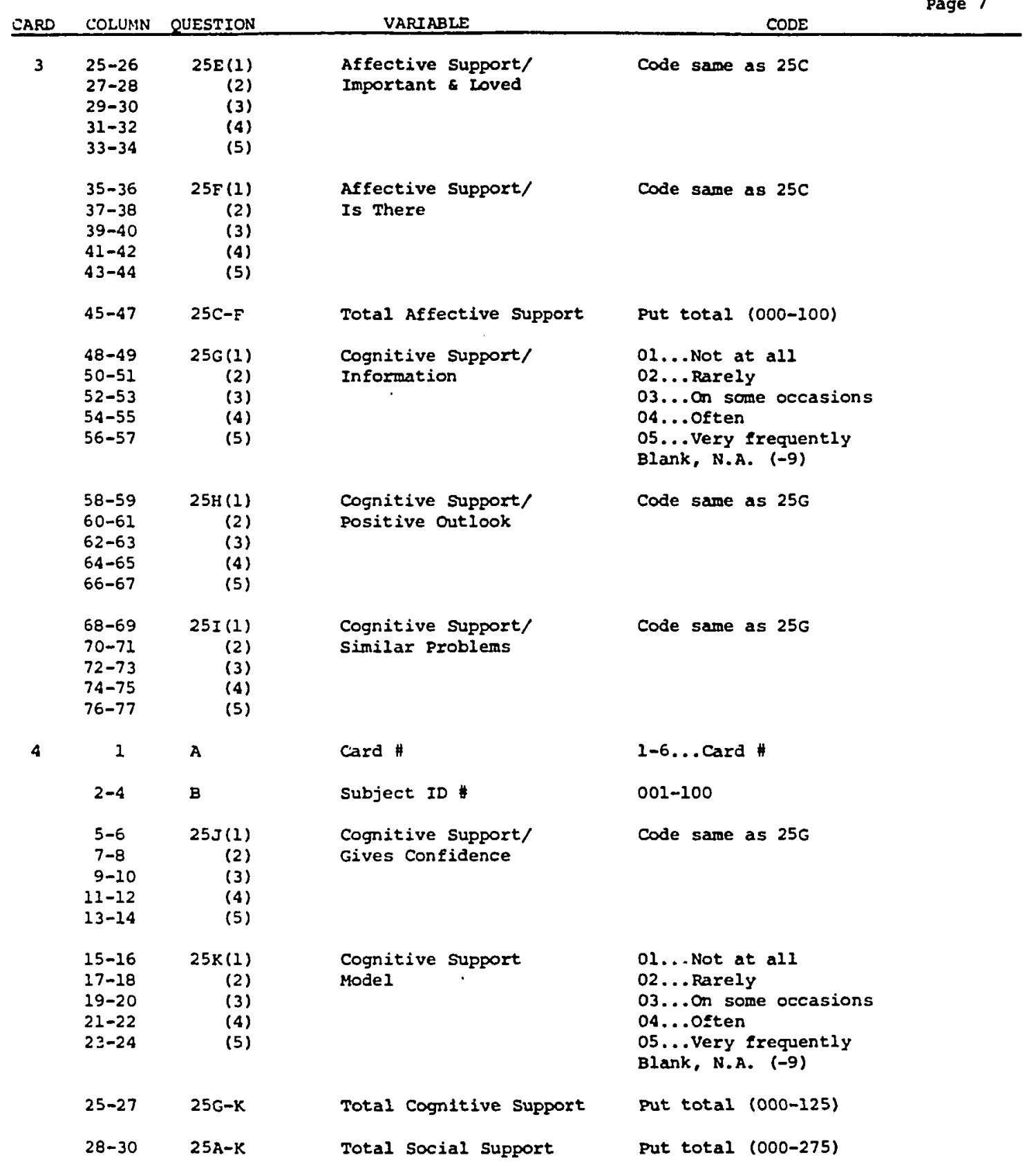




\begin{tabular}{|c|c|c|c|c|}
\hline CARD & COLUMN & QUESTION & VARIABLE & Page 8 \\
\hline \multirow[t]{10}{*}{4} & 31 & $25 A-K$ & $\begin{array}{l}\text { Level of Total Social } \\
\text { Support }\end{array}$ & $\begin{array}{l}1 \ldots \text { Low }(0-50) \\
2 \ldots \text { Moderate }(51-109) \\
\text { 3... High }(110-275)\end{array}$ \\
\hline & $\begin{array}{l}32-33 \\
34-35 \\
36-37 \\
38-39 \\
40-41\end{array}$ & $\begin{array}{r}26(1) \\
(2) \\
(3) \\
(4) \\
(5)\end{array}$ & Reciprocity & $\begin{array}{l}\text { 01... About the same } \\
02 \ldots \text { They help you more } \\
\text { 03... You help them more } \\
\text { Blank, N.A. (-9) }\end{array}$ \\
\hline & 42 & $26(1-5)$ & Total Reciprocity & $\begin{array}{l}\text { 1... Low (most nonreciprocal) } \\
2 . . \text { Moderate (equal) } \\
\text { 3... High (most reciprocal) }\end{array}$ \\
\hline & 43 & 27 & Density & $\begin{array}{l}\text { 1... Low (most don't know others) } \\
2 \ldots \text { Moderate (equal) } \\
\text { 3... High (most know others) }\end{array}$ \\
\hline & $\begin{array}{l}44-45 \\
46-47 \\
48-49 \\
50-51 \\
52-53\end{array}$ & $\begin{array}{r}28(1) \\
(2) \\
(3) \\
(4) \\
(5)\end{array}$ & Length of Relationship & $\begin{array}{l}\text { 01... Less than } 6 \text { months } \\
02 \ldots .6 \text { months }-1 \text { year } \\
03 \ldots .2-5 \text { years } \\
\text { 04... More than } 5 \text { years } \\
\text { Blank, N.A. (-9) }\end{array}$ \\
\hline & 54 & $28(1-5)$ & overall stability & $\begin{array}{l}\text { 1... Low (most } 0-1 \text { year) } \\
2 \ldots \text { Moderate (most } 1.1-j \text { years) } \\
3 . . \text { High (most }>5 \text { years) }\end{array}$ \\
\hline & $\begin{array}{l}55-56 \\
57-58 \\
59-60 \\
61-62 \\
63-64\end{array}$ & $\begin{array}{r}29(1) \\
(2) \\
(3) \\
(4) \\
(5)\end{array}$ & Frequency of Contact & $\begin{array}{l}01 . . \text {. Several times a year } \\
02 \ldots \text {. About once a month } \\
03 \ldots \text {. Several times a month } \\
04 \ldots \text {. Several times a week } \\
05 \ldots \text {... Almost daily } \\
\text { Blank, N.A. }(-9)\end{array}$ \\
\hline & 65 & $29(1-5)$ & Overall Frequency & $\begin{array}{l}\text { 1... Low (most < once/month) } \\
\text { 2... Hoderate (most several times/ } \\
\text { month) } \\
\text { 3... High (most several times a week } \\
\text { to daily) }\end{array}$ \\
\hline & $\begin{array}{r}66-67 \\
68-69 \\
70-71 \\
-72-73 \\
74-75\end{array}$ & $\begin{array}{r}30(1) \\
(2) \\
(3) \\
(4) \\
(5)\end{array}$ & $\begin{array}{l}\text { Satisfaction with } \\
\text { Relationships }\end{array}$ & $\begin{array}{l}\text { 01... Very dissatisfied } \\
02 . . \text {. Somewhat dissatisfied } \\
03 \ldots \text {. Neutral } \\
04 \ldots \text {. Somewhat satisfied } \\
\text { 05... Very satisfied } \\
\text { Blank, N.A. }(-9)\end{array}$ \\
\hline & 76 & $30(1-5)$ & $\begin{array}{l}\text { Total Relationship } \\
\text { Satisfaction }\end{array}$ & $\begin{array}{l}\text { 1... Low (most 01-02) } \\
2 \ldots \text { Noderate (most } 03 \text { ) } \\
3 \ldots \text { High (most } 04-05 \text { ) }\end{array}$ \\
\hline
\end{tabular}


Page 9

\begin{tabular}{|c|c|c|c|c|}
\hline ZARD & COLurse & QUESTION & VARIABLE & CODE \\
\hline \multirow[t]{11}{*}{5} & 1 & A & Card \# & $1-6 \ldots$ Card \\
\hline & $2-4$ & B & Subject ID " & $001-100$ \\
\hline & $\begin{array}{r}5-6 \\
7-8 \\
9-10 \\
11-12 \\
13-14\end{array}$ & $\begin{array}{r}31(1) \\
(2) \\
(3) \\
(4) \\
(5)\end{array}$ & Relationship Importance & $\begin{array}{l}\text { 01... Not important } \\
02 \ldots \text { Somewhat unimportant } \\
03 \ldots \text {. Neutral } \\
04 \ldots \text { Somewhat important } \\
05 \ldots \text { Very important } \\
\text { Blank, N.A. }(-9)\end{array}$ \\
\hline & 15 & $31(1-5)$ & $\begin{array}{l}\text { Total Relationship } \\
\text { Importance }\end{array}$ & $\begin{array}{l}\text { 1... Low (most 01-02) } \\
2 \ldots \text { Moderate (most 03) } \\
\text { 3... Higle (most 04-05) }\end{array}$ \\
\hline & 16 & $32 \mathrm{~A}$ & $\begin{array}{l}\text { Satisfaction with } \\
\text { Amount Social Contact }\end{array}$ & $\begin{array}{l}1 \ldots \text { Not at all satisfied } \\
2 \ldots \\
3 \ldots \\
4 \ldots \\
5 \ldots \text { very satisfied }\end{array}$ \\
\hline & 17 & $32 B$ & $\begin{array}{l}\text { Satisfaction with } \\
\text { guality Social Contact }\end{array}$ & Code same as $32 \mathrm{~A}$ \\
\hline & 18 & $33 \mathrm{~A}$ & Loss of Persons & $\begin{array}{l}2 \ldots \text { No } \\
2 \ldots \text { Yes }\end{array}$ \\
\hline & $\begin{array}{l}19-20 \\
21-22\end{array}$ & $\begin{array}{r}33 \mathrm{~B}(1) \\
(2)\end{array}$ & Who Lost & $\begin{array}{l}\text { 01... Spouse } \\
02 \ldots \text {. Parent } \\
03 \ldots \text {. Sibling } \\
04 \ldots \text {. Friend } \\
05 \ldots \text {. Other relative } \\
06 \ldots \text {. Pald caregiver } \\
\text {-8...Other } \\
\text { Blank, N.A. }(-9)\end{array}$ \\
\hline & $23-24$ & 34 & $\begin{array}{l}\text { How Good is wife } \\
\text { Situation }\end{array}$ & $\begin{array}{l}01 \\
\text { (worst) }\end{array}$ \\
\hline & 25 & 35 & Comparison Persons & $\begin{array}{l}1 \ldots \text { Disabled } \\
2 \ldots \text { Nondisabled } \\
\text { 3...No particular group }\end{array}$ \\
\hline & $\begin{array}{l}26-27 \\
28-29 \\
30-31\end{array}$ & $\begin{array}{l}36 \\
\text { a) } \\
\text { b) } \\
\text { c) }\end{array}$ & Comparison Characteristics & $\begin{array}{l}\text { 01... Health } \\
02 \ldots \text { Mobility/Independence } \\
03 \ldots \text {. Finances, live comfortably } \\
04 \ldots \text {. Family/Friends } \\
\text { 05... Appearance } \\
\text { 06... Personality, intellect } \\
\text { 07... Work/productivity/skills } \\
\text { 08... Nothing in particular } \\
09 \ldots \text { Pain } \\
\text {-8...0ther } \\
\text { Blank, N.A. (-9) }\end{array}$ \\
\hline
\end{tabular}




\begin{tabular}{|c|c|c|c|c|}
\hline CARD & COLUMN & QUESTION & VARIABLE & CODE \\
\hline \multirow[t]{13}{*}{5} & 32 & $37 A$ & Comparison/most People & $\begin{array}{l}\text { 1...Worse than most } \\
2 \ldots \text {. Worse than some } \\
3 . \text {. Same as most } \\
4 . \text {. Better than some } \\
5 . . \text { Better than most }\end{array}$ \\
\hline & 33 & $37 \mathrm{~B}$ & Comparison/Some Age & Code same as $37 \mathrm{~A}$ \\
\hline & 34 & $37 \mathrm{c}$ & $\begin{array}{l}\text { Comparison/Similar } \\
\text { Disability }\end{array}$ & Code same as $37 \mathrm{~A}$ \\
\hline & 35 & 370 & $\begin{array}{l}\text { Comparison/With } \\
\text { Before Disability }\end{array}$ & $\begin{array}{l}\text { 1... Much worse now } \\
2 \ldots \text { Sowewhat worse now } \\
3 \ldots \text { About the same } \\
4 \ldots \text {... Sowewhat better now } \\
5 . \text {. Much better now }\end{array}$ \\
\hline & 36 & $37 \mathrm{E}$ & $\begin{array}{l}\text { Comparison/without } \\
\text { Disability }\end{array}$ & $\begin{array}{l}\text { 5... Much worse } \\
4 . . \text {. Somewhat worse } \\
3 . . \text {. About the same } \\
2 \ldots \text {... Somewhat better } \\
1 . . \text { Much better }\end{array}$ \\
\hline & 37 & $37 A-E$ & Overall Comparisons & $\begin{array}{l}\text { 1... Negative ( } 3-5 \mathrm{neg} \text {. comparisons) } \\
2 \ldots \text { Neutral ( } 3 \text { not neg. or pos.) } \\
3 \text {...Positive }(3-5 \text { positive comparisons }\end{array}$ \\
\hline & $\begin{array}{l}38-39 \\
40-41 \\
42-43\end{array}$ & 38 & $\begin{array}{l}\text { values } \\
\text { a) } \\
\text { b) } \\
\text { c) }\end{array}$ & Code same as 36 \\
\hline & $\begin{array}{l}44 \\
45 \\
46 \\
47 \\
48\end{array}$ & $\begin{array}{r}39 A(a) \\
\text { (b) } \\
\text { (c) } \\
\text { (d) } \\
\text { (e) }\end{array}$ & $\begin{array}{l}\text { Life Controlled by: } \\
\text { Self } \\
\text { Other People } \\
\text { Luck/Chance } \\
\text { God } \\
\text { Other }\end{array}$ & $\begin{array}{l}1 \ldots \text { Not at all } \\
2 \ldots \\
3 \ldots \\
4 \ldots \\
5 \ldots \text {. Very much }\end{array}$ \\
\hline & 49 & 398 & Able to Achieve & $\begin{array}{l}1 \ldots \text { Not at all } \\
2 \ldots \\
3 \ldots \\
4 \ldots \\
5 \ldots \text { Completely }\end{array}$ \\
\hline & 50 & $39 c$ & $\begin{array}{l}\text { Able to Control } \\
\text { Interactions }\end{array}$ & Code sane as 398 \\
\hline & 51 & 390 & Cope with Stress & Code same as $39 \mathrm{~B}$ \\
\hline & 52 & $39 E$ & Solve Problers & Code same as 398 \\
\hline & 53 & $39 F$ & Good Things own Doing & Code same as $39 \mathrm{~B}$ \\
\hline
\end{tabular}


Page 11

\begin{tabular}{|c|c|c|c|c|}
\hline CARD & COLUNN & QUESTION & VARIABLE & CODE \\
\hline \multirow[t]{15}{*}{5} & 54 & $398-F$ & Total Perceived Control & $\begin{array}{l}\text { 1... Low (overall } 1-2 \text { ) } \\
2 \ldots \text { Hoderate (overall } 3 \text { ) } \\
3 \ldots \text { High (overall } 4-5 \text { ) }\end{array}$ \\
\hline & & $40 A$ & Blame for Disability & 1... Not at all \\
\hline & 55 & (a) & Self & $2 \ldots$ \\
\hline & 56 & (b) & Other People & $3 \ldots$ \\
\hline & 57 & (c) & Chance/Luck & $4 \ldots$ \\
\hline & $\begin{array}{l}58 \\
59\end{array}$ & $\begin{array}{l}\text { (d) } \\
\text { (e) }\end{array}$ & $\begin{array}{l}\text { cod } \\
\text { Other }\end{array}$ & 5... Very much \\
\hline & 60 & $40 B$ & Avoided Disability & $\begin{array}{l}1 \ldots \text { Not at all } \\
2 \ldots \\
3 \ldots \\
4 \ldots \\
5 \ldots \text { Completely }\end{array}$ \\
\hline & & $41 \mathrm{~A}$ & Major Difficulties & 01... None exist \\
\hline & $\begin{array}{l}61-62 \\
63-64 \\
65-66\end{array}$ & $\begin{array}{l}\text { (a) } \\
\text { (b) } \\
\text { (c) }\end{array}$ & & $\begin{array}{l}\text { 02... Health } \\
03 . . \text { Relationships, family problems } \\
04 . . \text { Finances }\end{array}$ \\
\hline & $67-68$ & (d) & & $\begin{array}{l}\text { 05... Dependency/Immolility } \\
\text { 06... Pain } \\
-8 \ldots \text { Other }\end{array}$ \\
\hline & & & & Blank, N.A. $(-9)$ \\
\hline & 69 & $41 B$ & Difficulties Own Doing & $\begin{array}{l}1 \ldots \text { Not at all } \\
2 \ldots \\
3 \ldots \\
4 \ldots \\
5 \ldots \text { Completely }\end{array}$ \\
\hline & 70 & $42 \mathrm{~A}$ & $\begin{array}{l}\text { Disability, from } \\
\text { Worst-Best }\end{array}$ & $\begin{array}{l}1 \ldots \text { Worst that could happen } \\
2 \ldots \\
3 \ldots \\
4 \ldots \\
5 \ldots \text { Best that could happen }\end{array}$ \\
\hline & 71 & $42 B$ & $\begin{array}{l}\text { Positive Meaning } \\
\text { Disability }\end{array}$ & $\begin{array}{l}1 \ldots \text { No } \\
2 \ldots \text { Yes }\end{array}$ \\
\hline & $\begin{array}{l}72-73 \\
74-75 \\
76-77\end{array}$ & $\begin{array}{l}42 \mathrm{C} \\
\text { (a) } \\
\text { (b) } \\
\text { (c) }\end{array}$ & Type of Meaning & 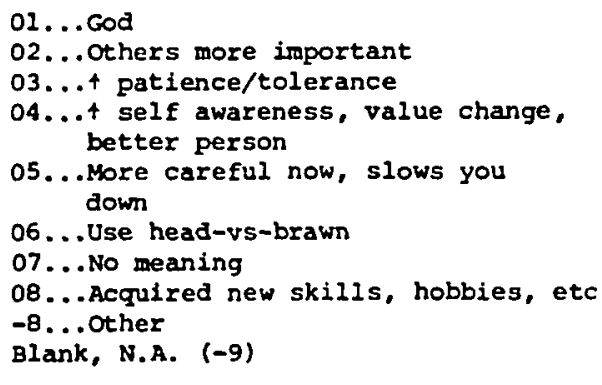 \\
\hline
\end{tabular}




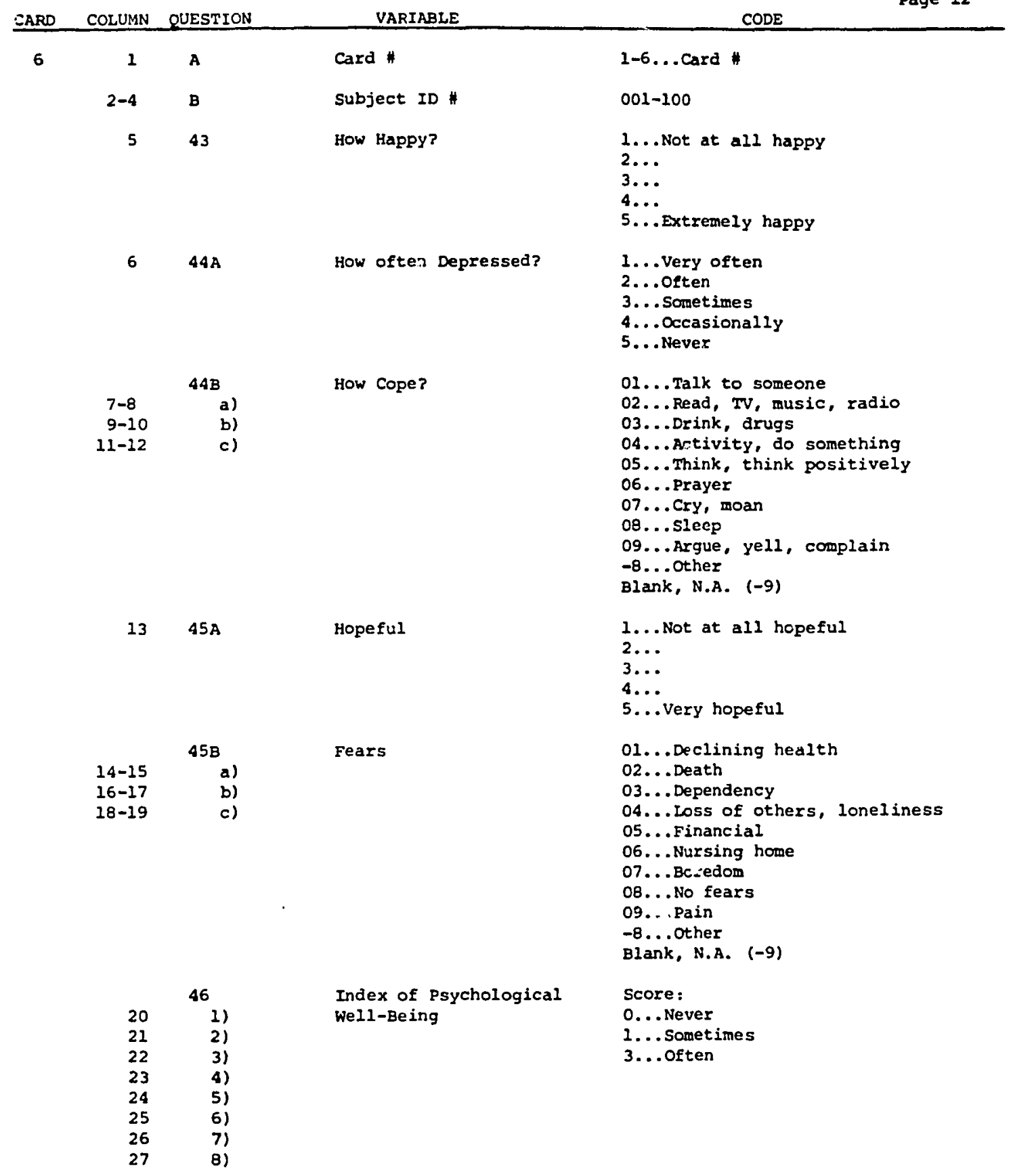




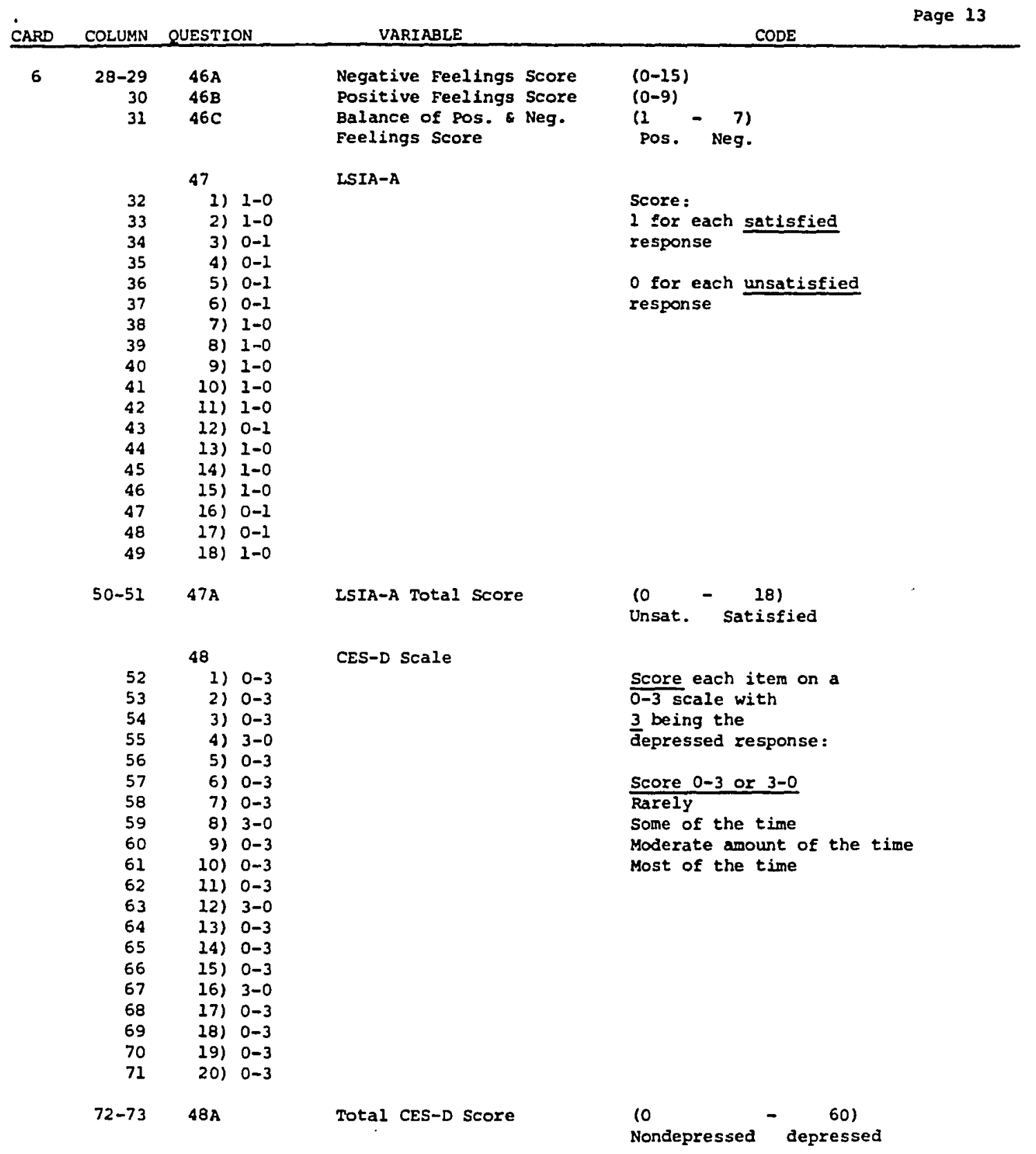




\begin{tabular}{|c|c|c|c|c|c|}
\hline ¿ARD & COLUPAN & QUESTION & VARIABLE & CODE & Page 18 \\
\hline 6 & 74 & 49 & How difficult to answer? & $\begin{array}{l}2 \ldots \text { Not at all difficult } \\
2 \ldots \\
3 \ldots \\
4 \ldots \\
5 \ldots \text {... very difficult }\end{array}$ & \\
\hline & 75 & 50 & Participate again? & $\begin{array}{l}1 \ldots \text { Yes } \\
2 \ldots \text { No }\end{array}$ & \\
\hline
\end{tabular}


APPENDIX C

CORRESPONDENCE 


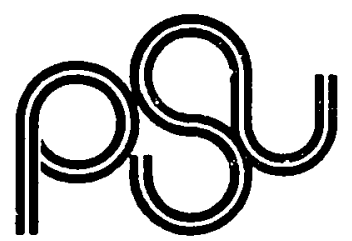

We at the Portland State University Institute on Aging have become increasingly interested in the speclal problems encountered by the spinal cord injured individual as he or she grows older-- into his

PORTLARID STATE DNIVES'TY portland oregen 9720 ? 503 229-395=

school : urban afla: or her forties, fifties, sixties, seventies, and beyond. Certain problem areas exist for many or most older Americans, generally (health, housing, finances, transportation, nutrition, activities, etc.), but the special problems of the spinal cord injured individual as he or she becomes older have not been studied to any extent. We feel that a survey of such areas will be important in determining future needs and how best to deal with them.

We are currently conducting a study of cord injured persons. To obtain the information that we feel will be necessary, we plan to interview a large number of cord injured persons.. Your particlpation in this study will be confidentlal and names will not be a part of the records of the survey.

We feel that the information obtained from this study may be very valuable in helping health care and other agencles understand the problems of older spinal cord injured persons and prepare to meet their needs in the future.

During the next month you will be phoned by one of the Portland State University staff to provide you with further information and to find out if you are willing to participate in this survey. If you are willing, a single interview of one to two hours will be scheduled at your convenlence in your home or such other place as you may wish. This will complete your involvement in this study.

For the survey to be complete and meaningful we will need the participation of a large number of persons, and we hope that you will be willing to help. In order for us to reach you as soon as possible, please call 229-3952 (the Institute on Aging at Portland State Un (versity) to give us your current telephone number and address.

Very sincerely,

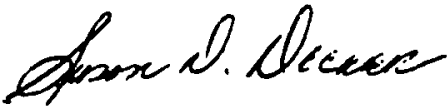

Susan D. Decker, M.S.N. 
APPENDIX D

INFORMED CONSENT FORM 
I hereby agree to participate in the study, "Elderly Spinal Cord Injured Persons: Surviving In The Community", conducted by Susan Decker, Doctoral candidate, under the supervision of Richard Schulz, Director, Institute on Aging at Portland State University; and in cooperation with Dr. Philip King, Heaci of Rehabilitation Medicine at the Oregon Veterans Administration Medical Center. I understand that the purpose of the study is to learn more about those factors that contribute to the well-being and life satisfaction of elderly community residing spinal cord injured persons, to determine the nature of the social support system of elderly community residing spinal cord injured persons and to project the future needs of this population as it ages.

I realize that parts of the interview may be sensitive, and I reserve the right to talk about only those things with which I feel. comfortable. My participation in the study will involve a personal. interview requiring approximately two hours of my time. While I may not receive any direct benefit from participating in the study, I realize that my participation will help to increase knowledge which may benefit others in the future.

The interviewer, , has offered to answer any questions I may have about the study, and I know I can reach her through the Institute on Aging, Portland State University University, (503) 229-3801. I also understand I may contact Dr. Philip King at (503) 222-9221, extension 416, regarding further concerns.

I understand that my responses will be completely confidential and that neither my nane nor identifying personal information will be used when the findings of the study are described. I also understand that my participation is voluntary and that I can withdraw at any time. I understand that refusal to participate or a decision to withdraw from the study will not involve any penalty or joss of benefits to which I am otherwise entitled. I understand that I may be asked to participate again in this study at a future time.

I have read the above information. Date (Interviewee's Signature) Date 